\title{
How drugs get into cells: tested and testable predictions to help discriminate between transporter-mediated uptake and lipoidal bilayer diffusion
}

\author{
Douglas B. Kell ${ }^{1,2 *}$ and Stephen G. Oliver ${ }^{3,4}$ \\ ${ }^{1}$ School of Chemistry, The University of Manchester, Manchester, UK \\ ${ }^{2}$ Manchester Institute of Biotechnology, The University of Manchester, Manchester, UK \\ ${ }^{3}$ Department of Biochemistry, University of Cambridge, Cambridge, UK \\ ${ }^{4}$ Cambridge Systems Biology Centre, University of Cambridge, Cambridge, UK
}

Edited by:

Harry P. De Koning, University of Glasgow, UK

\section{Reviewed by:}

Constantin Ion Mircioiu, Carol Davila

University of Medicine and

Pharmacy, Romania

Harry P. De Koning, University of

Glasgow, UK

*Correspondence:

Douglas B. Kell, Manchester Institute of Biotechnology, The

University of Manchester, 131,

Princess St., Manchester M1 7DN,

Lancs, UK

e-mail:dbk@manchester.ac.uk
One approach to experimental science involves creating hypotheses, then testing them by varying one or more independent variables, and assessing the effects of this variation on the processes of interest. We use this strategy to compare the intellectual status and available evidence for two models or views of mechanisms of transmembrane drug transport into intact biological cells. One (BDII) asserts that lipoidal phospholipid Bilayer Diffusion Is Important, while a second (PBIN) proposes that in normal intact cells Phospholipid Bilayer diffusion Is Negligible (i.e., may be neglected quantitatively), because evolution selected against it, and with transmembrane drug transport being effected by genetically encoded proteinaceous carriers or pores, whose "natural" biological roles, and substrates are based in intermediary metabolism. Despite a recent review elsewhere, we can find no evidence able to support BDII as we can find no experiments in intact cells in which phospholipid bilayer diffusion was either varied independently or measured directly (although there are many papers where it was inferred by seeing a covariation of other dependent variables). By contrast, we find an abundance of evidence showing cases in which changes in the activities of named and genetically identified transporters led to measurable changes in the rate or extent of drug uptake. PBIN also has considerable predictive power, and accounts readily for the large differences in drug uptake between tissues, cells and species, in accounting for the metabolite-likeness of marketed drugs, in pharmacogenomics, and in providing a straightforward explanation for the late-stage appearance of toxicity and of lack of efficacy during drug discovery programmes despite macroscopically adequate pharmacokinetics. Consequently, the view that Phospholipid Bilayer diffusion Is Negligible (PBIN) provides a starting hypothesis for assessing cellular drug uptake that is much better supported by the available evidence, and is both more productive and more predictive.

Keywords: drug transporters, systems pharmacology, pharmacogenomics, Recon2

\section{INTRODUCTION}

"The overthrow of the phlogiston theory involved the development of a superior conceptual theme" (Conant, 1950).

As part of an ongoing discussion of the importance of transporters in drug distribution that we (Dobson and Kell, 2008; Dobson et al., 2009a,b; Kell and Dobson, 2009; Kell et al., 2011, 2013; Lanthaler et al., 2011; Kell, 2013; Kell and Goodacre, 2014) and others (e.g., Sai and Tsuji, 2004; Shitara et al., 2006; Anderson and Thwaites, 2010; Franke et al., 2010; Giacomini et al., 2010, 2013; Lai et al., 2010; Burckhardt and Burckhardt, 2011; Fromm and Kim, 2011; König, 2011; Mruk et al., 2011; Nies et al., 2011; Thompson, 2011; Tirona, 2011; Zolk and Fromm, 2011; Degorter et al., 2012; Mandery et al., 2012; Riedmaier et al., 2012; Sprowl et al., 2012; Chu et al., 2013b; Estudante et al., 2013; Giacomini and Huang, 2013; Hagenbuch and Stieger, 2013; König et al., 2013; Schlessinger et al., 2013a,b; Tamai and Nakanishi, 2013; Lai and Hsiao, 2014; Sprowl and Sparreboom, 2014) have been highlighting, Smith and colleagues recently published a review (Smith et al., 2014) that claims that the hypothesis that drugs are usually transported into cells via protein carriers is "not a sound scientific principle and lacks experimental evidence." Smith et al. (2014) set out their arguments in considerable detail, and this allows us, in the present publication, to present a contrary view and rehearse the core arguments that pertain to the mechanism(s) of drug and xenobiotic transport across biological membranes.

First, we might usefully establish (or, more accurately, restate) what our views are. The abstract of the Smith article (Smith et al., 2014) ("Recently, it has been proposed that drug permeation is essentially carrier-mediated only and that passive lipoidal diffusion is negligible") recognizes that we imply a dominant role for 
transporter-mediated uptake of drugs into cells (note the titles of Dobson and Kell, 2008; Dobson et al., 2009a; Kell and Dobson, 2009; Kell et al., 2011, 2013). We do not assert that carriermediated transport is the only means by which drugs and other xenobiotics gain access to cells, nor do we seek to invalidate passive lipoidal diffusion as an alternate mechanism. Thus, we start by explaining, from a Popperian standpoint, why we do not seek to "invalidate" bilayer lipoidal diffusion. Figure 1 provides an overview of this article in the form of a mind map (Buzan, 2002).

\section{SCIENTIFIC PRINCIPLES}

A well-known scientific principle is that of hypothesis-driven or hypothetico-deductive science and scientific reasoning. It is due in its most widely recognized form to Karl Popper [see (Medawar, 1982; Popper, 1992; Chalmers, 1999), and for its iterative contrast with data-driven approaches see (Kell and Oliver, 2004; Franklin, 2005; Kell, 2006, 2012; Elliott, 2012)]. In this view (as it is applied to experimental science), one produces a hypothesis that allows one to vary something as an independent variable (properly, a parameter), and predicts the observable effects (data) to which one's hypothesis would lead, within a deductive framework. The data observed are then consistent or otherwise with those predicted on the basis of the hypothesis. In the Popperian view, then, hypotheses are there to be refuted but cannot be "proven." So, while we consider that bilayer lipoidal diffusion is normally probably negligible (i.e., may be neglected in quantitative terms) in intact biological cells, at no time have we tried to "invalidate" passive lipoidal diffusion across real and intact biological membranes, because we have neither tried to measure it directly nor to vary it as an independent variable. Neither, so far as we can tell, has anyone else. Thus, we merely point out that there is no actual evidence for it occurring in normal biomembranes; what there are (in abundance) are data sets of e.g., drugs appearing in cells when added externally, and we note that people choose to interpret this as evidence somehow supporting bilayer diffusion, but that is not at all the same thing (Ioannidis, 2005; Broadhurst and Kell, 2006) and, in fact, direct experimentation suggests quite the opposite.

So, to be clear: our views are that we find no serious evidence for bilayer lipoidal diffusion of drugs into cells. A major reason for our thinking comes from the fact there are so many cases (that we discuss below) in which drugs or other natural and xenobiotic molecules simply do not seem to enter or exit from cells, at least without identifiable transporters being present. This implies that the "background" rate of transport (from the exterior all the way into the aqueous cytoplasm) through any bilayer, as assumed to be present in all mammalian cells, must be negligible. We also consider it likely that evolution long ago selected against cells that might not be osmotically active if they became permeable to all kinds of small molecules. By contrast, we

\section{A mind map of this article}

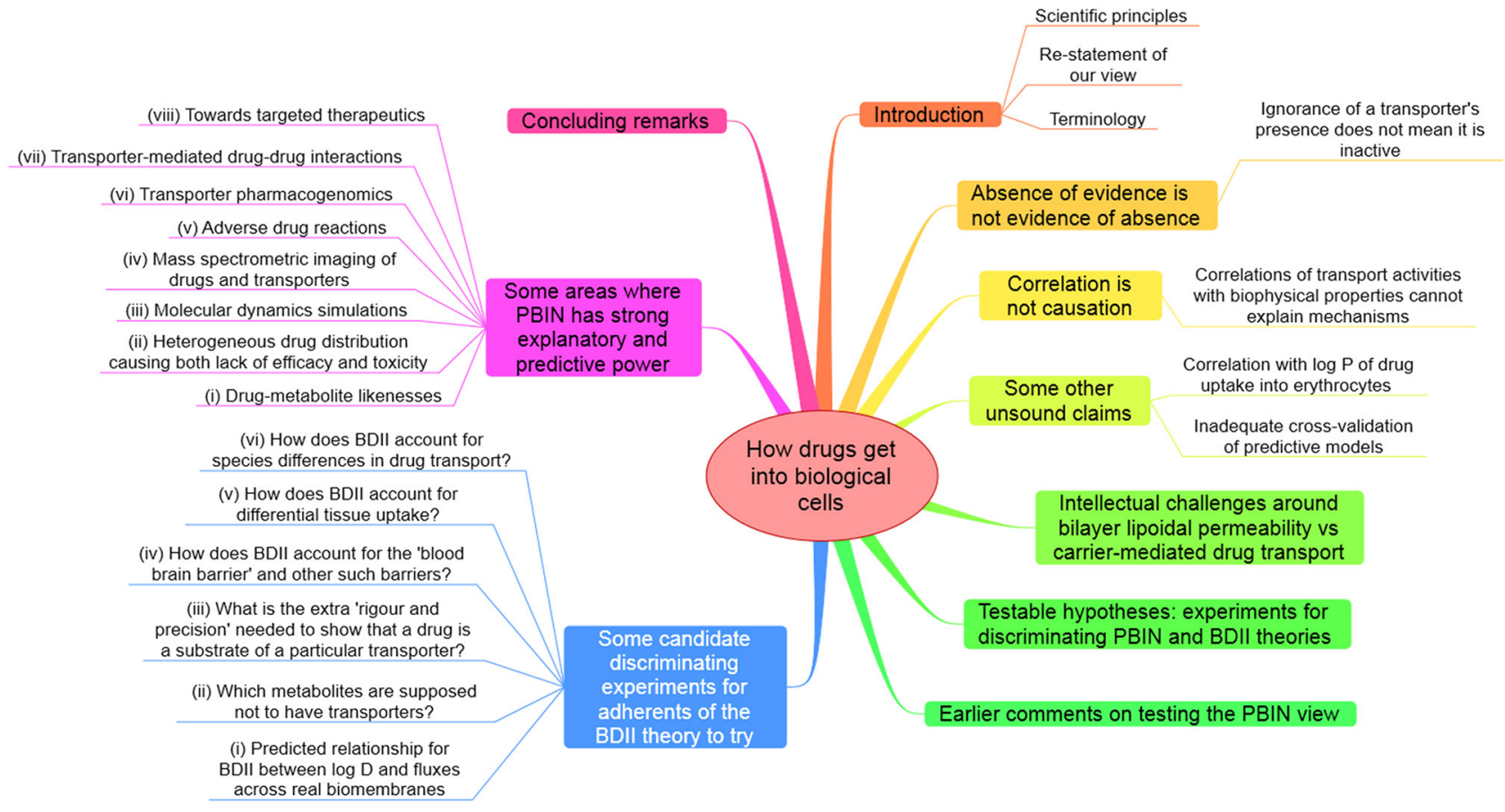

FIGURE 1 | A "mind map" (Buzan, 2002) summarizing the structure and contents of this paper. To follow this, start at the top and read clockwise. 
find much evidence (almost wherever we look) for the presence of carrier-mediated transport (whatever interpretations may be put on the data in any specific papers, whether by their original authors or by commentators), because such molecules allow for controlled permeability, and transporter activities can be and are varied experimentally as independent variables with predictable and measurable effects. Figure 2 re-plots data from a competition experiment (Lanthaler et al., 2011) in which we compared the ability of baker's yeast strains carrying single-gene deletants to display resistance to a toxic concentration of a drug (in this case diphenyleneiodonium, DPI), the idea being that a strain lacking a non-essential transporter for the drug would display resistance. We would also stress that this experiment can only work effectively to discriminate between the different mutant strains when any background Phospholipid Bilayer diffusion Is Negligible (PBIN). If there was a significant transporter-independent background rate, all strains would be selected (or otherwise) to virtually the same extent. Figure 2A highlights one transporter that displays a significant extent of such resistance (as the nrt1 deletant). NRT1 encodes a nicotinamide riboside transporter, which led us to hypothesize (i) that such a deletant would display resistance to DPI when cultured axenically, and (ii) that nicotinic acid would be able to compete with the DPI and effect phenotypic resistance. Figure 2B shows that both predictions are entirely fulfilled.

A related aspect of the hypothesis-driven approach, and note that we do also recognize the great (and perhaps greater) value of data-driven approaches (Kell and Oliver, 2004), is the view that a good theory or hypothesis has predictive power both for existing data and for other experiments not yet done. We give examples later.

\section{RE-STATEMENT OF OUR VIEW}

Our view for the transport of xenobiotic molecules (that include drugs) into intact cells might better be referred to as being that, in normal intact cells, drug molecules do not mysteriously float across any untrammeled bilayer portions of membranes that may exist, and thus that PBIN. This does not therefore have anything to say about endocytosis, paracellular transport or other modes of drug passage within tissues. Various corollaries or contingent and testable hypotheses follow from this (and see later), howeverfor instance that in many cases one ought to be able to find the transporters, that the permeability to drugs of intact biological membranes that lack any suitable transporters is negligible, and that transporter-mediation can easily account for the very heterogeneous distributions of drugs between different cells, tissues, individuals, or species. The PBIN hypothesis has the benefit of being simple (as per Occam's razor Westerhoff et al., 2009) and has high explanatory power for phenomena that we think are otherwise hard to explain on an alternative hypothesis that phospholipid Bilayer Diffusion Is Important (BDII). The Occam's razor argument means that if we can explain available data in terms of transporters (PBIN vs. BDII) without any need to invoke bilayer diffusion, then PBIN is a preferable hypothesis, that like all good hypotheses can also be tested with well-designed (i.e., genuinely discriminating) experiments and, in principle, refuted in particular cases.
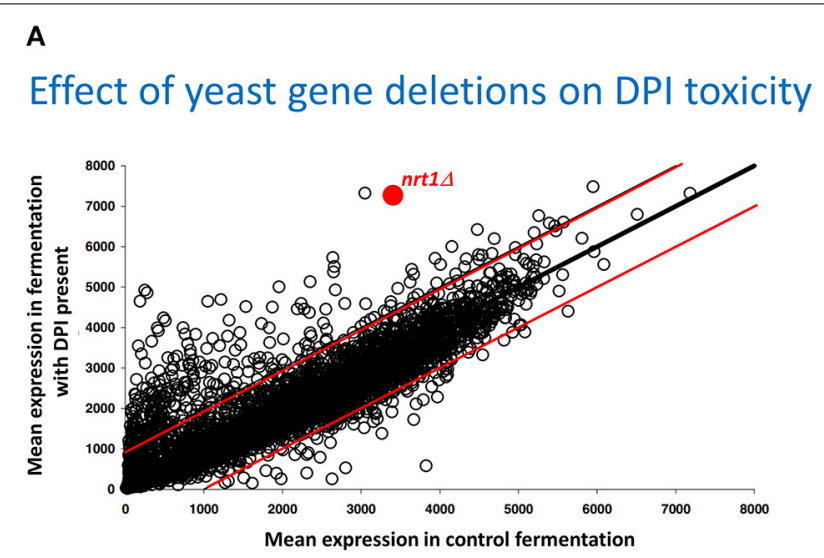

B

Effect of $n$ rt1 deletion on DPI toxicity and

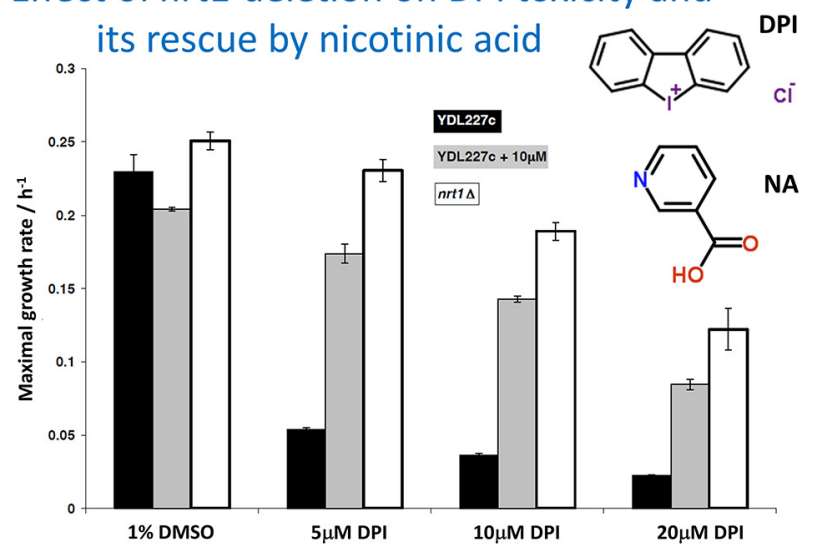

FIGURE 2 | Variation of transporter expression in the yeast gene knockout collection, as an independent variable, leads to measurable changes in the selection of different strains when exposed to toxic concentrations of a drug (here diphenyleneiodonium chloride, DPI), shown in Figure (A). The experiment is replotted and reannotated from Lanthaler et al. (2011). (A) the strains are competed in a fermentor that either does or does not contain diphenyleneiodonium, each strain being an independent variable, and their effective selection plotted as the mean amount of each strain (on the ordinate) remaining relative to the mean amount of each strain in the controls (on the abscissa), both being dependent variables. The data imply that resistance to the drug is conferred when the nrt1 transporter is knocked out, and that this is the ones to test directly for transporter activity. The two red lines show the range in which $98 \%$ of deletant lie in duplicate control experiments, thereby giving an indication of the experimental noise. (B). Assessment via maximal growth rate of the resistance of wild type (YDL 227c) and nrt1 deletant strains to different amounts of DPI and its protection by $10 \mu \mathrm{M}$ nicotinic acid (NA). The structures of DPI and NA are also shown (NA was used as nicotinamide riboside was unavailable). For further information, see Lanthaler et al. (2011).

\section{TERMINOLOGY}

Let us also restate and clarify the confused terminology that dogs this field: (i) "active" transport means uptake or indeed efflux (usually_and in this context more or less inevitably-via one or more transporters) that is concentrative in nature (and necessarily driven by an "external" energy source); (ii) "passive" transport simply means transport that is not concentrative in nature, i.e., it is equilibrative of transmembrane thermodynamic activities. 
Often, the latter is assumed to mean via lipoidal diffusion, but in general (in the field of biological transmembrane transport) no mechanism is implied by the term, and it is best if one always states what (if any) mechanism is implied. If we state "bilayer lipoidal" that is what we mean, but if we do not state a mechanism we leave it open. Passive transport through transporters is also equilibrative (of thermodynamic activities, related to free concentrations) and is normally (and correctly and usefully) referred to as "facilitated diffusion."

\section{ABSENCE OF EVIDENCE IS NOT EVIDENCE OF ABSENCE: IF YOU DO NOT KNOW ABOUT A DRUG TRANSPORTER, IT DOES NOT MEAN THAT IT IS NOT THERE AND ACTIVE}

A typical device used by those claiming "evidence" for the BDII hypothesis is to find a system and substrate in which there is uptake that is at least partially through a known transporter, to inhibit that transporter, and then simply to state that the rest of the uptake is therefore by lipoidal diffusion. This is, rather obviously, an inadequate and illogical interpretation since, in most cases, where one transporter is known so are a number of others [e.g., (Kell et al., 2011, 2013; Lanthaler et al., 2011; Sprowl and Sparreboom, 2014), and the same is true for ligands generally (Kell et al., 2013)]. At all events, it is clearly illogical to consider that this constitutes any kind of evidence for BDII when one knows nothing about the other transporters that may be active in the same tissues on the substrate of interest (Kell et al., 2011, 2013).

Quoting from a recent example Smith et al. (2014): “Additional recent (sic) data (Xu et al., 1998) from fluorine NMR studies on uptake of modified nucleosides (L-FMAU) into erythrocytes (biological systems that include transporters) provide clear indication (sic) of two different mechanism (sic) governing uptake of L-FMAU in erythrocytes: facilitated transport via nucleoside transporter and non-facilitated diffusion." In fact, they do not. What Xu et al. (1998) actually showed was that some of the uptake of the nucleoside was inhibited by an inosine analog, considered to be an inhibitor of "the" nucleoside transporter, but the rest of the uptake was not affected either by thiol reagents or by uracil (a substrate for a nucleobase-rather than nucleosidetransporter). They did not actually measure lipoidal diffusionthey simply assumed it on the basis that they were not aware of any other transporters, so there is not even the possibility of a "clear indication." However, in the 16 years since that publication, what we do have clear evidence for is that there are at least seven major transporters for nucleosides in humans (He et al., 2009; Hediger et al., 2013) (http://slc.bioparadigms.org/) [viz. concentrative nucleoside transporters CNT1-3 of the SLC (Schlessinger et al., 2013b) 28 family (Gray et al., 2004; Young et al., 2013) and equilibrative nucleoside transporters ENT1-4 of the SLC29 family (Baldwin et al., 2004; Young et al., 2013)], albeit some nucleobases will also use these transporters (Quashie et al., 2008, 2010). Of the SLC29 family, mainly ENT1 seems to be expressed in erythrocytes (Endres et al., 2009a,b), but there are indications that other transporters contribute to the very active nucleoside uptake into erythrocytes (Löffler et al., 2007); the expression levels in erythrocytes of the other SLC29 family members and of the widely expressed CNT1-3 are apparently unknown. All nucleoside transporters (including those of the CNT family) are expressed, often quite strongly, in lymphocytes (Conklin et al., 2012), however. There are also some 31 nucleotide-sugar transporters (members of the SLC35 family; Ishida and Kawakita, 2004; Song, 2013) whose expression levels and specificities in erythrocytes are not known, and other transporters may also be involved (Trigueros-Motos et al., 2012). In conclusion, it is not appropriate to claim "evidence" for a process (lipoidal diffusion) when one is not in fact measuring it, but simply assuming or inferring it (while ignoring many other possible mechanisms).

\section{CORRELATION OF PARTICULAR ACTIVITIES WITH ANY OTHER ACTIVITIES OR WITH BIOPHYSICAL PROPERTIES IS NOT CAUSATION AND CANNOT EXPLAIN MECHANISMS}

Many papers used to construct arguments as to the mechanisms of transmembrane drug transport show correlations between various things and take them as evidence for mechanisms (particularly BDII). We have pointed out many times that these kinds of correlations show nothing except that they exist in the systems stated. An attempt to indicate causation requires that something is varied (and usually plotted on the abscissa) as an independent variable. Note that dependent variables cannot be stated as causes; only independent variables or parameters play these roles (Kell and Westerhoff, 1986). Many of the correlations given (e.g., Smith et al., 2014) (and they always seem to be given in log.log. space) have points that are two orders of magnitude apart in one axis. Even if the correlations were valid, they still would not tell us about mechanisms (Kenny et al., 2014); this requires other kinds of experiments. Thus, there are also excellent correlations between the anaesthetic potency of various molecules and their lipophilicity, but equally good correlations exist for the same molecules between lipophilicity and the ability to inhibit luciferase, a soluble enzyme (that is not considered to be involved

\section{The terminology of transport reactions}

\begin{tabular}{|c|c|c|}
\hline & \multicolumn{2}{|c|}{ Means of transport } \\
\hline & Purely lipoidal & Transporter-mediated \\
\hline 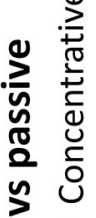 & $\begin{array}{l}\text { May be driven by } \\
\text { e.g. a pH gradient } \\
\text { or membrane } \\
\text { potential }\end{array}$ & Active transport \\
\hline 竞蒙 & Simple diffusion & Facilitated diffusion \\
\hline
\end{tabular}

FIGURE 3 | Transport reactions may be discriminated both by whether they are equilibrative or concentrative in nature (a thermodynamic property) and whether they involve solely any phospholipid bilayer that may be present or instead rely on specific transporters (a mechanistic assessment). It is important not to confuse the two. 
in mammalian anesthesia as it is not in fact present in mammals) (Franks and Lieb, 1984).

It is also important to recognize that thermodynamics (and any other state variables) cannot tell you about mechanism either. The "pH-partition theory" (Hogben et al., 1959), of which much is made (e.g., Smith et al., 2014), simply tells one that protonable molecules that can exist at a certain $\mathrm{pH}$ in both ionized and nonionized forms, and that are mainly permeable in the uncharged form, will distribute themselves according to any existing transmembrane $\mathrm{pH}$ gradients. This is extremely well-known (and not a recent observation), and such distributions have indeed long been used to estimate such pH gradients (Waddell and Butler, 1959), including by us (Kell et al., 1978a,b; Sorgato et al., 1978). Osmotic swelling methods may also be used to estimate the nature (but not the pathway or mechanism) of the most strongly permeating species (Kell et al., 1981). However, again, it is important to recognize that while the absence of a concentration gradient may indicate "the passive diffusion nature of (a transport) process," the absence of such a gradient does not permit one to conclude whether the transport is through a bilayer by lipoidal diffusion or is carrier-mediated. Thermodynamics can speak to whether a process is passive in nature (i.e., not energy coupled) but not to its molecular mechanism. These two aspects form the orthogonal axes of a "Boston matrix" (Figure 3).

Smith et al. (2014) also repeat claims that a correlation between drug uptake rates of MDCK and Caco-2 cells shows that there must be lipoidal diffusion. This claim is, at best, questionable, when a large fraction of the drugs in the study cited (Irvine et al., 1999) have known transporters (that we have listed previously, Kell et al., 2011).

\section{CORRELATION OF DRUG UPTAKE INTO ERYTHROCYTES WITH LOG P}

According to Smith et al. (2014), their "Figure 4 shows that the uptake of drugs into human red blood cells significantly correlates with $\log$ P." We reproduce their Figure 4 as our Figure 4A below. The ordinate data are in fact taken from a review by Hinderling (1997) and an earlier monograph. What is plotted on the ordinate, however, is not the uptake (or partitioning) but (for whatever reason) the logarithm of the uptake/partitioning. When we plot erythrocyte uptake against the ability to partition (and not its logarithm) into octanol (Figure 4B), we find that there is, in fact, little correlation. This is unsurprising given that the slope of Figure 4 in Smith et al. (2014) in log-log space is just 0.22 and that some pairs of data points are more than two orders of magnitude away from others with a similar ordinate or abscissa value. We would repeat our advice (Kell et al., 2011) against putting one's faith in log-log plots when their slope is far from unity. Other examples of a lack of correlation of uptake with $\log \mathrm{P} / \log \mathrm{D}$ are given below. [Phenomena that do correlate with $\log \mathrm{P}$, however, include protein binding (Hughes et al., 2008), drug promiscuity (Azzaoui et al., 2007; Leeson and Springthorpe, 2007; Hann, 2011; Kell et al., 2013) and toxicity (Hughes et al., 2008; Hann, 2011)].

\section{INADEQUATE CROSS-VALIDATION OF PREDICTIVE MODELS}

According to Smith et al. (2014) "The CNS represents an important vascular/cellular barrier that is accessed in most cases by

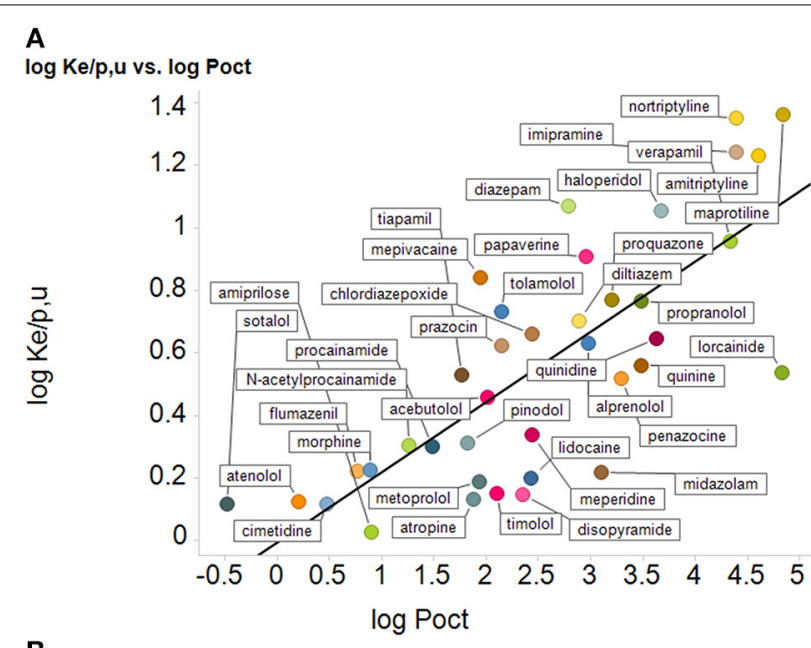

$\mathrm{Ke} / \mathrm{p}, \mathrm{u}$ vs. Poct

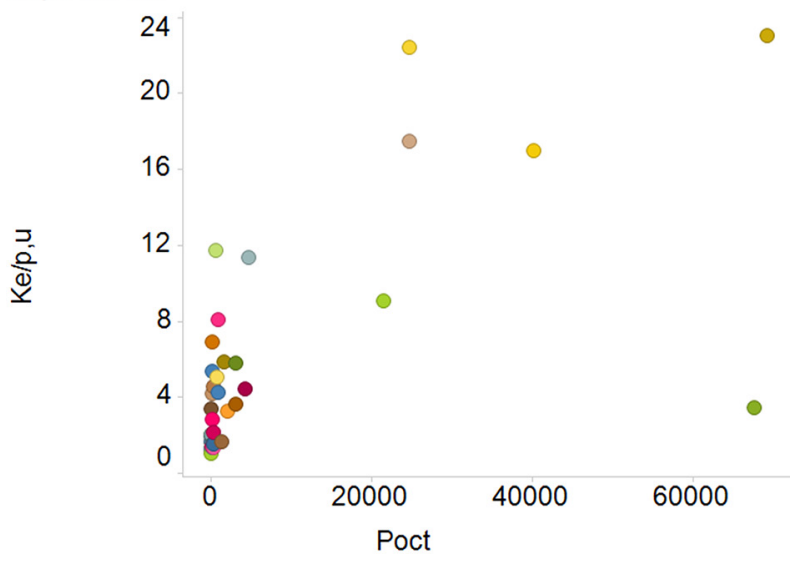

FIGURE 4 | Relationships between uptake of drugs into erythrocyte and their $\log P,(A)$ as redrawn from the plot in Figure 4 of Smith et al. (2014), along with their best-fit straight line $\left(\log K_{e / p, u}=-0.013+\right.$ $\left.0.22 \log P_{\text {oct }}\right), r^{2}=0.59$, and (B) the same data plotted with the ordinate encoded linearly, using the same colored symbols as in Figure 4A. We do not try to fit a straight line through the left-hand 32 drugs and the right-hand 6 drugs.

lipoidal diffusion and is amenable to quantitative structurepermeation relations (Ooms et al., 2002).” Apart from the fact that this is again merely a self-defining assertion (and, see below, because there is little or no paracellular transport, the blood-brain barrier (BBB) arguably represents a system that is in fact hard to explain in this way), the paper cited (Ooms et al., 2002) is a very poor example of statistical modeling. A four-latent-variable partial least squares model (effectively a form of correlation) is formed based on (variously) 79-83 objects (compounds) (four inconvenient "outliers" were removed...; Ooms et al., 2002) and 31-72 variables (descriptors), using a version of leave-one-out cross validation. Even with this, the correlation coefficient $r^{2}$ in log-log space between experimental and predicted values of BBB permeation is only $0.68-0.76$ (the slope is not given in the paper), and the $q^{2}$ values are just $0.5-0.65$. However, this approach to QSAR/QSPR has since been questioned seriously (e.g., Golbraikh and Tropsha, 2002; Cronin and Schultz, 2003; Eriksson et al., 
2003; Golbraikh et al., 2003; Tropsha et al., 2003; Broadhurst and Kell, 2006; Tropsha, 2010), and was before (Kell and Sonnleitner, 1995), as the failure to use any kind of external validation set (and the paper cited Ooms et al., 2002 did not) makes it extremely prone to over-fitting.

\section{INTELLECTUAL CHALLENGES AROUND BILAYER LIPOIDAL PERMEABILITY vs. CARRIER-MEDIATED DRUG TRANSPORT}

Smith et al. (2014) raise 15 points that we have made in earlier papers, and offer alternative views. We rehearse these now, since they cover the space of the subject matter quite effectively. The overall aim is (presumably) to find good experiments that will allow us to differentiate between lipoidal diffusion and carriermediated transport of different xenobiotics across the membranes of real biological cells, and, where relevant, we shall seek to suggest some based on the 15 points. Later, we suggest others that we think are rather better. In the following, it should be noted that "statements" and "responses" come verbatim from Smith et al. (2014), the former are that review's summary of our position and the latter represent its rebuttal of our position; “counters" represent this review's answers to the points made in those rebuttals.

1. Statement: "Lipophilic cations are charged and cannot cross membranes owing to Born charging. Response: Drug molecule ions are in equilibrium with neutral non-ionized drug molecules, which have much higher lipophilicity and much higher passive diffusion permeation rate. According to the $\mathrm{pH}$-partition theory, permeation rate varies with solution $\mathrm{pH}$ and a compound's $\mathrm{pK}_{\mathrm{a}}$ such that an increasing ratio of non-ionized/ionized forms correlates with increasing permeation rate." Counter: Smith et al. (2014) seem to miss what we indicated is meant by a lipophilic cation in this context. A typical example given (Dobson and Kell, 2008) is that of the dibenzyldimethylamonium lipophilic cation, that enters yeast via a thiamine transporter (Barts et al., 1980). Lipophilic cations of this type contain quaternary nitrogen atoms with no protons bound directly to the nitrogen; in other words, at any biologically relevant $\mathrm{pH}$, they are always cationic, and they are not "in equilibrium with neutral nonionized drug molecules." The same is true for other lipophilic cations of this type, including those we have used-such as butyltriphenylphosphonium (Mccarthy et al., 1981).

2. Statement: "The mass ratio of protein:lipid in vivo (1/1 to 3/1) affects the transport properties of lipids. Artificial membranes do not model biological membranes, owing to the high protein content in vivo. Response: These ratios include the cytoplasmic and exoplasmic portions of membrane protein mass, not just the relevant transmembrane fraction. The lipid:protein molar ratio is estimated as 40:1, making lipid an important portion of the membrane exposed to drug molecules. A further refined consideration would take into account the relative cross-sectional area at the membrane surface of the 40 phospholipid molecules to one typical protein. The lipid surface area would still be significantly greater than that of the transporter protein." Counter: The surface area per se is not the question. What matters is the extent to which the presence of high amounts of protein in a cell membrane (Dupuy and Engelman, 2008), often binding specific lipids (Laganowsky et al., 2014) (including cholesterol; Song et al., 2014) and certainly altering their organization (Mitra et al., 2004; Engelman, 2005; Mclaughlin and Murray, 2005; Beswick et al., 2011; Coskun and Simons, 2011; Kusumi et al., 2011; Lee, 2011a,b; Domański et al., 2012; Koldsø and Sansom, 2012; Magalon et al., 2012; Mueller et al., 2012; Smith, 2012; Goose and Sansom, 2013; Javanainen et al., 2013; Van Der Cruijsen et al., 2013) (and vice versa; Li et al., 2012; Denning and Beckstein, 2013), alters any ability of drug molecules to cross via the lipoidal bilayer part of the membranes in which these proteins exist. This means that any direct change of lipids will also have the potential likelihood of affecting transporters, so is not of itself a discriminating experiment if transporter activities are not measured. We see an important role for molecular dynamics simulation studies here [see e.g., those of Sansom and colleagues (Stansfeld and Sansom, 2011; Stansfeld et al., 2013), of Tajkhorshid and colleages (Khalili-Araghi et al., 2009; Wang et al., 2010b; Enkavi et al., 2013; Moradi and Tajkhorshid, 2013; Shaikh et al., 2013; Han et al., 2014; Mishra et al., 2014), and of others (e.g., Gedeon et al., 2010; Skovstrup et al., 2012; Denning and Beckstein, 2013; Koldsø et al., 2013; Schlessinger et al., 2013b)], and note that even $\mathrm{CO}_{2}$ can traverse membranes via the central pore in aquaporin (Wang et al., 2010b; Kaldenhoff et al., 2014; Li et al., 2014). It is here worth reminding readers of what membranes actually look like (in cartoon form) (Engelman, 2005), of the size of phospholipid head groups relative to the size of a drug such as atorvastatin (Figures 5A,B), and of the consequent unlikelihood of a drug floating unaided swiftly through a phospholipid bilayer in a real biomembrane.

3. Statement: "Correlations of drug uptake with $\log \mathrm{P}$ and Caco-2 permeation can be weak. Response: For drugs permeating predominantly by passive lipoidal diffusion, the apparent Caco-2 permeability coefficient, $\mathrm{P}_{\text {app }}$, can be (and often is) affected by the aqueous boundary layer, filter, paracellular, and lipoidal (transcellular) permeability, as well as the solution $\mathrm{pH}$, as illustrated by the examples in Figure 5 of Smith et al. (2014). $\log$ P cannot be directly compared to log $\mathrm{P}_{\mathrm{app}}$. The Caco-2 intrinsic permeability, $\log \mathrm{P}_{0}$, is the rational term to compare to $\log \mathrm{P} . \mathrm{P}_{0}$ is easy to deduce from $\mathrm{P}_{\mathrm{app}}$, but this is seldom done, which often leads to "weak" correlation, as "apple seeds are compared to whole watermelons." Caco-2 cells from 10 different laboratories were compared in terms of transporter mRNA levels of 72 drug and nutrient transporters, and 17 other targets. It was concluded that "Caco-2 cells from different laboratories produce different results even when using standard protocols for transport studies. The differences may be due to transporter expression as shown for e.g., PepT1 and MDR1 which in turn is determined by the culture conditions. Although the majority of the laboratories used similar culture conditions, absolute expression of genes was variable indicating that even small differences in culture conditions have a significant impact on gene expression, although the overall expression patterns 


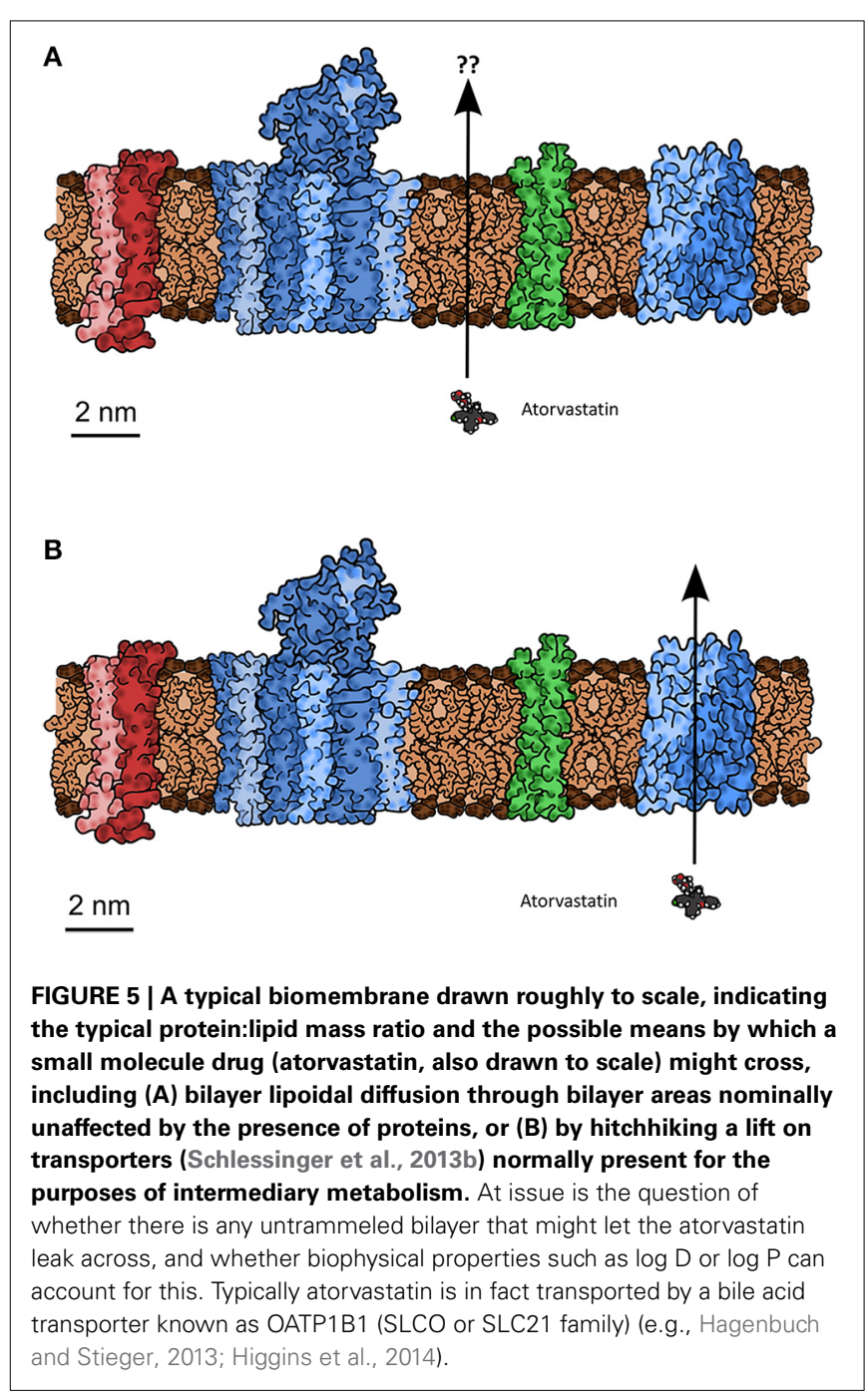

were similar." Therefore, it is not astonishing that results of Caco-2 cell based permeabilities, when correlated with octanol log P/D values, sometimes show differences in correlations. This is mainly due to the origin and composition of the analyzed data set [ratio actively vs. passively (lipoidal diffusion) transported compounds] and use of partition coefficients $(\log \mathrm{P})$ or $\mathrm{pH}$-dependent distribution coefficients (log D). Interestingly, correlations of transport studies performed with different cell lines (e.g., Caco-2/MDCK) commonly used in absorption prediction, with presumably different transporter expression levels, often give excellent correlations, further supporting the coexistence of active and passive transport in biological systems." Counter: So many different things are confused here that it is hard to know what point is actually being made. First, there is the self-defining prophecy (or circular argument) that starts by asserting "for drugs permeating predominantly by passive lipoidal diffusion" when this is what we are trying to assess! Then the fact that there is experimental (inter-laboratory) noise in Caco2 cell measurements is used simultaneously to argue both that it is unsurprising that differences are found, but also that one finds similarities. Finally, there is then a complete jump in logic ("further supporting the coexistence of active and passive transport in biological systems") that relates concentrative uptake (active) to correlations found in two different cell lines that each express hundreds of transporters (Anderle et al., 2004; Landowski et al., 2004; Pshezhetsky et al., 2007; Ahlin et al., 2009; Chen et al., 2010; Volpe, 2011) (and the human genome encodes more; Hediger et al., 2013; Schlessinger et al., 2013b; Viereck et al., 2014). To reiterate: such correlations, if found, can occur regardless of mechanism. When found, and when transport is equilibrative rather than active, they have nothing at all to say about mechanism (whether passive lipoidal or facilitated diffusion, or both, or neither). When they are not found (and there are many examples), one mechanism that can underpin this is carriermediated active transport that may occur in some cases but not others depending on the presence of relevant transporters and suitable thermodynamic gradients providing a source of free energy.

4. Statement: "Transport across model artificial membranes is stated to occur via pore defects or dissolution in the lipid mixture that are not seen in vivo. Response: The studies cited are computational simulations (so-called molecular dynamics) of $\mathrm{Na}^{+}$and $\mathrm{Cl}^{-}$ion (non-drug-like) transport under unusual conditions. No convincing experimental evidence for the relevance of pores has been reported. Other experiments indicate the unimportance of pores. Membrane resistance excluding pore diffusion is usually determined by conductivity measurements. Otherwise function of, e.g., ion channels could not be determined." Counter: molecular dynamics (and other) simulations are a highly important part of science (and engineering), and these and other computational analyses will become increasingly so (Hey et al., 2009), not least in systems biology (Kell and Knowles, 2006; Herrgård et al., 2008; Thiele et al., 2013). The nonzero conductivity of e.g., black lipid membranes (Jain, 1972; Tien, 1974; Tien and Ottova-Leitmannova, 2003) can only be due to aqueous pores because the Born charging energy is so large that it is inconceivable that $\mathrm{Na}^{+}$and $\mathrm{Cl}^{-}$ions pass through a membrane dielectric with a permittivity of 2-4 (Parsegian, 1969; Bordi et al., 1999). As stated previously Kell et al. (2013), it is possible to make artificial membranes with negligible conductivity [e.g., for biosensors (Aojula et al., 2002), for nanopore sequencing (Bayley, 2006; Stoddart et al., 2009; Rincon-Restrepo et al., 2011), or with Gigaseal patches (Sakmann and Neher, 1984; Neher and Sakmann, 1992)], but this does not mean that experimenters normally do so (and they do not, including ourselves as in a study of liposomal transmembrane proton transport; Kell and Morris, 1980). Moreover, artificial membranes are not biomembranes, which is what we wish to know about.

5. Statement: "A dominant role for carrier-mediated transport (and against passive diffusion) is inferred from the hundreds of publications on drug transporters. Response: A large number of papers have been published in recent years on transporters. These result from the recent intense research on transporters. However, it is a logical fallacy and a sleight 
of hand to state that this is evidence of the rate and extent of dominance of carrier-mediated permeation over passive lipoidal diffusion. (An analogy would be to state that newspapers contain a predominance of articles about bad events (e.g., fires, wars, violence, accidents), therefore, bad events dominate good events in the world.) Thus, the large number of citations of publications on transporter research is misleading, because the research they report or review was not undertaken nor concluded by the publication authors as evidence that supports CMOC, as is implied ("There is considerable and increasing evidence that drugs get into cells more or less solely by hitchhiking on carriers normally used for the transport of nutrients and intermediary metabolites)." Counter: Most science involves interactions between two important elements, viz. observable data and inferential causation (Kell and Oliver, 2004). One cannot avoid context in discussions of mechanisms. If one observes that the grass is wet that represents an observation or a dataset. However, one cannot infer mechanism simply from an observation (e.g., it was raining vs. someone used a hose to water the garden). The job of the inferential scientist is to take all available data and generalize to the explanation that best accounts for them. This is what we do. Reviews summarizing hundreds of papers can do this in a way that authors of individual papers usually would not. We expect to take most data at face value (albeit some will be wrong), and have a hypothesis that (essentially) says that drugs entering cells always use one or more transporters; (the abundant) data showing the existence of transporters for particular drugs are entirely consistent with that hypothesis (and with PBIN), but have nothing to say about BDII unless bilayer diffusion is actually being measured directly (which it is not, in contrast to "good" or "bad" events in the above newspaper analogy, which are) or varied independently (which it is not).

6. Statement: "Selected small molecules, urea and glycerol, which cross BLM (bilayer or "black lipid" membranes), permeate to some extent in vivo via transporters, except in yeast because glycerol is an osmolyte. Response: Urea and glycerol are more hydrophilic than typical drugs that permeate membranes, thus, they are not good models of permeants on which to support theories." Counter: our PBIN hypothesis is entirely general, including for both natural molecules and xenobiotics, and states that there should be transporters even for small molecules (whatever their lipophilicity, and regardless of whether the FDA has approved or not their use as drugs - there is nothing special about drugs per se) and that bilayer lipoidal transport is probably negligible. The observable data are consistent with this. PBIN provides a ready explanation for the lack of membrane permeability of molecules for which the membrane lacks transporters. This is also true for the $\mathrm{BBB}$, and other tissue and species differences in membrane permeability (see below).

7. Statement: "In liposomes the rate of transfer of nonelectrolytes depends on MW rather than log P. Response: Liposomes correlate well with the permeation behaviors usually observed in artificial and biological membranes. Molecular weight is partly correlated with lipophilicity and hydrogen-bonding capacity, and as molecular weight increases in drugs normally so does hydrogen bonding. Molecular weight is therefore a hybrid term expected to show a relationship to lipoidal membrane permeation." Counter: In fact, MW and $\log \mathrm{P}$ are rather weakly correlated anyway (e.g., Hughes et al., 2008) and we have no specific preference for either in the absence of an objective function. What we need to be provided with are some predictive hypotheses (see below).

8. Statement: "In vitro models of diffusion rates across membranes are not based on large sample numbers and validated with compounds not used in the method development. Response: This is out of date information." Counter: It is odd merely to refer to this as "out of date information" without providing any evidence, but this could be settled by providing the examples in real biomembranes in which all the other relevant transporter-mediated fluxes are removed by deleting the transporter genes (or by any other means).

9. Statement: "The flux across in vitro PAMPA membranes can be poor even when human absorption is good (e.g., cephalexin, tiacrilast). Response: This is out of date information and also is misleading. PAMPA membranes serve to model passive diffusion, whereas cephalexin and a number of other molecules are carrier-mediation transported, as extensively compiled. The present authors claim that passive and active transport processes coexist. PAMPA has been described to only account for passive membrane permeation processes. Therefore, it is not astonishing that actively transported compounds like, e.g., cephalexin cannot be correctly predicted regarding human absorption by methods exclusively focusing on passive transport." Counter: Leaving aside the thermodynamic confusion of "active" and "passive," we agree that there are many cases for which PAMPA is a poor predictor of the permeability across biological membranes; such cases provide good examples in which passive lipoidal diffusion is not sensibly invoked as a mechanism of xenobiotic transport. (For readers who do not know, PAMPA membranes are various artificial more-or-less hydrophobic barriers that have been used to model transport.) Certainly some molecules can cross protein-free PAMPA membranes very effectively, but this does not tell us about how this relates mechanistically to transport through biological membranes, in which our interests lie. If PAMPA correlates with some calculations based e.g., on $\log \mathrm{D}$ or other variables, then one could of course use the latter alone to calculate PAMPA behavior if one is interested in it.

10. Statement: "Activities of anesthetics were previously thought to be controlled by passive diffusion and correlated to $\log \mathrm{P}$, but are now thought to be protein-binding related. Response: There is common agreement that drug molecules and anesthetics might interact with proteins, but this is misleading in the context of the discussion, which is around drug transport and not mechanism of action. A recent publication on anesthetics has summarized thus: 'The molecular mechanism of general anesthesia is still a controversial issue. Direct effect by linking of anesthetics to proteins and indirect action on the lipid membrane properties are the two hypotheses 
in conflict?" Counter: this is an example of highly selective reporting; the paper cited is not even about biological membranes, and the apodosis of the title of the paper ("looking for a lipid-mediated mechanism of anesthesia") implies an agenda that seeks to pre-judge the answer. We have discussed the extensive literature of general anesthetics many times (Dobson and Kell, 2008; Dobson et al., 2009a,b; Kell and Dobson, 2009; Kell et al., 2011, 2013; Kell, 2013; Kell and Goodacre, 2014), and the available data show clearly the involvement of a variety of proteins such as $\mathrm{GABA}_{\mathrm{A}}$ receptors (Mihic et al., 1997; Jurd et al., 2003; Bonin and Orser, 2008), potassium channels (Patel et al., 1999; Thompson and Wafford, 2001; Franks and Honoré, 2004; Gruss et al., 2004; Heurteaux et al., 2004; Grasshoff et al., 2006; Andres-Enguix et al., 2007; Bertaccini and Trudell, 2012), glycine receptors (Mihic et al., 1997; Lobo and Harris, 2005; Dickinson et al., 2007; Bertaccini et al., 2010), and NMDA receptors (Sanders et al., 2003; Dickinson et al., 2007; Dickinson and Franks, 2010). The sites of interaction of general anesthetics with a number of their target membrane proteins are now known with molecular resolution, including their variation in mutant forms of the same proteins (that correlate with changes in anesthetics potency-see e.g., Nury et al., 2011; Stansfeld and Sansom, 2011). Such evidence makes clear precisely what the protein targets of general anesthetics are. We invoke the story of the changes over time in our understanding of the mechanisms of narcosis (general anesthesia) because the whole discussion is precisely about the mechanism of action (i.e., transport) of drugs crossing membranes, and because this purportedly (according to Smith et al. (2014) and others) occurs passively through bilayers according to their lipophilicity, just as was once believed for general anesthetics. The analogy is both appropriate and clear-cut, and the change in understanding over time is likely to be of a similar nature.

11. Statement: "Many molecules (e.g., ethanol) have relatively specific receptors, so they may have similar protein binding (unidentified) that effects membrane permeation. Response: This is an assumption and generalization awaiting to be proven by experimental data, but which currently does not rule out transport by passive (lipoidal diffusion) mechanism." Counter: As explained, the Popperian view does not allow one to rule out anything for which a specific mechanistic hypothesis has not been given, nor to "prove" it, and the bilayer lipoidal diffusion hypothesis for intact biomembranes is not set down in a properly testable way. By contrast, PBIN states that binding proteins and transporters will be found for all kinds of molecules. Another recently discovered binding protein for ethanol [additional to $\mathrm{GABA}_{\mathrm{A}}$ receptor subtypes (Wallner et al., 2003, 2006; Nutt et al., 2007; Olsen et al., 2007; Santhakumar et al., 2007; Bonin and Orser, 2008; Lobo and Harris, 2008; Mody, 2008; Meera et al., 2010; Johnson et al., 2012) and many others where the binding site is known to atomic resolution (Howard et al., 2011b)] is GLIC, a prokaryotic member of the pentameric ligandgated ion channel (pLGIC) family (Stansfeld and Sansom, 2011; Howard et al., 2011a, 2014). Other recent papers on ethanol-binding proteins include ones on Munc13-1 (Das et al., 2013) and alcR (Sakvarelidze et al., 2007) (which was discovered in 1985; Doy et al., 1985), so ethanol receptors are not "unidentified." The final identification of e.g., yeast ethanol transporters is not yet certain, but assessing the contributions of such membrane proteins to solvent tolerance is one experimental approach to detecting them (Kieboom et al., 1998a). While other mechanisms are also possible (Dikicioglu et al., 2014), the ABC transporter (Sá-Correia et al., 2009) Pdr18 (Teixeira et al., 2012) and the glyceroaquaporin Fps1 (Teixeira et al., 2009) have properties consistent with such a role as ethanol transporters in yeast, a fact of considerable biotechnological relevance (Dunlop et al., 2011). In the context of biofuels production (and ethanol is a biofuel), and based on similar strategies of toxicity resistance to the one that we exploited earlier (Lanthaler et al., 2011), we now also know them for a variety of other rather lipophilic substances such as alkanes (Tsukagoshi and Aono, 2000; Fernandes et al., 2003; Ankarloo et al., 2010; Chen et al., 2013; Doshi et al., 2013; Foo and Leong, 2013; Ling et al., 2013; Nishida et al., 2013), arenes (Kieboom et al., 1998b), terpenoids (Jasiński et al., 2001; Yazaki, 2006; Foo and Leong, 2013), long-chain fatty acids (Wu et al., 2006a,b; Khnykin et al., 2011; Lin and Khnykin, 2014; Villalba and Alvarez, 2014), short-chain fatty acids (Gimenez et al., 2003; Islam et al., 2008; Moschen et al., 2012; Sá-Pessoa et al., 2013), etc. These are all substances for which bilayer lipoidal diffusion was "once widely assumed" (and presumably still is in some quarters). Ethanolamine transporters are well-established in certain salmonellae (Stojiljkovic et al., 1995; Penrod et al., 2004).

12. Statement: "Carrier-mediated drug uptake is observed where it has been studied. (Presumably this circumstantially indicates that transporters will be found for all drugs.) Response: Carrier-mediated drug uptake may be observed, but it may not account for $100 \%$ of the transport. In Michaelis-Menten analysis, the non-saturable term usually is related to the passive diffusion contribution." Counter: reiterating the fact that something (the transport via carriers you do not know about) does not exist because you have not found it is illogical. See the section about absence of evidence not being evidence of absence. By contrast, PBIN is testable because we make specific predictions about drug transporters and the effects of removing them (by deleting their cognate genes) or increasing their activities (and, yes, we consider it likely that transporters will be found for all drugs). Saturability is not a useful criterion. One would hardly deny the existence of aquaporins because of the fact that they may not be observably saturable in the experimentally testable range.

13. Statement: "Drugs can concentrate in specific tissues beyond the stoichiometry of internal binding sites. This phenomenon absolutely requires an active uptake process. Response: This can be due to $\mathrm{pH}$ gradients between intracellular and extracellular compartments as described for, e.g., basic amines and safety relevant lysosome accumulation (phospholipidosis)." Counter: agreed, see above; this is well-known (and a 
$\mathrm{pH}$ gradient can provide a thermodynamic drive that could cause transport to be active, i.e., concentrative, whatever the mechanism of transmembrane transfer). The same general idea is true (in principle) for charged molecules or those whose transport is ion-coupled accumulating (or not; Kell, 1992) in compartments where there is a membrane potential difference relative to elsewhere. These are thermodynamic statements, not mechanistic ones.

14. Statement: "Biophysical forces in drug-lipid membrane interactions (e.g., lipophilicity, hydrogen bonding) are no different from drug-protein interaction. Thus, physicochemical properties and the rule of 5 need not be evidence of passive diffusion. Response: Of course biophysical forces apply to both transporters and bilayers. However, the physical property differences between the rate limiting barriers for a particular drug in carriers and bilayers can dictate the predominant route of transport. A second argument is that ligand-protein recognition is dominated by highly selective stereoelectronic features far more than by global (molecular) physicochemical properties." Counter: One potential approach to discriminating bilayer lipoidal diffusion from transport via proteins with similar biophysical characteristics is to compare their biophysical characteristics and make and test some specific predictions. The effects are likely to be subtle, but may be measurable. We invite the proponents of BDII to do this, if they can work out a means for actually measuring (as opposed to assuming) bilayer lipoidal diffusion in real biological membranes. However, arguments based on the substrate specificity of enzymes, when you do not even know them, are utterly pointless. We have tried to explain several times (e.g., Kell et al., 2011, 2013) the extremely well-known fact that some enzymes are highly promiscuous (and see e.g., O'brien and Herschlag, 1999; Hopkins et al., 2006; Ma and Lu, 2008; Nobeli et al., 2009; Carbonell and Faulon, 2010; Khersonsky and Tawfik, 2010; Gatti-Lafranconi and Hollfelder, 2013). If an enzyme uses a great many substrates it is not very likely that it will be very discriminative of e.g., stereoisomers of the same molecule [although some transporters are stereoselective (Zhou et al., 2014), e.g., those for propranolol (Wang et al., 2010a; Zheng et al., 2013)]. By contrast, the activity of many promiscuous enzymes (e.g., the cytochromes P450, e.g., O'reilly et al., 2011, 2013; Munro et al., 2013) can be related (up to a cut-off) to the lipophilicity of the substrate. This is very simply explained in terms of the possession of a hydrophobic substrate pocket.

15. Statement: "The notion of passive lipoidal permeation is traced back to artificial membrane systems, which are not successful predictors of membrane permeation. Response: On the contrary, artificial membrane models have been successful predictors of passive lipoidal permeation." Counter: although not especially relevant, the notion of passive lipoidal permeation is in fact traced back to long before the invention of model membrane systems, or even our knowledge (Gorter and Grendel, 1925) of the bilayer thickness of biological membranes; Smith and colleagues do in fact cite the work of Overton in 1899 that initiated it (Overton, 1899). We have dealt with correlations enough.

\section{TESTABLE HYPOTHESES: EXPERIMENTS THAT MAY BE USEFUL FOR DISCRIMINATING PBIN AND BDII}

The importance of transporters to the uptake of existing clinical drugs is a backward-looking enterprise, but we have previously given a variety of examples of drugs, such as the (Lipinskicompliant; Lipinski et al., 1997; Lipinski, 2004) nucleoside antipancreatic cancer drug gemcitabine, that clearly are efficacious only when transported by relevant transporters (e.g., Mackey et al., 1998, 1999; Rauchwerger et al., 2000; Huang and Sadée, 2003; Mangravite et al., 2003; Huang et al., 2004; Spratlin et al., 2004; Giovannetti et al., 2006; King et al., 2006; Marcé et al., 2006; Mori et al., 2007; Nakano et al., 2007; Oguri et al., 2007; Molina-Arcas et al., 2008; Andersson et al., 2009; Farrell et al., 2009; Maréchal et al., 2009, 2012; Hagmann et al., 2010; MolinaArcas and Pastor-Anglada, 2010; Bhutia et al., 2011; Komori et al., 2011; Parkinson et al., 2011; Santini et al., 2011; Wang et al., 2011; Borbath et al., 2012; Damaraju et al., 2012, 2014; Gesto et al., 2012; Murata et al., 2012; Ansari et al., 2013; Jordheim and Dumontet, 2013; Nakagawa et al., 2013; Skrypek et al., 2013; Xiao et al., 2013; De Sousa Cavalcante and Monteiro, 2014; Lee et al., 2014; Nordh et al., 2014; Tong et al., 2014). We do not know of any evidence that gemcitabine (or any other nucleoside) exhibits any significant bilayer lipoidal diffusion across intact cellular membranes, although the question of whether a molecule is "thought to permeate mainly by passive lipoidal diffusion" does of course depend on who is doing the thinking.

We stress that our analyses are based on all kinds of molecules, whether the FDA has approved them as drugs or not. Consequently, we shall use as examples clinical drug candidates and other xenobiotics, as well as marketed drugs.

\section{TESTING THE PBIN VIEW}

Smith et al. (2014) made some suggestions as to how the PBIN view may be tested. Rather than quoting them verbatim, we summarize the relevant topics.

\section{IDENTIFYING RELEVANT TRANSPORTERS}

This is very important, and websites such as Transportal (Morrissey et al., 2012) http://bts.ucsf.edu/fdatransportal/, DrugBank (Law et al., 2014) http://www.drugbank.ca/ and others reviewed in Viereck et al. (2014) contain literally hundreds of examples in which known drugs use known transporters, complete with quantitative data, sometimes for genetic variants that change activity or expression. While the BDII view merely assumes lipoidal transport and varies nothing systematically to try to assess it, PBIN makes specific predictions via causing variation in the activities of specified transporters, and the starting point is that one should find out which they are.

To this end, we would cite the work of Brummelkamp, SupertiFurga and colleagues, who have developed a near-haploid mammalian cell line (Carette et al., 2009, 2011; Bürckstümmer et al., 2013) along with a suitable retrovirus (actually a gene trap (GT) retrovirus) that can insert into more-or-less any gene, thereby inactivating it. In a manner similar to that which we used in yeast (Lanthaler et al., 2011), they have been studying the efficacy of an anticancer drug, sepantronium bromide (also known as YM155, see e.g., Giaccone et al., 2009; Nakahara et al., 2011; 
Aoyama et al., 2013; Murakami et al., 2013), in various cell lines. They find (Winter et al., 2014) (and cf. Minematsu et al., 2009, 2010) that the uptake of this drug, and thus its ability to kill mammalian cells, essentially depends entirely (and quantitatively) on the expression of a single, specific transporter, viz SLC35F2 (see Ishida and Kawakita, 2004; Song, 2013). They find precisely no evidence for any lipoidal diffusion (nor of efflux transporters). This general method can only really "work" (i.e., serve to illuminate the transporters effecting significant fluxes of cytotoxic or other drugs) if the "non-specific" background rate (e.g., via bilayer lipoidal transport) is negligible, and will clearly be of very great utility in discovering precisely which drugs use which transporters (Bassik and Kampmann, 2011; Reiling et al., 2011; Bürckstümmer et al., 2013).

In a similar vein, cloned or recombinant transporters are a very useful strategy (and one widely used, e.g., Mackey et al., 1999; Srimaroeng et al., 2008; Giacomini et al., 2010; Brouwer et al., 2013; Winter et al., 2014) but, as mentioned above, saturability, the availability of inhibitors or the extent of promiscuity or otherwise are not at all discriminatory (Kell et al., 2011). Much better criteria relate to varying the activities or expression levels genetically (e.g., by cloning transporters-independent variable) and then seeing the consequent effects of their expression levels (here an independent variable) on drug transport (dependent variable). QConCats (e.g., Pratt et al., 2006; Rivers et al., 2007; Brownridge et al., 2011; Carroll et al., 2011; Achour et al., 2014; Chen and Turko, 2014) provide an important (Harwood et al., 2013) and absolute means of measuring expression levels of target proteins, including transporters (Russell et al., 2013), while other absolute approaches to transporter quantification are also emerging (Ohtsuki et al., 2011, 2013; Uchida et al., 2011b, 2013; Obuchi et al., 2013; Qiu et al., 2014).

In a similar vein, the $\mathrm{pH}$-dependence of uptake and $\mathrm{pH}$ partition theories are both very hard to interpret and essentially irrelevant to the question of mechanism; the latter depends solely upon which species happens to be most permeable (and they are not always those expected; Mazák and Noszál, 2014).

\section{VARYING TRANSPORTER EXPRESSION IN ESTABLISHED CELL LINES}

Worthwhile experiments on this will be doable using genetic knockouts, gene traps, or siRNA, etc. Fortunately we know many of the relevant transporters from genome sequencing, and the expression of hundreds of proteins in the membranes of MDCK (Chen et al., 2010) and Caco-2 (Anderle et al., 2004; Landowski et al., 2004; Pshezhetsky et al., 2007; Ahlin et al., 2009) cells are known from transcriptome and proteome studies. The example of SLC35F2 is very pertinent-the recognition of its activity in transporting sepantronium is new (Winter et al., 2014) but the transporter (albeit not its natural substrate) was known (Ishida and Kawakita, 2004; Song, 2013). Thus, we can now predict that the transport of sepantronium into Caco-2 or MDCK will depend upon the activity of a transporter that will likely be the same as or homologous to SLC35F2.

\section{VARYING LIPOIDAL DIFFUSION AS AN INDEPENDENT VARIABLE}

For those who believe that BDII, the hypothetico-deductive approach requires that one varies it as an independent variable and/or measures it as a dependent variable. Since we believe that passive lipoidal bilayer diffusion in real biomembranes is initially negligible, and give many examples, it is not obvious how we could slow it down! However, we would stress that broad changes such as e.g., temperature will affect both lipids and transporters and are not suitably discriminatory (especially if transporter fluxes are not measured). Neither is changing lipid composition alone discriminatory, since (see above) changes in lipids can have profound effects on the activities of membrane proteins, including transporters. So, to be discriminatory it is necessary to measure any such effects on known and relevant transporters as a control. We have also explained many times that only tests in real membranes can tell us what is happening in real membranes, and that there is no "observed passive lipoidal permeation of biological membranes," only an inferencing of it. It is also important to make well-defined comparisons with a given species and cell type or line. Species differences (see below) can be enormous, let alone differences between real biological membranes and model membranes lacking proteins. Adding small amounts of lipids that can be made to crosslink to each other but not to proteins (nor to bind to them) may or may not be informative.

\section{WE PROPOSE SOME CANDIDATE DISCRIMINATING EXPERIMENTS THAT ADHERENTS OF THE BDII THEORY AND OTHERS MIGHT CARE TO PERFORM OR ASSESS}

According to our reading, the BDII view allows all kinds of xenobiotics to cross biomembranes, by diffusing through whatever phospholipid bilayer portions that they may contain, thereby equilibrating their internal and external concentrations according to whatever thermodynamic forces may be operating, regardless of cell, tissue, individual, or species. A considerable number of corollaries follow from this BDII view. We think that the existing data do not follow those corollaries, at least without adding ad hoc and extra hypotheses to make special cases. However, it will be important to be clear as to precisely what the adherents of the BDII theory claim to be true in a testable manner, so we can evaluate whether the data are or are not consistent with these predictions. We make some suggestions as to where discriminatory experiments are likely to serve.

\section{WHAT IS THE PREDICTED RELATIONSHIP FOR THE BDII THEORY BETWEEN LOG D AND FLUXES ACROSS REAL BIOMEMBRANES?}

According to Smith et al. (2014), "Passive lipoidal permeability is correlated positively with lipophilicity (e.g., as expressed by the $\log$ of the octanol-water partition, $\log \mathrm{P}$, or the apparent value at a given $\mathrm{pH}$, often $7.4, \log \mathrm{D})$." Such a statement requires that we have a precise prediction as to the form of this relationship over a stated range of values of $\log \mathrm{P}$ and $\log \mathrm{D}$ (and state which variant of $\log \mathrm{P}$ is used if it is calculated, and with which software so that this may be reproduced).

While it is not obvious which actual measurements (as opposed to assumptions) of passive lipoidal permeability in biological membranes are being claimed (and we know of none), the above statement would also predict that if lipoidal bilayer permeability of drugs were a dominant means of drug uptake there should thus be a good correlation between cellular uptake and log $\mathrm{P}$. 
This is a very important and testable prediction. Our very first review (Dobson and Kell, 2008) displayed a typical example taken from a paper by Corti et al. (2006), showing that there is not, and we would like to stress that this paper was not specifically selected-it just happened to be the first paper we looked at for this question. We here discuss another, rather famous, dataset. The Biopharmaceutics Classification System (BCS), based on the work of Amidon and colleagues (e.g., Amidon et al., 1995; Dahan et al., 2009; Chen et al., 2011), was developed to indicate a "bioequivalence," and divides drugs into four classes based on their solubility and presumed (human jejunal) permeability, with "class 1" drugs that display high solubility and permeability deemed favorable and a waiver given http://www. fda.gov/AboutFDA/CentersOffices/OfficeofMedicalProductsand Tobacco/CDER/ucm128219.htm (and see Lennernäs et al., 2014). The experimental jejunal permeability is not always available, and so it is estimated based on a "correlation" between the permeability of a drug's neutral form and $\mathrm{c} \log \mathrm{P}$ determined for a small number of drugs. The data for 27 or 29 such drugs vs. "estimated $\log \mathrm{P}$ " and c $\log \mathrm{P}$ are re-plotted from Table 4 and Figures 5, 6 of Kasim et al. (2004) (who very helpfully provided data in both tabular and graphical forms) in our Figure 6. We note there the extremely modest extent of the correlation between the experimental permeability and either the "estimated $\log \mathrm{P}$ " or c log P. We also note that six of the eight "false negative" drugs (D-glucose, L-leucine, L-Dopa, L-phenylalanine, cephalexin, and valacyclovir) that were predicted to have low permeability but in fact had high permeability were recognized by the original authors as having transporters (Kasim et al., 2004). It is not clear whether it was assumed that the other drugs in Table 4 of Kasim et al. (2004) crossed passively by lipoidal bilayer diffusion (as opposed to facilitated diffusion through a transporter, that is also passive, Figure 3). At all events, whether it was so assumed or not, we can find evidence for interactions with transporters for each of the other drugs except for antipyrine, carbamazepine, and terbutaline. These are: $\alpha$-methyldopa (Uchino et al., 2002), amoxicillin (Li et al., 2006; Sala-Rabanal et al., 2006; Fujiwara et al., 2011, 2012), atenolol (Kato et al., 2009), cimetidine (Collett et al., 1999; Burckhardt et al., 2003; Motohashi et al., 2004; Pavek et al., 2005; Matsushima et al., 2009; Tsuda et al., 2009), creatinine (Schömig et al., 2006; Chen et al., 2009; Zhou et al., 2009; Hosoya and Tachikawa, 2011; Tachikawa and Hosoya, 2011; Torres et al., 2011), desipramine (Wu et al., 2000; Haenisch et al., 2012), enalapril (Pang et al., 1998), enalaprilat (Ishizuka et al., 1998), fluvastatin (Varma et al., 2011; Sharma et al., 2012), furosemide (Uwai et al., 2000a; Eraly et al., 2006; Vallon et al., 2008), hydrochlorothiazide (Race et al., 1999; Uwai et al., 2000a; Hasannejad et al., 2004; Han et al., 2011), ketoprofen (Khamdang et al., 2002; Morita et al., 2005), Lisinopril (Knütter et al., 2008), losartan (Edwards et al., 1999; Race et al., 1999; Knütter et al., 2009; Sato et al., 2010), metoprolol (Dudley et al., 2000), naproxen (Apiwattanakul et al., 1999; Mulato et al., 2000; Khamdang et al., 2002; El-Sheikh et al., 2007), piroxicam (Jung et al., 2001; Khamdang et al., 2002), propranolol (Dudley et al., 2000; Wang et al., 2010a; Kubo et al., 2013b; Zheng et al., 2013), ranitidine (Collett et al., 1999; Müller et al., 2005; Ming et al., 2009), and verapamil (Döppenschmitt et al., 1999; Kubo et al.,

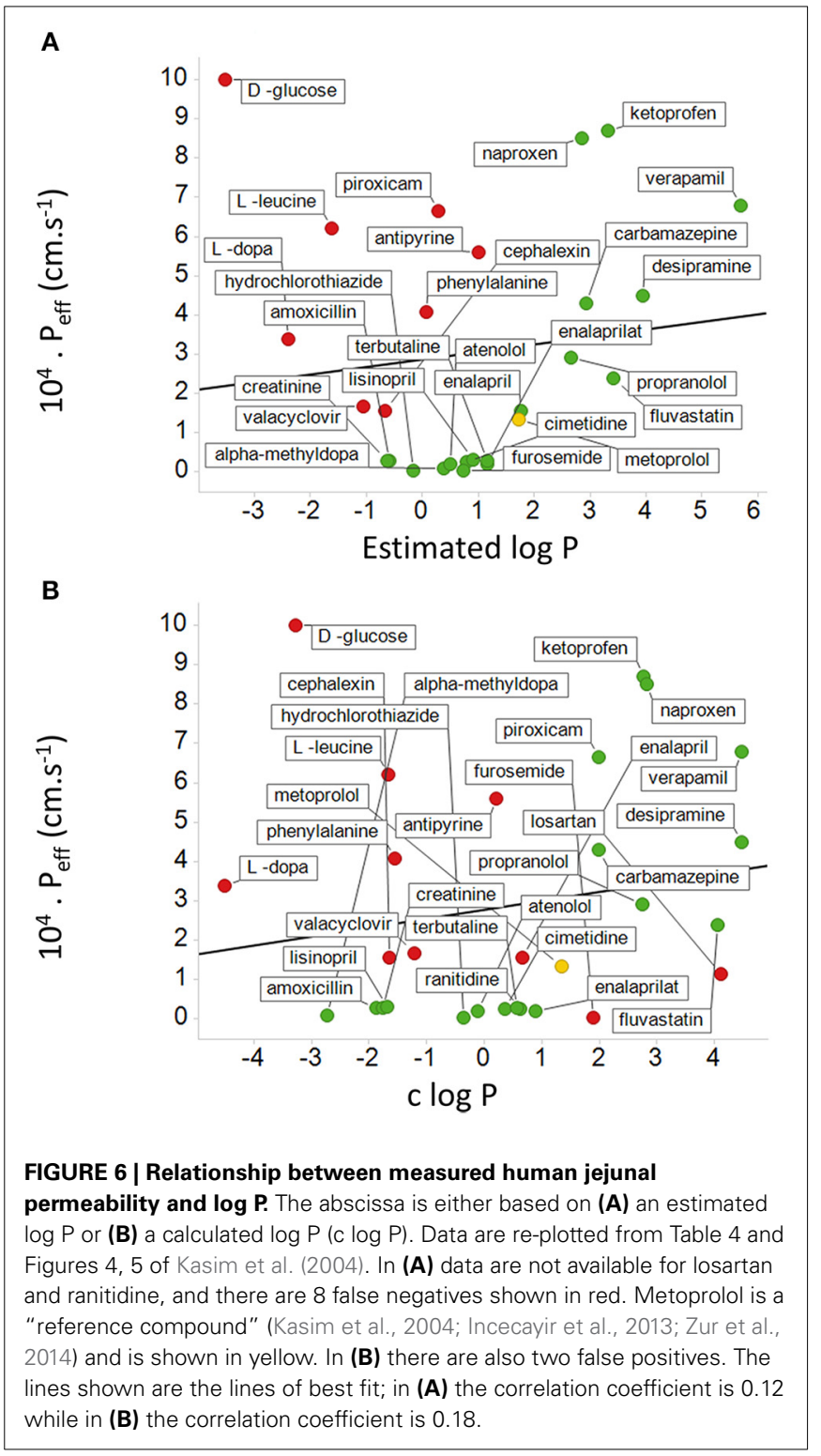

2013a). We have also plotted (Figure 7) data from the Oral Drugs in the Core WHO Essential Medicines List (Table 2 of Kasim et al., 2004). These show the essential lack of a major relationship between solubility and $\mathrm{c} \log \mathrm{P}$ (and neither is well-correlated with bioavailability; Sutherland et al., 2012). A more recent predictive modeling study (Ghosh et al., 2014), in which the word "transporter" does not appear once, developed a theoretical framework for "passive permeability" and applied it to nine substances; these are, with some references indicating that they each have known transporter interactions, as follows: testosterone (Hamada et al., 2008; Sharifi et al., 2008), warfarin (Marchetti et al., 2007), dexamethasone (Polli et al., 2001; Schwab et al., 2003; Uchida et al., 2011a), raffinose (Tyx et al., 2011), metoprolol (Dudley et al., 2000), propranolol (Wang et al., 2010a; Zheng et al., 2013), verapamil (Döppenschmitt et al., 1999; Kubo et al., 2013a), ibuprofen (Uwai et al., 2000b) and (the lipophilic cation) crystal violet (Burse et al., 2004a,b). 


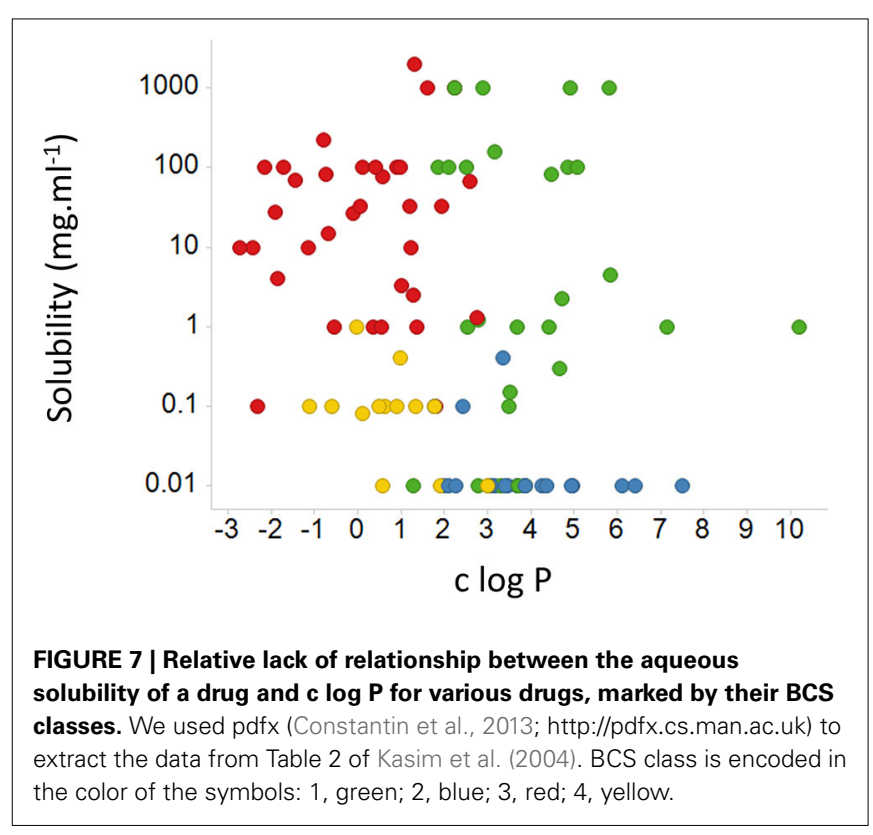

According to the Biopharmaceutics Drug Disposition Classification System (BDDCS) (Benet et al., 2008, 2011; Benet, 2010), which bears at least some similarities to the BCS, the disposition of drugs represented in its class 1 (high permeability and high metabolism) category is considered to be completely unaffected by the presence of transporters in the gut and liver. At least two interpretations of this are possible (Estudante et al., 2013): (i) there are no transporters interacting with these drugs and all the transport is by lipoidal diffusion, or (ii) there are so many high-flux transporters that they simply do not provide a barrier to uptake. A surrogate for cellular uptake and metabolism in the BDDCS system is the extent to which drugs are excreted unchanged in the urine (low extent unchanged implying high metabolism, hence cellular uptake), and we have redrawn (Figure 8) plots of this against both measured and calculated $\log \mathrm{P}$ values for 350 of the 351 BDDCS class 1 drugs tabulated (rather than being visualized) in Benet et al. (2011). It is obvious that the amount of drug excreted unchanged in the urine (and thus presumably its cellular permeability) can take almost any value whatever the value of $\log \mathrm{P}$, over an extremely wide range of values of $\log \mathrm{P}$. We have not chosen to fit a statistical line to either of these figures. Thus, we also suggest that it is useful if data that are supposed to support claims are made available in both tabular and graphical form, the latter with linear coordinates on both axes.

WHICH METABOLITES ARE SUPPOSED NOT TO HAVE TRANSPORTERS? Supporters of BDII regularly make claims about molecules that are supposed to be transported by bilayer diffusion, without telling readers which molecules they are. However, many of those that are stated to use bilayer lipoidal diffusion do in fact have known transporters, which thus makes any discrimination impossible. Presumably supporters of BDII have some ideas about biological systems and/or drugs for which they consider that there is no transporter acting on the molecule in question. It

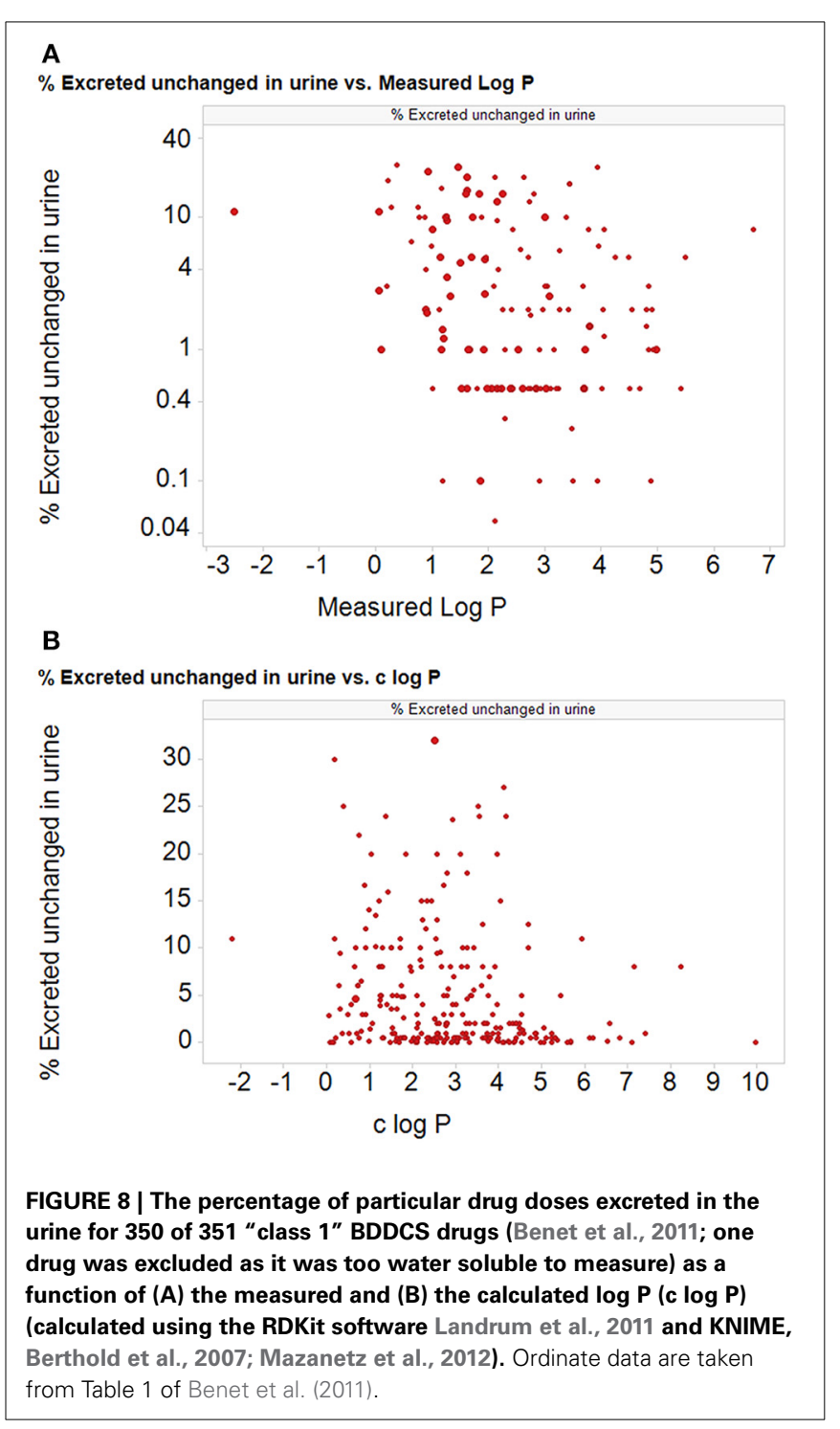

would be helpful if those who believe that BDII were to provide a reasonably extensive list of molecules (including marketed drugs) that (on whatever stated criteria) are supposed to be transported solely via bilayer diffusion so that those who expect to find suitable transporters can seek them. Note the evidence we gave above for transporters for quite lipophilic molecules, including alkanes.

We also note that there is much available online data and evidence of drugs that have known transporters, for instance at Transportal (Morrissey et al., 2012) and DrugBank (Law et al., 2014).

\section{CRITERIA THAT MIGHT REASONABLY BE REQUIRED TO INDICATE THAT A DRUG IS A SUBSTRATE FOR A PARTICULAR TRANSPORTER?}

Smith et al. (2014) bring up for discussion whether the identification of some drug transporters was conducted with due "rigor and precision," but the nature of their objection is unclear. In microbiology, it is common to use Koch's postulates (see Kell et al., 1998) to argue that microbe $\mathrm{X}$ is the "cause" of disease $\mathrm{Y}$. 
In a similar vein in molecular genetics, one usually takes it that to claim that gene (product) $\mathrm{X}$ is causative (at least in part) of phenotype $\mathrm{Y}$, the removal or change in activity of gene (product) $\mathrm{X}$ as an independent variable should have predictable effects on phenotype $\mathrm{Y}$. If we claim that transporter $\mathrm{X}$ transports drug $\mathrm{Y}$ (and it may also be annotated as being a transporter of natural metabolite Z) the conventional "rigor and precision" is to vary (including to zero) the activity of gene product $\mathrm{X}$, whether by genetic means or otherwise, and observe the effects on (the transport of) Y. If it is considered from known arguments that metabolite $\mathrm{Z}$ is also a substrate (or inhibitor) of transporter $\mathrm{X}$ then the prediction is that adding $Z$ will decrease the (contribution of transporter $\mathrm{X}$ to the) uptake of drug $\mathrm{Y}$, according to standard enzyme kinetic mechanisms (Keleti, 1986; CornishBowden, 1995; Fersht, 1999). This is precisely what was done in papers such as (Lanthaler et al., 2011; Winter et al., 2014). It would be valuable if supporters of BDII would provide any arguments that state that these are not seen as proper criteria for claiming, or at least contributing substantially to a claim, that a particular drug is transported by a particular, genetically identified, transporter, as well as any criteria that can be applied with the same logic or rigor to the assessment of phospholipid bilayer uptake.

Overall, these kinds of rigorous, genetically modulated changes leading to predictable outcomes contrast entirely with statements that observable phenomena are caused by bilayer diffusion when there has been no attempt to modulate that as an independent variable nor to measure it directly. As stated above, however, we note that changing lipids per se, without knowing about their contingent effects on transporter proteins at the same time (see references on protein-lipid interactions, above), is not a suitably discriminatory experiment.

\section{HOW DOES BDII ACCOUNT FOR THE "BLOOD-BRAIN BARRIER" (AND OTHER SUCH “BARRIERS” WITHIN AN ORGANISM), WITHOUT INVOKING EFFLUX TRANSPORT REACTIONS THAT HAVE NOT BEEN MEASURED?}

As is well-known, many (if not most) drugs fail to cross the BBB (Pardridge, 2012), despite the fact that brain lipids are not thought to differ substantively from lipids in other tissues. Certainly paracellular routes that exist in other tissues are not apparently available at the $\mathrm{BBB}$, which helps to sharpen the arguments. Leaving aside efflux transporters (Bagal and Bungay, 2014), PBIN has no trouble explaining this in terms of a relative lack of suitable transporters at the $\mathrm{BBB}$-indeed a lack of permeability in their absence is expected. (a) for drugs for which efflux transporters at the BBB are not known, it would be useful to know how proponents of the BDII theory explain the virtually complete lack of uptake of those drugs, including lipophilic drugs, that do not penetrate across a functioning BBB (i.e., in the absence of its significant breakdown in states such as stroke)?

In previous reviews (e.g., Kell et al., 2011, 2013) we have provided a large list of known influx transporters that might in fact be exploited, as well as pointing out that no attempt to increase lipophilicity had ever turned a drug that failed to penetrate the BBB into one that did (Pardridge, 2007).

\section{HOW DOES BDII ACCOUNT FOR THE DIFFERENTIAL UPTAKE INTO DIFFERENT TISSUES WITHIN AN ORGANISM (WITHOUT INVOKING EFFLUX TRANSPORT REACTIONS THAT HAVE NOT BEEN MEASURED)?}

In a similar vein, there is a highly heterogeneous uptake of specific drugs into different tissues, again despite the fact that lipids are not thought to differ substantively between tissues. As above, PBIN has no trouble explaining this in terms of a differential expression of suitable transporters in different tissuesand again a lack of permeability in their absence is expected. For drugs for which efflux transporters in specific tissues are not known, how do proponents of the BDII theory explain the virtually complete lack of uptake of those drugs, including lipophilic drugs, by different tissues or different cells of the same tissue?

Surprisingly few good data on this are available in the open literature, though in some cases one can see that the variation in concentration of a drug in different tissues (e.g., as measured by tissue:plasma ratio) can be massive (e.g., Miraglia et al., 2010; Oballa et al., 2011; Pagliarusco et al., 2011; Pfefferkorn et al., 2012). Note that when these kinds of measurements are made directly there is a highly heterogeneous distribution of drugs between different cells in the same tissue (e.g., Khatib-Shahidi et al., 2006; Cornett et al., 2008; Nilsson et al., 2010; Römpp et al., 2010, 2011; Castellino et al., 2011; Marko-Varga et al., 2011, 2012; Ait-Belkacem et al., 2012; Shahidi-Latham et al., 2012; El-Mashtoly et al., 2014; Gessel et al., 2014). The PBIN theory explains this straightforwardly in terms of the heterogeneous distribution of transporters, which is both well-known and measurable [see e.g., (http://proteinatlas.org/) (Persson et al., 2006; Pontén et al., 2008)]. A consequence of this highly heterogeneous distribution (Figure 9) is that one can find or predict circumstances in which, while the gross PK/PD of a drug's interactions

Heterogeneous distributions of a drug in a tissue can lead to a lack of efficacy and to toxicity while retaining the same gross PK/PD
A
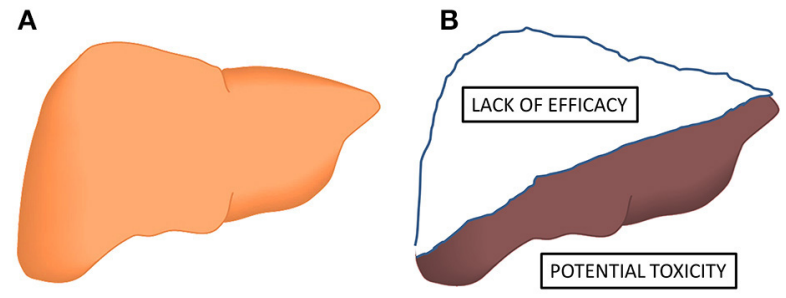

The total amount of drug in organ may be the same, but in (b) it has efficacy in only a fraction of the cells relative to (a) (as it does not enter them all) and may exhibit toxicity (as it is more highly concentrated in some)

FIGURE 9 | A set of circumstances in which two otherwise identical organs, that take up the same total amount of a drug and may have indistinguishable PK/PD, nevertheless display entirely different behaviors because of the intercellular heterogeneity. Organ (A) may display favorable efficacy and toxicity profiles, while in organ (B) shows both a lack of efficacy (in at least part of the organ) and toxicity (in another part). Note that the total amount of tissue is the same in $(\mathbf{A}, \mathbf{B})$. Such phenomena may well underlie the two most common causes of attrition (Cook et al., 2014). 
at the level of an organ may not change, the heterogeneous distribution of a drug that might otherwise be efficacious and non-toxic means that it is simultaneously both non-efficacious and toxic (the two main causes of attrition in drug development; Arrowsmith, 2011; Hann, 2011; Arrowsmith and Miller, 2013; Cook et al., 2014).

\section{HOW DOES BDII ACCOUNT FOR THE DIFFERENTIAL UPTAKE INTO THE SAME TISSUES IN DIFFERENT ORGANISMS (WITHOUT INVOKING EFFLUX TRANSPORT REACTIONS THAT HAVE NOT BEEN MEASURED)?}

In a variant of the same question, there are considerable differences in uptake of specific drugs into similar tissues of different organisms (often used as models for human pharmacokinetics and pharmacodynamics), again despite the fact that lipid biophysical properties are not thought to differ substantively between tissues of human and animal models. Again, PBIN has no trouble explaining this in terms of a differential expression of different transporters in different species-and a lack of permeability in their absence is expected. For drugs for which efflux transporters in the specific tissues of different species are not known, how do proponents of the BDII theory explain the extremely large variability in uptake of drugs, including lipophilic drugs, that can be observed between the same organs and tissues in different species?

Such data are comparatively unavailable in the academic literature, and we strongly encourage their publication so that people can see the extent of the inter-species variation of drug uptake into particular organs or tissues, which variation can again be considerable (e.g., Shilling et al., 2006; Shitara et al., 2006; Li et al., 2008; Furihata et al., 2010; Chu et al., 2013a; Grime and Paine, 2013; Musther et al., 2014).

\section{SOME FURTHER AREAS WHERE THE HYPOTHESIS OF DOMINANT TRANSPORTER ACTIVITY (PBIN) HAS STRONG PREDICTIVE AND EXPLANATORY POWER, BUT WHERE A BIOPHYSICAL VIEW BASED ON BILAYER LIPOIDAL DIFFUSION (BDII) DOES NOT}

The above described a number of areas where the expectations of BDII did not provide easy explanations of observable phenomena (in a way that PBIN could). Another important scientific tenet relates to the idea that theories with predictive power are to be preferred over those that lack useful and novel predictions. Thus, we next mention a number of areas in which the view that drugs hitchhike on transporters as their dominant mode of transmembrane transport (PBIN) makes important predictions that do not follow obviously (or even at all) from the view that most or all of drug transport is by diffusion across lipid bilayers (BDII).

\section{DRUG-METABOLITE LIKENESSES}

Since the influx transporters that are used by pharmaceutical drugs were not selected by natural evolution for these purposes, nor for the benefit of the pharmaceutical industry more generally, they must be there for other reasons. The most obvious "other reasons" are for the transport of small molecule nutrients or intermediary metabolites (and, in at least some cases, the natural substrates are indeed known), and of course the molecular targets of many drugs are proteins that interact with natural metabolites. The recent availability of a consensus reconstruction of the human metabolic network (Swainston et al., 2013; Thiele et al., 2013) means that it is now possible to compare "all" known metabolites with "all” drugs. The principle of molecular similarity (Gasteiger, 2003; Bender and Glen, 2004; Oprea, 2004; Sheridan et al., 2004; Maldonado et al., 2006; Eckert and Bajorath, 2007) indicates that drugs, especially those that are transported, should therefore resemble metabolites to a greater or lesser extent. The full analysis is presented elsewhere (O'Hagan et al., 2014), but, in line with previous indications (Feher and Schmidt, 2003; Karakoc et al., 2006; Gupta and Aires-De-Sousa, 2007; Dobson et al., 2009b; Khanna and Ranganathan, 2009, 2011; Peironcely et al., 2011; Zhang et al., 2011a; Chen et al., 2012; Walters, 2012; Hamdalla et al., 2013), it seems that the chemical structures of drugs do indeed resemble natural human metabolites. It is not obvious that BDII has anything to contribute to this, whereas PBIN has clear and strong predictive power. In particular (O'Hagan et al., 2014), using the MACCS encoding of 166 common substructures (Durant et al., 2002), we find that $90 \%$ of all marketed drugs have a Tanimoto similarity (Maggiora et al., 2014) of at least 0.5 to at least one metabolite (and in most cases to many more). "While this does not mean, of course, that a molecule obeying (that) rule is likely to become a marketed drug for humans, it does mean that a molecule that fails to obey the rule is statistically most unlikely to do so" (O'Hagan et al., 2014). This provides a useful filter for candidate drugs, as well as a major incentive to make candidate drugs more metabolite-like.

\section{HETEROGENEOUS DRUG DISTRIBUTION AS A CAUSE OF BOTH UNEXPECTED TOXICITY AND LACK OF EFFICACY}

Nowadays, the two most common causes of attrition in drug development are lack of efficacy and toxicity (Hann, 2011; Cook et al., 2014). The latter is arguably more understandable since (on elementary statistical grounds alone) every individual is biochemically very different from others (Williams, 1956). As the numbers of recipients tested increases during drug development phases $1-3$, one is more likely to find individuals that display toxicity as a result of comparatively rare differences in genetic make-up, lifestyle ("environment"), or Gene x Environment interactions. Even a small amount of toxicity may thus be enough to kill off a drug candidate during its development. The former is less easy to understand, however, since if a drug was efficacious in early phases why may it not be later? One possible explanation comes from the heterogeneous distribution of drug transporters. Thus, Figure 9 shows two otherwise identical organs that take up the same total amount of a drug and may thus have indistinguishable PK/PD. In (a) the drug is distributed homogeneously, while in (b) only ca one third of the cells take up the drug [to three times the concentration of that in (a)], while ca two-thirds of the cells take up none. Obviously those cells (hence the tissue) in (b) will suffer from a lack of efficacy, even though the gross PK/PD measured macroscopically (across the organ) appeared normal, while the "unexpected" accumulation of drugs in other cells might well lead to toxicity. The solution to this is to use singlecell analyses (Davey and Kell, 1996) (and see above), because biochemical systems are neither homogeneous nor ergodic (Kell et al., 1991). 


\section{MOLECULAR DYNAMICS SIMULATIONS}

We noted (above) the rather dismissive attitude taken toward computational modeling in some quarters ["The studies cited (Leontiadou et al., 2004, 2007) are computational simulations (so-called molecular dynamics, MD) of $\mathrm{Na}^{+}$and $\mathrm{Cl}^{-}$ion (nondrug-like) transport under unusual conditions" (Smith et al., 2014)]. It is not clear what the "unusual conditions" are supposed to be, but molecular dynamics simulations provide an approach to many experimentally intractable problems that is extremely well-established throughout science and engineering (see above and e.g., Karplus and Kuriyan, 2005; Dror et al., 2012), and indeed the 2013 Nobel Prize in Chemistry was awarded to three of its pioneers - Martin Karplus, Michael Levitt, and Arieh Warshel. Historically, such simulations have been somewhat limited by the discrepancy between the required and available amounts of computational power, but the growth in computer power, improvements in sampling regimes and other aspects of software (and in some cases the development of dedicated hardware, e.g., Shaw et al., 2008; Dror et al., 2011) are opening up de novo simulation on unprecedented timescales (e.g., in protein folding; Lindorff-Larsen et al., 2011; Raval et al., 2012; Piana et al., 2013). We predict that very soon it will be possible to provide accurate simulations of phospholipid bilayer membranes that both lack and contain proteins (and lipids) of the correct type and volume fraction (as in Figure 4), and that these will show precisely the molecular pathways that important drug (and other) molecules do and do not use to cross them. We also predict that as experimental systems more closely approximate real biomembranes, the transport occurring via any lipoidal bilayer portion will become increasingly negligible.

\section{MASS SPECTROMETRIC IMAGING OF DRUGS AND TRANSPORTERS}

As mentioned above, a great many examples now exist of the heterogeneous distribution of drugs in and between tissues as assessed by imaging mass spectrometry (e.g., Khatib-Shahidi et al., 2006; Cornett et al., 2008; Nilsson et al., 2010; Römpp et al., 2010, 2011; Castellino et al., 2011; Marko-Varga et al., 2011, 2012; Ait-Belkacem et al., 2012; Shahidi-Latham et al., 2012; Rumiato et al., 2013; El-Mashtoly et al., 2014; Gessel et al., 2014). We predict that the imaging of both proteins (or signature peptides derived therefrom) and drugs in the same locations in tissues will continue to be a powerful strategy for assessing which drugs are taken up by which transporters. It is not obvious that BDII can predict any such thing such as a relationship between particular lipids and particular transmembrane drug uptake (in an external validation set).

\section{ADVERSE DRUG REACTIONS}

As well as their immense therapeutic benefits, pharmaceutical drugs can have unwelcome effects on those who take them, another huge topic usually referred to as "adverse drug reactions" (ADRs). It is a massively important issue (e.g., Uetrecht, 2010), accounting for more than 5\% of UK hospital admissions (Pirmohamed et al., 2004; Davies et al., 2007; Kongkaew et al., 2008) and even more adverse events after hospital admission (Clavenna and Bonati, 2009; Davies et al., 2009; Miguel et al., 2012; Smyth et al., 2012) (and these are probably underestimates;
Hazell and Shakir, 2006). Most are avoidable (Pirmohamed et al., 2004; Smyth et al., 2012), and considerable pharmacogenetic, and pharmacogenomics evidence reflects the roles of drug transporters in ADRs (Meyer, 2000; Nakamura, 2008; Ward, 2008; Pirmohamed, 2010, 2012, 2014; Tohkin et al., 2010; Uetrecht, 2010; Clarke and Cherrington, 2012; Daly, 2012, 2013; Giacomini et al., 2012; Wei et al., 2012; Stankov et al., 2013; Yip et al., 2014), again reflecting their considerable significance relative to any bilayer lipoidal diffusion (where again it is not obvious how BDII has anything of substance to say).

\section{TRANSPORTER PHARMACOGENOMICS}

A further prediction that follows from the recognition of the widespread use of transporters by drugs (but not from models of bilayer lipoidal diffusion) is that one ought to be able to detect these transporters via the effects of genetic mutations (i.e., polymorphisms) on transport activity (they may either increase or decrease transport activity for a given substrate) (e.g., Ishikawa et al., 2004, 2013a,b; Bosch, 2008; Errasti-Murugarren and PastorAnglada, 2010; Franke et al., 2010; Lee, 2010; Nies and Schwab, 2010; Sissung et al., 2010, 2012; Aw et al., 2011; Li and Bluth, 2011; Pirmohamed, 2011, 2013, 2014; Stieger and Meier, 2011; Yonezawa and Inui, 2011; Kiyotani et al., 2012; Lai et al., 2012; Saadatmand et al., 2012; Wei et al., 2012; Giacomini et al., 2013; Yiannakopoulou, 2013). One well-known example, based on genome-wide association studies, is the effect of a particular SNP in SLCO1B1, previously known as OATP1B1, a bile acid and statin transporter (Hagenbuch and Meier, 2004; Hagenbuch and Stieger, 2013), on the myopathy that can be induced by particular statins (Link et al., 2008; Becquemont, 2009; Voora et al., 2009; Amur et al., 2010; Fahrmayr et al., 2010; Donnelly et al., 2011; Giorgi et al., 2011; Maggo et al., 2011; Nakanishi and Tamai, 2012; Wilke et al., 2012; Carr et al., 2013; Giacomini et al., 2013; Shitara et al., 2013; Yiannakopoulou, 2013; Ramsey et al., 2014; Rose et al., 2014; Tsamandouras et al., 2014).

\section{TRANSPORTER-MEDIATED DRUG-DRUG INTERACTIONS}

Yet another area for which the transporter-mediated route gives straightforward understanding and predictions (whereas the bilayer lipoidal diffusion mechanism has little to say) is in the area of transporter-mediated drug-drug interactions (DDI) (and indeed food-drug interactions). An elementary consequence of standard enzyme kinetics is that molecules using the same protein may compete with or inhibit each other, in this case each other's transport. This is a simply vast topic, so (notwithstanding earlier critiques of summarizing via the enormous review literature), we here simply point out several useful and recent reviews (from the last 3 years only) that describe in detail the many named and genetically identified transporters that are involved in DDI (Han, 2011; Kido et al., 2011; Klatt et al., 2011; König, 2011; Maeda et al., 2011; Marzolini et al., 2011; Müller and Fromm, 2011; Riches et al., 2011; Shitara, 2011; Zhang et al., 2011b; Bi et al., 2012; Elsby et al., 2012; Feng et al., 2012, 2013, 2014; Fromm, 2012; Grandvuinet et al., 2012; Karlgren et al., 2012; Keogh, 2012; Lepist and Ray, 2012; Nies et al., 2012; Sissung et al., 2012; Sprowl and Sparreboom, 2012, 2014; Takanohashi et al., 2012; Varma et al., 
2012; Yeo et al., 2012, 2013; Yoshida et al., 2012, 2013; Kis et al., 2013; König et al., 2013; Maeda and Sugiyama, 2013; Sugiyama and Steffansen, 2013; Tang et al., 2013; Zamek-Gliszczynski et al., 2013; Goswami et al., 2014; Tannenbaum and Sheehan, 2014; Vildhede et al., 2014). We are not aware of any papers that showed such DDI based on any measured competition for transport via the phospholipid bilayer.

\section{TOWARD TARGETED THERAPEUTICS}

Knowledge of transporters and their heterogeneous selectivities and distributions can be used to target particular drugs to particular tissues (Dobson and Kell, 2008). Thus, "In recent years, drug discovery researchers have also utilized knowledge about transporter uptake to enhance drug exposure to certain tissues. For example, liver specific transporters (OATP1B1 and 1B3) selectively increase liver concentration of their substrates, which minimize the exposure to peripheral tissue and reduce toxicity (Oballa et al., 2011; Pfefferkorn et al., 2012)" (Smith et al., 2014), though we also note that this can lead to toxicities in particular cases, e.g., Zhang et al. (2013).

Indeed, one can devise a $2 \times 2$ matrix of molecular vs. tissue targeting in drug development (Figure 10); however, its most important quadrant is presently missing (see Figure 10). Thus, the "magic bullet" is a phrase that was coined by Paul Ehrlich (Bosch and Rosich, 2008), initially with regard to anti-infectives, to describe a chemical that specifically inhibits a disease-causing target. Much of modern pharmacology relies precisely upon this principle, and many highly potent drugs have been developed (Strebhardt and Ullrich, 2008). However, most effective drugs are, in fact, active on multiple targets (e.g., Hopkins, 2008; Mestres and Gregori-Puigjané, 2009; Kell et al., 2013) and there is an increasing recognition (e.g., Boran and Iyengar, 2010; Metz and Hajduk, 2010; Xie et al., 2012; Jalencas and Mestres, 2013; Medina-Franco et al., 2013; Peters, 2013; Anighoro et al., 2014) as we move toward a network or systems pharmacology (e.g., Hopkins, 2008; Van Der

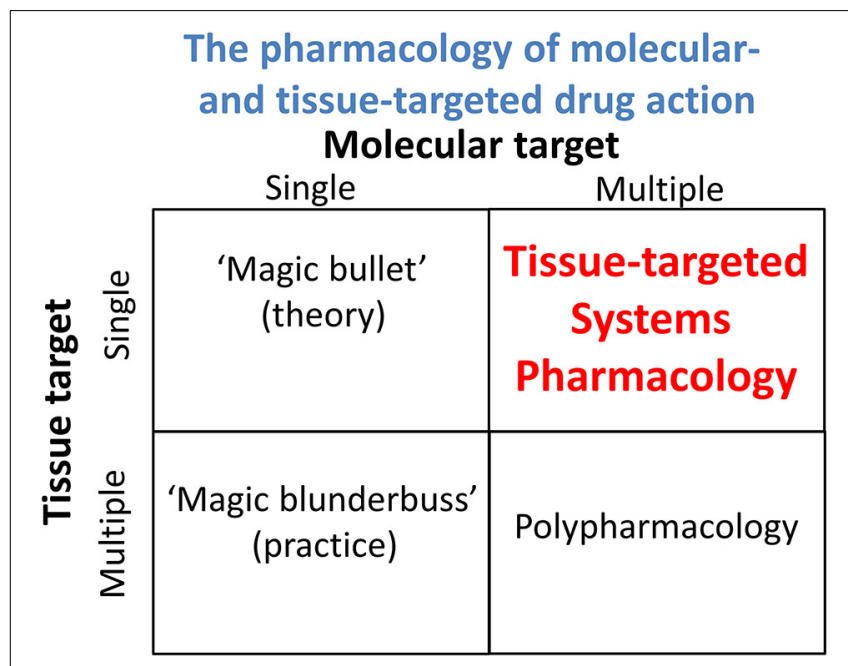

FIGURE 10 | A "Boston matrix" comparing the activities of drugs in terms of whether their molecular and/or their tissue targets are each either single or multiple.
Graaf and Benson, 2011; Cucurull-Sanchez et al., 2012; RostamiHodjegan, 2012; Waldman and Terzic, 2012; Bai and Abernethy, 2013; Csermely et al., 2013; Jenkins and Ma'ayan, 2013; Kell and Goodacre, 2014) that polypharmacology (one drug, multiple targets) is actually a desirable goal. While this can be achieved with combination therapies (multiple drugs, multiple targets) (e.g., Borisy et al., 2003; Zimmermann et al., 2007; Lehár et al., 2008), an advantage of polypharmacology is that the pharmacokinetics of a single agent are considerably simpler. However, with regard to tissue targeting, the "magic bullet" is more like a "magic blunderbuss" in that the drug can, in principle, bind to its targets in whichever tissue they are found so that it is largely unselective, and this is also true for agents exhibiting polypharmacology. This is obviously particularly undesirable for cytotoxic drugs such as anti-cancer agents, and leads to many examples of unwanted toxicity. By including tissue targeting as an explicit goal, much lower amounts of active drug can be given, thereby improving their therapeutic index massively. The starting point for achieving this is indeed the recognition that drugs enter cells more or less solely by hitchhiking on transporters normally involved in the transport of intermediary metabolites, rather than by diffusing indiscriminately through any and every phospholipid bilayer. A striking example comes from the work of Pfefferkorn and colleagues, who noted a value of 250,000 for the hepatocyte:myocyte ratio of a particular transporter-targeted drug (Pfefferkorn et al., 2011). It is not obvious how any view of a significant bilayer transport occurring (as in BDII) can sensibly account for this without ad hoc extra hypotheses, whereas the view that any "background" lipoidal bilayer transport is negligible finds it very easy to do so.

Thus, this possibility of cell or tissue targeting is a very clear prediction from PBIN that we consider has considerable utility in improving the potential therapeutic windows of active drugs, and highlights the need to develop pharmacophores for the more important transporters (Gleeson et al., 2011). As with all the other predictions and postdictions of PBIN, the predicted potential for selective, transporter-mediated targeting is amply fulfilled (e.g., Friend and Pangburn, 1987; Erion, 2007; Oballa et al., 2011; Pfefferkorn et al., 2011; Powell et al., 2011; Ramtohul et al., 2011; Reiling et al., 2011; Brunschweiger and Hall, 2012; Lachance et al., 2012a,b; Birsoy et al., 2013; Filipski et al., 2013; Liu, 2013; Pfefferkorn, 2013; Stevens et al., 2013; Tu et al., 2013; Sun et al., 2014; Tsume et al., 2014).

\section{CONCLUDING REMARKS}

There is considerable value in having an intellectual debate in this space; "accurate understanding of drug permeation mechanisms is important for drug development success" (Smith et al., 2014). Here, rather than being entirely fundamentalist ("When one admits that nothing is certain one must, I think, also admit that some things are much more nearly certain than others"; Russell, 1947), we have chosen to rehearse the common Popperian view of science as a scientific principle that can help to discriminate the virtues of the two competing hypotheses that we term BDII and PBIN. In laboratory and experimental science, this means varying parameters (often referred to as "independent variables" or causes) and observing their effects. This 
contrasts completely with the many observations, widely cited in support of BDII, of the mere covariation of two dependent variables.

While we think that the case is strongly made for the far greater utility and explanatory power of PBIN, we trust that this analysis will help readers of this journal to draw their own conclusions and to design better experiments to assist the modern drug discovery process. Hopefully this will also help us overcome the problem of what have been called the "'unknown knowns'; these are those things that are known but have become unknown, either because we have never learnt them, or forgotten about them, or more dangerously chosen to ignore" (Hann, 2011).

\section{ACKNOWLEDGMENTS}

We thank the Biotechnology and Biological Sciences Research Council (BB/D007747/1) for financial support. Work in SGO's lab is supported by the Wellcome Trust/MRC (grant code: 089703/Z/09/Z).

\section{REFERENCES}

Achour, B., Russell, M. R., Barber, J., and Rostami-Hodjegan, A. (2014). Simultaneous quantification of the abundance of several cytochrome P450 and uridine $5^{\prime}$-diphospho-glucuronosyltransferase enzymes in human liver microsomes using multiplexed targeted proteomics. Drug Metab. Dispos. 42, 500-510. doi: $10.1124 / \mathrm{dmd} .113 .055632$

Ahlin, G., Hilgendorf, C., Karlsson, J., Szigyarto, C. A., Uhlén, M., and Artursson, P. (2009). Endogenous gene and protein expression of drug-transporting proteins in cell lines routinely used in drug discovery programs. Drug Metab. Dispos. 37, 2275-2283. doi: 10.1124/dmd.109.028654

Ait-Belkacem, R., Sellami, L., Villard, C., Depauw, E., Calligaris, D., and Lafitte, D. (2012). Mass spectrometry imaging is moving toward drug protein co-localization. Trends Biotechnol. 30, 466-474. doi: 10.1016/j.tibtech.2012. 05.006

Amidon, G. L., Lennernäs, H., Shah, V. P., and Crison, J. R. (1995). A theoretical basis for a biopharmaceutic drug classification: the correlation of in vitro drug product dissolution and in vivo bioavailability. Pharm. Res. 12, 413-420. doi: 10.1023/A:1016212804288

Amur, S., Zineh, I., Abernethy, D. R., Huang, S. M., and Lesko, L. J. (2010). Pharmacogenomics and adverse drug reactions. Pers. Med. 7, 633-642. doi: 10.2217/pme.10.63

Anderle, P., Huang, Y., and Sadée, W. (2004). Intestinal membrane transport of drugs and nutrients: genomics of membrane transporters using expression microarrays. Eur. J. Pharm. Sci. 21, 17-24. doi: 10.1016/S0928-0987(03) 00169-6

Anderson, C. M., and Thwaites, D. T. (2010). Hijacking solute carriers for protoncoupled drug transport. Physiology (Bethesda) 25, 364-377. doi: 10.1152/physiol.00027.2010

Andres-Enguix, I., Caley, A., Yustos, R., Schumacher, M. A., Spanu, P. D., Dickinson, R., et al. (2007). Determinants of the anesthetic sensitivity of two-pore domain acid-sensitive potassium channels: molecular cloning of an anesthetic-activated potassium channel from Lymnaea stagnalis. J. Biol. Chem. 282, 20977-20990. doi: 10.1074/jbc.M610692200

Andersson, R., Aho, U., Nilsson, B. I., Peters, G. J., Pastor-Anglada, M., Rasch, W., et al. (2009). Gemcitabine chemoresistance in pancreatic cancer: molecular mechanisms and potential solutions. Scand. J. Gastroenterol. 44, 782-786. doi: 10.1080/00365520902745039

Anighoro, A., Bajorath, J., and Rastelli, G. (2014). Polypharmacology: challenges and opportunities in drug discovery. J. Med. Chem. 57, 7874-7887. doi: $10.1021 /$ jm5006463

Ankarloo, J., Wikman, S., and Nicholls, I. A. (2010). Escherichia coli mar and acrAB mutants display no tolerance to simple alcohols. Int. J. Mol. Sci. 11, 1403-1412. doi: 10.3390/ijms11041403

Ansari, D., Tingstedt, B., and Andersson, R. (2013). Pancreatic cancer cost for overtreatment with gemcitabine. Acta Oncol. 52, 1146-1151. doi: 10.3109/0284186X.2012.744140
Aojula, H. S., Offerman, S., Aojula, R. R., Hutchinson, A. P., Nicklin, S., and Clarke, D. J. (2002). Cloaking cytolytic peptides for liposome-based detection and potential drug delivery. Biochim. Biophys. Acta 1564, 73-81. doi: 10.1016/S0005-2736(02)00403-0

Aoyama, Y., Kaibara, A., Takada, A., Nishimura, T., Katashima, M., and Sawamoto, T. (2013). Population pharmacokinetic modeling of sepantronium bromide (YM155), a small molecule survivin suppressant, in patients with non-small cell lung cancer, hormone refractory prostate cancer, or unresectable stage III or IV melanoma. Invest. New Drugs 31, 443-451. doi: 10.1007/s10637-0129867-x

Apiwattanakul, N., Sekine, T., Chairoungdua, A., Kanai, Y., Nakajima, N., Sophasan, S., et al. (1999). Transport properties of nonsteroidal antiinflammatory drugs by organic anion transporter 1 expressed in Xenopus laevis oocytes. Mol. Pharmacol. 55, 847-854.

Arrowsmith, J. (2011). Trial watch: phase III and submission failures: 2007-2010. Nat. Rev. Drug Discov. 10:87. doi: 10.1038/nrd3375

Arrowsmith, J., and Miller, P. (2013). Trial watch: phase II and phase III attrition rates 2011-2012. Nat. Rev. Drug Discov. 12:569. doi: 10.1038/nrd4090

Aw, W., Lezhava, A., Hyashizaki, Y., and Ishikawa, T. (2011). A new trend in personalized medicine: rapid detection of SNPs in drug transporter genes by the SmartAmp method. Clin. Pharmacol. Ther. 89, 617-620. doi: 10.1038/clpt.2011.13

Azzaoui, K., Hamon, J., Faller, B., Whitebread, S., Jacoby, E., Bender, A., et al. (2007). Modeling promiscuity based on in vitro safety pharmacology profiling data. ChemMedChem 2, 874-880. doi: 10.1002/cmdc.200700036

Bagal, S., and Bungay, P. (2014). Restricting CNS penetration of drugs to minimise adverse events: role of drug transporters. Drug Discov. Today Technol. 12, e79-e85. doi: 10.1016/j.ddtec.2014.03.008

Bai, J. P., and Abernethy, D. R. (2013). Systems pharmacology to predict drug toxicity: integration across levels of biological organization. Annu. Rev. Pharmacol. Toxicol. 53, 451-473. doi: 10.1146/annurev-pharmtox-011112-140248

Baldwin, S. A., Beal, P. R., Yao, S. Y., King, A. E., Cass, C. E., and Young, J. D. (2004). The equilibrative nucleoside transporter family, SLC29. Pflugers Arch. 447, 735-743. doi: 10.1007/s00424-003-1103-2

Barts, P. W. J. A., Hoeberichts, J. A., Klaassen, A., and Borst-Pauwels, G. W. F. H. (1980). Uptake of the lipophilic cation dibenzyldimethylammonium into Saccharomyces cerevisiae. Interaction with the thiamine transport system. Biochim. Biophys. Acta 597, 125-136. doi: 10.1016/0005-2736(80)90156-X

Bassik, M. C., and Kampmann, M. (2011). Knocking out the door to tunicamycin entry. Proc. Natl. Acad. Sci. U.S.A. 108, 11731-11732. doi: 10.1073/pnas.110 9035108

Bayley, H. (2006). Sequencing single molecules of DNA. Curr. Opin. Chem. Biol. 10, 628-637. doi: 10.1016/j.cbpa.2006.10.040

Becquemont, L. (2009). Pharmacogenomics of adverse drug reactions: practical applications and perspectives. Pharmacogenomics 10, 961-969. doi: $10.2217 /$ pgs.09.37

Bender, A., and Glen, R. C. (2004). Molecular similarity: a key technique in molecular informatics. Org. Biomol. Chem. 2, 3204-3218. doi: 10.1039/ b409813g

Benet, L. Z. (2010). Predicting drug disposition via application of a biopharmaceutics drug disposition classification system. Basic Clin. Pharmacol. Toxicol. 106, 162-167. doi: 10.1111/j.1742-7843.2009.00498.x

Benet, L. Z., Amidon, G. L., Barends, D. M., Lennernas, H., Polli, J. E., Shah, V. P., et al. (2008). The use of BDDCS in classifying the permeability of marketed drugs. Pharm. Res. 25, 483-488. doi: 10.1007/s11095-007-9523-x

Benet, L. Z., Broccatelli, F., and Oprea, T. I. (2011). BDDCS applied to over 900 drugs. AAPS J. 13, 519-547. doi: 10.1208/s12248-011-9290-9

Bertaccini, E. J., and Trudell, J. R. (2012). Induced changes in protein receptors conferring resistance to anesthetics. Curr. Opin. Anesthesiol. 25, 405-410. doi: 10.1097/ACO.0b013e328354fda8

Bertaccini, E. J., Wallner, B., Trudell, J. R., and Lindahl, E. (2010). Modeling anesthetic binding sites within the glycine alpha one receptor based on prokaryotic ion channel templates: the problem with TM4. J. Chem. Inf. Model. 50, 2248-2255. doi: 10.1021/ci100266c

Berthold, M. R., Cebron, N., Dill, F., Gabriel, T. R., Kötter, T., Meinl, T., et al. (2007). "The Konstanz Information Miner," in Studies in Classification, Data Analysis, and Knowledge Organization (GfKL 2007), eds C. Preisach, H. Burkhardt, L. Schmidt-Thieme, and R. Decker (Heidelberg: Springer), 319-326. 
Beswick, V., Isvoran, A., Nedellec, P., Sanson, A., and Jamin, N. (2011). Membrane interface composition drives the structure and the tilt of the single transmembrane helix protein PMP1: MD studies. Biophys. J. 100, 1660-1667. doi: 10.1016/j.bpj.2011.02.002

Bhutia, Y. D., Hung, S. W., Patel, B., Lovin, D., and Govindarajan, R. (2011). CNT1 expression influences proliferation and chemosensitivity in drug-resistant pancreatic cancer cells. Cancer Res. 71, 1825-1835. doi: 10.1158/00085472.CAN-10-2736

Bi, Y. A., Kimoto, E., Sevidal, S., Jones, H. M., Barton, H. A., Kempshall, S., et al. (2012). In vitro evaluation of hepatic transporter-mediated clinical drug-drug interactions: hepatocyte model optimization and retrospective investigation. Drug Metab. Dispos. 40, 1085-1092. doi: 10.1124/dmd.111.043489

Birsoy, K., Wang, T., Possemato, R., Yilmaz, O. H., Koch, C. E., Chen, W. W., et al. (2013). MCT1-mediated transport of a toxic molecule is an effective strategy for targeting glycolytic tumors. Nat. Genet. 45, 104-108. doi: 10.1038/ng.2471

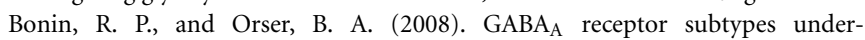
lying general anesthesia. Pharmacol. Biochem. Behav. 90, 105-112. doi: 10.1016/j.pbb.2007.12.011

Boran, A. D. W., and Iyengar, R. (2010). Systems approaches to polypharmacology and drug discovery. Curr. Opin. Drug Discov. Devel. 13, 297-309. doi: 10.1016/j.jep.2013.02.004

Borbath, I., Verbrugghe, L., Lai, R., Gigot, J. F., Humblet, Y., Piessevaux, H., et al. (2012). Human equilibrative nucleoside transporter 1 (hENT1) expression is a potential predictive tool for response to gemcitabine in patients with advanced cholangiocarcinoma. Eur. J. Cancer 48, 990-996. doi: 10.1016/j.ejca.2011. 11.006

Bordi, F., Cametti, C., and Naglieri, A. (1999). Ion transport in lipid bilayer membranes through aqueous pores. Coll. Surf. A. 159, 231-237. doi: 10.1016/S09277757(99)00277-0

Borisy, A. A., Elliott, P. J., Hurst, N. W., Lee, M. S., Lehar, J., Price, E. R., et al. (2003). Systematic discovery of multicomponent therapeutics. Proc. Natl. Acad. Sci. U.S.A. 100, 7977-7982. doi: 10.1073/pnas. 1337088100

Bosch, F., and Rosich, L. (2008). The contributions of Paul Ehrlich to pharmacology: a tribute on the occasion of the centenary of his Nobel Prize. Pharmacology 82, 171-179. doi: 10.1159/000149583

Bosch, T. M. (2008). Pharmacogenomics of drug-metabolizing enzymes and drug transporters in chemotherapy. Methods. Mol. Biol. 448, 63-76. doi: 10.1007/9781-59745-205-2_5

Broadhurst, D., and Kell, D. B. (2006). Statistical strategies for avoiding false discoveries in metabolomics and related experiments. Metabolomics 2, 171-196. doi: 10.1007/s11306-006-0037-z

Brouwer, K. L. R., Keppler, D., Hoffmaster, K. A., Bow, D. A., Cheng, Y., Lai, Y., et al. (2013). In vitro methods to support transporter evaluation in drug discovery and development. Clin. Pharmacol. Ther. 94, 95-112. doi: 10.1038/clpt.2013.81

Brownridge, P., Holman, S. W., Gaskell, S. J., Grant, C. M., Harman, V. M., Hubbard, S. J., et al. (2011). Global absolute quantification of a proteome: challenges in the deployment of a QconCAT strategy. Proteomics 11, 2957-2970. doi: 10.1002/pmic.201100039

Brunschweiger, A., and Hall, J. (2012). A decade of the human genome sequence: how does the medicinal chemist benefit? ChemMedChem 7, 194-203. doi: $10.1002 / \mathrm{cmdc} .201100498$

Burckhardt, B. C., Brai, S., Wallis, S., Krick, W., Wolff, N. A., and Burckhardt, G. (2003). Transport of cimetidine by flounder and human renal organic anion transporter 1. Am. J. Physiol. Renal Physiol. 284, F503-F509. doi: 10.1152/ajprenal.00290.2002

Burckhardt, G., and Burckhardt, B. C. (2011). In vitro and in vivo evidence of the importance of organic anion transporters (OATs) in drug therapy. Handb. Exp. Pharmacol. 201, 29-104. doi: 10.1007/978-3-642-14541-4_2

Bürckstümmer, T., Banning, C., Hainzl, P., Schobesberger, R., Kerzendorfer, C., Pauler, F. M., et al. (2013). A reversible gene trap collection empowers haploid genetics in human cells. Nat. Methods 10, 965-971. doi: 10.1038/nmeth.2609

Burse, A., Weingart, H., and Ullrich, M. S. (2004a). NorM, an Erwinia amylovora multidrug efflux pump involved in in vitro competition with other epiphytic bacteria. Appl. Env. Microbiol. 70, 693-703. doi: 10.1128/AEM.70.2.693703.2004

Burse, A., Weingart, H., and Ullrich, M. S. (2004b). The phytoalexin-inducible multidrug efflux pump AcrAB contributes to virulence in the fire blight pathogen, Erwinia amylovora. MPMI 17, 43-54. doi: 10.1094/MPMI.2004. 17.1.43
Buzan, T. (2002). How to Mind Map. London: Thorsons.

Carbonell, P., and Faulon, J. L. (2010). Molecular signatures-based prediction of enzyme promiscuity. Bioinformatics 26, 2012-2019. doi: 10.1093/bioinformatics/btq317

Carette, J. E., Guimaraes, C. P., Varadarajan, M., Park, A. S., Wuethrich, I., Godarova, A., et al. (2009). Haploid genetic screens in human cells identify host factors used by pathogens. Science 326, 1231-1235. doi: 10.1126/science. 1178955

Carette, J. E., Guimaraes, C. P., Wuethrich, I., Blomen, V. A., Varadarajan, M., Sun, C., et al. (2011). Global gene disruption in human cells to assign genes to phenotypes by deep sequencing. Nat. Biotechnol. 29, 542-546. doi: 10.1038/nbt. 1857

Carr, D. F., O’meara, H., Jorgensen, A. L., Campbell, J., Hobbs, M., Mccann, G., et al. (2013). SLCO1B1 genetic variant associated with statin-induced myopathy: a proof-of-concept study using the clinical practice research datalink. Clin. Pharmacol. Ther. 94, 695-701. doi: 10.1038/clpt.2013.161

Carroll, K. M., Simpson, D. M., Eyers, C. E., Knight, C. G., Brownridge, P., Dunn, W., et al. (2011). Absolute quantification of the glycolytic pathway in yeast: deployment of a complete QconCAT approach. Mol. Cell. Proteomics 10:M111 007633. doi: 10.1074/mcp.M111.007633

Castellino, S., Groseclose, M. R., and Wagner, D. (2011). MALDI imaging mass spectrometry: bridging biology and chemistry in drug development. Bioanalysis 3, 2427-2441. doi: 10.4155/bio.11.232

Chalmers, A. F. (1999). What is This Thing Called Science? An Assessment of the Nature and Status of Science and its Methods. Maidenhead: Open University Press.

Chen, B., Ling, H., and Chang, M. W. (2013). Transporter engineering for improved tolerance against alkane biofuels in Saccharomyces cerevisiae. Biotechnol. Biofuels. 6:21. doi: 10.1186/1754-6834-6-21

Chen, H. M., Engkvist, O., Blomberg, N., and Li, J. (2012). A comparative analysis of the molecular topologies for drugs, clinical candidates, natural products, human metabolites and general bioactive compounds. MedChem Comm 3, 312-321. doi: 10.1039/c2md00238h

Chen, J. J., and Turko, I. V. (2014). Trends in QconCATs for targeted proteomics. Trends Anal. Chem. 57, 1-5. doi: 10.1016/j.trac.2013.12.013

Chen, M. L., Amidon, G. L., Benet, L. Z., Lennernas, H., and Yu, L. X. (2011). The BCS, BDDCS, and regulatory guidances. Pharm. Res. 28, 1774-1778. doi: 10.1007/s11095-011-0438-1

Chen, Y., Li, S., Brown, C., Cheatham, S., Castro, R. A., Leabman, M. K., et al. (2009). Effect of genetic variation in the organic cation transporter 2 on the renal elimination of metformin. Pharmacogenet. Genomics 19, 497-504. doi: 10.1097/FPC.0b013e32832cc7e9

Chen, Y. S., Mathias, R. A., Mathivanan, S., Kapp, E. A., Moritz, R. L., Zhu, H. J., et al. (2010). Proteomic profiling of MDCK plasma membranes reveals Wnt-5a involvement during oncogenic H-Ras/TGF-\{beta $\}$-mediated epithelial-mesenchymal transition. Mol. Cell. Proteomics 10:M110.001131. doi: 10.1074/mcp.M110.001131

Chu, X., Bleasby, K., and Evers, R. (2013a). Species differences in drug transporters and implications for translating preclinical findings to humans. Expert Opin. Drug Metab. Toxicol. 9, 237-252. doi: 10.1517/17425255.2013.741589

Chu, X., Korzekwa, K., Elsby, R., Fenner, K., Galetin, A., Lai, Y., et al. (2013b). Intracellular drug concentrations and transporters: measurement, modeling, and implications for the liver. Clin. Pharmacol. Ther 94, 126-141. doi: 10.1038/clpt.2013.78

Clarke, J. D., and Cherrington, N. J. (2012). Genetics or environment in drug transport: the case of organic anion transporting polypeptides and adverse drug reactions. Expert Opin. Drug Metab. Toxicol. 8, 349-360. doi: $10.1517 / 17425255.2012 .656087$

Clavenna, A., and Bonati, M. (2009). Adverse drug reactions in childhood: a review of prospective studies and safety alerts. Arch. Dis. Child 94, 724-728. doi: 10. 1136/adc.2008.154377

Collett, A., Higgs, N. B., Sims, E., Rowland, M., and Warhurst, G. (1999). Modulation of the permeability of $\mathrm{H} 2$ receptor antagonists cimetidine and ranitidine by P-glycoprotein in rat intestine and the human colonic cell line Caco-2. J. Pharmacol. Exp. Ther. 288, 171-178.

Conant, J. B. (1950). The Overthrow of the Phlogiston theory: the Chemical Revolution of 1775-1789. Cambridge, MA: Harvard University Press.

Conklin, L. S., Cuffari, C., Okazaki, T., Miao, Y. L., Saatian, B., Chen, T. E., et al. (2012). 6-mercaptopurine transport in human lymphocytes: correlation 
with drug-induced cytotoxicity. J. Dig. Dis. 13, 82-93. doi: 10.1111/j.17512980.2011.00556.x

Constantin, A., Pettifer, S., and Voronkov, A. (2013). PDFX: fully-automated PDF-to-XML conversion of scientific literature. DocEng' 13, 177-180. doi: $10.1145 / 2494266.2494271$

Cook, D., Brown, D., Alexander, R., March, R., Morgan, P., Satterthwaite, G., et al. (2014). Lessons learned from the fate of AstraZeneca's drug pipeline: a five-dimensional framework. Nat. Rev. Drug Discov. 13, 419-431. doi: 10.1038/nrd4309

Cornett, D. S., Frappier, S. L., and Caprioli, R. M. (2008). MALDI-FTICR imaging mass spectrometry of drugs and metabolites in tissue. Anal. Chem. 80, 5648-5653. doi: 10.1021/ac800617s

Cornish-Bowden, A. (1995). Fundamentals of Enzyme Kinetics, 2nd edn. London: Portland Press.

Corti, G., Maestrelli, F., Cirri, M., Zerrouk, N., and Mura, P. (2006). Development and evaluation of an in vitro method for prediction of human drug absorption II. Demonstration of the method suitability. Eur. J. Pharm. Sci. 27, 354-362. doi: 10.1016/j.ejps.2005.11.005

Coskun, Ü., and Simons, K. (2011). Cell membranes: the lipid perspective. Structure 19, 1543-1548. doi: 10.1016/j.str.2011.10.010

Cronin, M. T. D., and Schultz, T. W. (2003). Pitfalls in QSAR. J. Mol. Struct. 622, 39-51. doi: 10.1016/S0166-1280(02)00616-4

Csermely, P., Korcsmáros, T., Kiss, H. J. M., London, G., and Nussinov, R. (2013). Structure and dynamics of molecular networks: a novel paradigm of drug discovery. A comprehensive review. Pharmacol. Ther. 138, 333-408. doi: 10.1016/j.pharmthera.2013.01.016

Cucurull-Sanchez, L., Spink, K. G., and Moschos, S. A. (2012). Relevance of systems pharmacology in drug discovery. Drug Discov. Today 17, 665-670. doi: 10.1016/j.drudis.2012.01.015

Dahan, A., Miller, J. M., and Amidon, G. L. (2009). Prediction of solubility and permeability class membership: provisional BCS classification of the world's top oral drugs. AAPS J. 11, 740-746. doi: 10.1208/s12248-0099144-x

Daly, A. K. (2012). Using genome-wide association studies to identify genes important in serious adverse drug reactions. Annu. Rev. Pharmacol. Toxicol. 52, 21-35. doi: 10.1146/annurev-pharmtox-010611-134743

Daly, A. K. (2013). Pharmacogenomics of adverse drug reactions. Genome Med. 5, 5. doi: 10.1186/gm409

Damaraju, V. L., Mowles, D., Yao, S., Ng, A., Young, J. D., Cass, C. E., et al. (2012). Role of human nucleoside transporters in the uptake and cytotoxicity of azacitidine and decitabine. Nucleosides Nucleotides Nucleic Acids 31, 236-255. doi: $10.1080 / 15257770.2011 .652330$

Damaraju, V. L., Scriver, T., Mowles, D., Kuzma, M., Ryan, A. J., Cass, C. E., et al. (2014). Erlotinib, gefitinib, and vandetanib inhibit human nucleoside transporters and protect cancer cells from gemcitabine cytotoxicity. Clin. Cancer Res. 20, 176-186. doi: 10.1158/1078-0432.CCR-13-2293

Das, J., Xu, S., Pany, S., Guillory, A., Shah, V., and Roman, G. W. (2013). The presynaptic Munc13-1 binds alcohol and modulates alcohol self-administration in Drosophila. J. Neurochem. 126, 715-726. doi: 10.1111/jnc.12315

Davey, H. M., and Kell, D. B. (1996). Flow cytometry and cell sorting of heterogeneous microbial populations: the importance of single-cell analysis. Microbiol. Rev. 60, 641-696.

Davies, E. C., Green, C. F., Mottram, D. R., and Pirmohamed, M. (2007). Adverse drug reactions in hospitals: a narrative review. Curr. Drug Saf. 2, 79-87. doi: 10.2174/157488607779315507

Davies, E. C., Green, C. F., Taylor, S., Williamson, P. R., Mottram, D. R., and Pirmohamed, M. (2009). Adverse drug reactions in hospital in-patients: a prospective analysis of 3695 patient-episodes. PLoS ONE 4:e4439. doi: 10.1371/journal.pone.0004439

Degorter, M. K., Xia, C. Q., Yang, J. J., and Kim, R. B. (2012). Drug transporters in drug efficacy and toxicity. Annu. Rev. Pharmacol. Toxicol. 52, 249-273. doi: 10.1146/annurev-pharmtox-010611-134529

Denning, E. J., and Beckstein, O. (2013). Influence of lipids on protein-mediated transmembrane transport. Chem. Phys. Lipids 169, 57-71. doi: 10.1016/j. chemphyslip.2013.02.007

De Sousa Cavalcante, L., and Monteiro, G. (2014). Gemcitabine: metabolism and molecular mechanisms of action, sensitivity and chemoresistance in pancreatic cancer. Eur. J. Pharmacol. 741C, 8-16. doi: 10.1016/j.ejphar.2014. 07.041
Dickinson, R., and Franks, N. P. (2010). Bench-to-bedside review: molecular pharmacology and clinical use of inert gases in anesthesia and neuroprotection. Crit. Care 14:229. doi: 10.1186/cc9051

Dickinson, R., Peterson, B. K., Banks, P., Simillis, C., Martin, J. C., Valenzuela, C. A., et al. (2007). Competitive inhibition at the glycine site of the N-methyl$\mathrm{D}$-aspartate receptor by the anesthetics xenon and isoflurane: evidence from molecular modeling and electrophysiology. Anesthesiology 107, 756-767. doi: 10.1097/01.anes.0000287061.77674.71

Dikicioglu, D., Oc, S., Rash, B., Dunn, W. B., Pir, P., Kell, D. B., et al. (2014). Yeast cells with impaired drug resistance accumulate glycerol and glucose. Mol. Biosyst. 10, 93-102. doi: 10.1039/c2mb25512j

Dobson, P. D., and Kell, D. B. (2008). Carrier-mediated cellular uptake of pharmaceutical drugs: an exception or the rule? Nat. Rev. Drug Discov. 7, 205-220. doi: $10.1038 / \mathrm{nrd} 2438$

Dobson, P. D., Patel, Y., and Kell, D. B. (2009b). "Metabolite-likeness" as a criterion in the design and selection of pharmaceutical drug libraries. Drug Discov. Today 14, 31-40. doi: 10.1016/j.drudis.2008.10.011

Dobson, P., Lanthaler, K., Oliver, S. G., and Kell, D. B. (2009a). Implications of the dominant role of cellular transporters in drug uptake. Curr. Top. Med. Chem. 9, 163-184. doi: 10.2174/156802609787521616

Domański, J., Marrink, S. J., and Schäfer, L. V. (2012). Transmembrane helices can induce domain formation in crowded model membranes. Biochim. Biophys. Acta 1818, 984-994. doi: 10.1016/j.bbamem.2011.08.021

Donnelly, L. A., Doney, A. S. F., Tavendale, R., Lang, C. C., Pearson, E. R., Colhoun, H. M., et al. (2011). Common nonsynonymous substitutions in SLCO1B1 predispose to statin intolerance in routinely treated individuals with type 2 diabetes: a go-DARTS study. Clin. Pharmacol. Ther. 89, 210-216. doi: $10.1038 /$ clpt.2010.255

Döppenschmitt, S., Langguth, P., Regårdh, C. G., Andersson, T. B., Hilgendorf, C., and Spahn-Langguth, H. (1999). Characterization of binding properties to human P-glycoprotein: development of a $[3 \mathrm{H}]$ verapamil radioligand-binding assay. J. Pharmacol. Exp. Ther. 288, 348-357.

Doshi, R., Nguyen, T., and Chang, G. (2013). Transporter-mediated biofuel secretion. Proc. Natl. Acad. Sci. U.S.A. 110, 7642-7647. doi: 10.1073/pnas.13013 58110

Doy, C. H., Pateman, J. A., Olsen, J. E., Kane, H. J., and Creaser, E. H. (1985). Genomic clones of Aspergillus nidulans containing alcA, the structural gene for alcohol dehydrogenase and alcR, a regulatory gene for ethanol metabolism. DNA 4, 105-114. doi: 10.1089/dna.1985.4.105

Dror, R. O., Dirks, R. M., Grossman, J. P., Xu, H., and Shaw, D. E. (2012). Biomolecular simulation: a computational microscope for molecular biology. Annu. Rev. Biophys. 41, 429-452. doi: 10.1146/annurev-biophys-042910155245

Dror, R. O., Grossman, J. P., Mackenzie, K. M., Towles, B., Chow, E., Salmon, J. K., et al. (2011). Overcoming communication latency barriers in massively parallel scientific computation. IEEE Micro 31, 8-19. doi: 10.1109/MM.2011.38

Dudley, A. J., Bleasby, K., and Brown, C. D. (2000). The organic cation transporter OCT2 mediates the uptake of beta-adrenoceptor antagonists across the apical membrane of renal LLC-PK 1 cell monolayers. Br. J. Pharmacol. 131, 71-79. doi: 10.1038/sj.bjp.0703518

Dunlop, M. J., Dossani, Z. Y., Szmidt, H. L., Chu, H. C., Lee, T. S., Keasling, J. D., et al. (2011). Engineering microbial biofuel tolerance and export using efflux pumps. Mol. Syst. Biol. 7:487. doi: 10.1038/msb.2011.21

Dupuy, A. D., and Engelman, D. M. (2008). Protein area occupancy at the center of the red blood cell membrane. Proc. Natl. Acad. Sci. U.S.A. 105, 2848-2852. doi: 10.1073/pnas.0712379105

Durant, J. L., Leland, B. A., Henry, D. R., and Nourse, J. G. (2002). Reoptimization of MDL keys for use in drug discovery. J. Chem. Inf. Comput. Sci. 42, 1273-1280. doi: $10.1021 / \mathrm{ci0} 10132 \mathrm{r}$

Eckert, H., and Bajorath, J. (2007). Molecular similarity analysis in virtual screening: foundations, limitations and novel approaches. Drug Discov. Today 12, 225-233. doi: 10.1016/j.drudis.2007.01.011

Edwards, R. M., Stack, E. J., and Trizna, W. (1999). Transport of [3H]losartan across isolated perfused rabbit proximal tubule. J. Pharmacol. Exp. Ther. 290, 38-42.

Elliott, K. C. (2012). Epistemic and methodological iteration in scientific research. Stud. Hist. Philos. Sci. 43, 376-382. doi: 10.1016/j.shpsa.2011.12.034

El-Mashtoly, S. F., Petersen, D., Yosef, H. K., Mosig, A., Reinacher-Schick, A., Kotting, C., et al. (2014). Label-free imaging of drug distribution 
and metabolism in colon cancer cells by Raman microscopy. Analyst 139, 1155-1161. doi: 10.1039/c3an01993d

Elsby, R., Hilgendorf, C., and Fenner, K. (2012). Understanding the critical disposition pathways of statins to assess drug-drug interaction risk during drug development: it's not just about OATP1B1. Clin. Pharmacol. Ther. 92, 584-598. doi: $10.1038 /$ clpt.2012.163

El-Sheikh, A. A., Van Den Heuvel, J. J., Koenderink, J. B., and Russel, F. G. (2007). Interaction of nonsteroidal anti-inflammatory drugs with multidrug resistance protein (MRP) 2/ABCC2- and MRP4/ABCC4-mediated methotrexate transport. J. Pharmacol. Exp. Ther. 320, 229-235. doi: 10.1124/jpet.106.110379

Endres, C. J., Moss, A. M., Govindarajan, R., Choi, D. S., and Unadkat, J. D. (2009a) The role of nucleoside transporters in the erythrocyte disposition and oral absorption of ribavirin in the wild-type and equilibrative nucleoside transporter 1-/- mice. J. Pharmacol. Exp. Ther. 331, 287-296. doi: 10.1124/jpet.109.153130

Endres, C. J., Moss, A. M., Ke, B., Govindarajan, R., Choi, D. S., Messing, R. O., et al. (2009b). The role of the equilibrative nucleoside transporter 1 (ENT1) in transport and metabolism of ribavirin by human and wild-type or ent1(-/-) mouse erythrocytes. J. Pharmacol. Exp. Ther. 329, 387-398. doi: 10.1124/jpet.108.145854

Engelman, D. M. (2005). Membranes are more mosaic than fluid. Nature 438, 578-580. doi: 10.1038/nature04394

Enkavi, G., Li, J., Mahinthichaichan, P., Wen, P. C., Huang, Z., Shaikh, S. A., et al. (2013). Simulation studies of the mechanism of membrane transporters. Methods Mol. Biol. 924, 361-405. doi: 10.1007/978-1-62703-017-5_14

Eraly, S. A., Vallon, V., Vaughn, D. A., Gangoiti, J. A., Richter, K., Nagle, M., et al. (2006). Decreased renal organic anion secretion and plasma accumulation of endogenous organic anions in OAT1 knock-out mice. J. Biol. Chem. 281, 5072-5083. doi: 10.1074/jbc.M508050200

Eriksson, L., Jaworska, J., Worth, A. P., Cronin, M. T., Mcdowell, R. M., and Gramatica, P. (2003). Methods for reliability and uncertainty assessment and for applicability evaluations of classification- and regression-based QSARs. Environ. Health Perspect. 111, 1361-1375. doi: 10.1289/ehp.5758

Erion, M. D. (2007). Prodrugs for liver-targeted drug delivery. Biotechnol. Pharm. Asp. 5, 541-572. doi: 10.1007/978-0-387-49785-3_16

Errasti-Murugarren, E., and Pastor-Anglada, M. (2010). Drug transporter pharmacogenetics in nucleoside-based therapies. Pharmacogenomics 11, 809-841. doi: $10.2217 /$ pgs. 10.70

Estudante, M., Morais, J. G., Soveral, G., and Benet, L. Z. (2013). Intestinal drug transporters: an overview. Adv. Drug Deliv. Rev. 65, 1340-1356. doi: 10.1016/j.addr.2012.09.042

Fahrmayr, C., Fromm, M. F., and König, J. (2010). Hepatic OATP and OCT uptake transporters: their role for drug-drug interactions and pharmacogenetic aspects. Drug Metab. Rev. 42, 380-401. doi: 10.3109/03602530903491683

Farrell, J. J., Elsaleh, H., Garcia, M., Lai, R., Ammar, A., Regine, W. F., et al. (2009). Human equilibrative nucleoside transporter 1 levels predict response to gemcitabine in patients with pancreatic cancer. Gastroenterology 136, 187-195. doi: 10.1053/j.gastro.2008.09.067

Feher, M., and Schmidt, J. M. (2003). Property distributions: differences between drugs, natural products, and molecules from combinatorial chemistry. J. Chem. Inf. Comput. Sci. 43, 218-227. doi: 10.1021/ci0200467

Feng, B., El-Kattan, A. F., and Radi, Z. A. (2012). Renal transporters in drug disposition, drug-drug interactions, and nephrotoxicity. Curr. Protoc. Toxicol. 23, 21-15. doi: 10.1002/0471140856.tx2303s53

Feng, B., Hurst, S., Lu, Y., Varma, M. V., Rotter, C. J., El-Kattan, A., et al. (2013). Quantitative prediction of renal transporter-mediated clinical drug-drug interactions. Mol. Pharm. 10, 4207-4215. doi: 10.1021/mp400295c

Feng, B., Varma, M. V., Costales, C., Zhang, H., and Tremaine, L. (2014). In vitro and in vivo approaches to characterize transporter-mediated disposition in drug discovery. Expert Opin. Drug Discov. 9, 873-890. doi: 10.1517/17460441.2014.922540

Fernandes, P., Ferreira, B. S., and Cabral, J. M. (2003). Solvent tolerance in bacteria: role of efflux pumps and cross-resistance with antibiotics. Int. J. Antimicrob. Agents 22, 211-216. doi: 10.1016/S0924-8579(03)00209-7

Fersht, A. (1999). Structure and Mechanism in Protein Science: A Guide to Enzyme Catalysis and Protein Folding. San Francisco, CA: W. H. Freeman.

Filipski, K. J., Varma, M. V., El-Kattan, A. F., Ambler, C. M., Ruggeri, R. B., Goosen, T. C., et al. (2013). Intestinal targeting of drugs: rational design approaches and challenges. Curr. Top. Med. Chem. 13, 776-802. doi: 10.2174/1568026611 313070002
Foo, J. L., and Leong, S. S. J. (2013). Directed evolution of an E. coli inner membrane transporter for improved efflux of biofuel molecules. Biotechnol. Biofuels 6:81. doi: 10.1186/1754-6834-6-81

Franke, R. M., Gardner, E. R., and Sparreboom, A. (2010). Pharmacogenetics of drug transporters. Curr. Pharm. Des. 16, 220-230. doi: 10.2174/1381612107 90112683

Franklin, L. R. (2005). Exploratory experiments. Philos. Sci. 72, 888-899. doi: $10.1086 / 508117$

Franks, N. P., and Honoré, E. (2004). The TREK $\mathrm{K}_{2 \mathrm{P}}$ channels and their role in general anaesthesia and neuroprotection. Trends Pharmacol. Sci. 25, 601-608. doi: 10.1016/j.tips.2004.09.003

Franks, N. P., and Lieb, W. R. (1984). Do general anaesthetics act by competitive binding to specific receptors? Nature 310, 599-601. doi: 10.1038/310599a0

Friend, D. R., and Pangburn, S. (1987). Site-specific drug delivery. Med. Res. Rev. 7, 53-106. doi: 10.1002/med.2610070104

Fromm, M. F. (2012). Prediction of transporter-mediated drug-drug interactions using endogenous compounds. Clin. Pharmacol. Ther. 92, 546-548. doi: 10.1038/clpt.2012.145

Fromm, M. F., and Kim, R. B. (eds.). (2011). Drug Transporters. Berlin: Springer. doi: 10.1007/978-3-642-14541-4

Fujiwara, K., Shin, M., Miyazaki, T., and Maruta, Y. (2011). Immunocytochemistry for amoxicillin and its use for studying uptake of the drug in the intestine, liver, and kidney of rats. Antimicrob. Agents Chemother. 55, 62-71. doi: 10.1128/AAC.01031-10

Fujiwara, K., Shin, M., Yoshizaki, Y., Miyazaki, T., and Saita, T. (2012). An in vivo role of Mrp2 in the rat hepatocytes by immunocytochemistry for amoxicillin using the transporter-deficient EHBR. J. Mol. Histol. 43, 371-378. doi: 10.1007/s10735-012-9406-2

Furihata, T., Fukuchi, Y., Iikura, M., Hashizume, M., Miyajima, A., Nagai, M., et al. (2010). Striking species difference in the contribution of concentrative nucleoside transporter 2 to nucleoside uptake between mouse and rat hepatocytes. Antimicrob. Agents Chemother. 54, 3035-3038. doi: 10.1128/AAC. 00010-10

Gasteiger, J. (ed.). (2003). Handbook of Chemoinformatics: From Data to Knowledge. Weinheim: Wiley/VCH. doi: 10.1002/3527601643

Gatti-Lafranconi, P., and Hollfelder, F. (2013). Flexibility and reactivity in promiscuous enzymes. ChemBioChem 14, 285-292. doi: 10.1002/cbic.201200628

Gedeon, P. C., Indarte, M., Surratt, C. K., and Madura, J. D. (2010). Molecular dynamics of leucine and dopamine transporter proteins in a model cell membrane lipid bilayer. Proteins 78, 797-811. doi: 10.1002/prot.22601

Gessel, M. M., Norris, J. L., and Caprioli, R. M. (2014). MALDI imaging mass spectrometry: spatial molecular analysis to enable a new age of discovery. J. Proteomics 107, 71-82. doi: 10.1016/j.jprot.2014.03.021

Gesto, D. S., Cerqueira, N. M., Fernandes, P. A., and Ramos, M. J. (2012). Gemcitabine: a critical nucleoside for cancer therapy. Curr. Med. Chem. 19, 1076-1087. doi: 10.2174/092986712799320682

Ghosh, A., Scott, D. O., and Maurer, T. S. (2014). Towards a unified model of passive drug permeation I: origins of the unstirred water layer with applications to ionic permeation. Eur. J. Pharm. Sci. 52, 109-124. doi: 10.1016/j.ejps.2013. 10.004

Giaccone, G., Zatloukal, P., Roubec, J., Floor, K., Musil, J., Kuta, M., et al. (2009). Multicenter phase II trial of YM155, a small-molecule suppressor of survivin, in patients with advanced, refractory, non-small-cell lung cancer. J. Clin. Oncol. 27, 4481-4486. doi: 10.1200/JCO.2008.21.1862

Giacomini, K. M., Balimane, P. V., Cho, S. K., Eadon, M., Edeki, T., Hillgren, K. M., et al. (2013). International transporter consortium commentary on clinically important transporter polymorphisms. Clin. Pharmacol. Ther. 94, 23-26. doi: 10.1038/clpt.2013.12

Giacomini, K. M., and Huang, S. M. (2013). Transporters in drug development and clinical pharmacology. Clin. Pharmacol. Ther. 94, 3-9. doi: 10.1038/clpt.2013.86

Giacomini, K. M., Huang, S. M., Tweedie, D. J., Benet, L. Z., Brouwer, K. L., Chu, X., et al. (2010). Membrane transporters in drug development. Nat. Rev. Drug Discov. 9, 215-236. doi: 10.1038/nrd3028

Giacomini, K. M., Yee, S. W., Ratain, M. J., Weinshilboum, R. M., Kamatani, N., and Nakamura, Y. (2012). Pharmacogenomics and patient care: one size does not fit all. Sci. Transl. Med. 4:153ps18. doi: 10.1126/scitranslmed. 3003471

Gimenez, R., Nuñez, M. F., Badia, J., Aguilar, J., and Baldoma, L. (2003). The gene yjcG, cotranscribed with the gene acs, encodes an acetate permease 
in Escherichia coli. J. Bacteriol. 185, 6448-6455. doi: 10.1128/JB.185.21.64486455.2003

Giorgi, M. A., Caroli, C., Arazi, H. C., and Di Girolamo, G. (2011). Pharmacogenomics and adverse drug reactions: the case of statins. Expert Opin. Pharmacother. 12, 1499-1509. doi: 10.1517/14656566.2011. 563734

Giovannetti, E., Del Tacca, M., Mey, V., Funel, N., Nannizzi, S., Ricci, S., et al. (2006). Transcription analysis of human equilibrative nucleoside transporter1 predicts survival in pancreas cancer patients treated with gemcitabine. Cancer Res. 66, 3928-3935. doi: 10.1158/0008-5472.CAN-05-4203

Gleeson, M. P., Hersey, A., and Hannongbua, S. (2011). In-silico ADME models: a general assessment of their utility in drug discovery applications. Curr. Top. Med. Chem. 11, 358-381. doi: 10.2174/156802611794480927

Golbraikh, A., Shen, M., Xiao, Z. Y., Xiao, Y. D., Lee, K. H., and Tropsha, A. (2003). Rational selection of training and test sets for the development of validated QSAR models. J. Comput. Aided Mol. Des. 17, 241-253. doi: 10.1023/A:1025386326946

Golbraikh, A., and Tropsha, A. (2002). Beware of $\mathrm{q}^{2} !$ J. Mol. Graph. Model. 20, 269-276. doi: 10.1016/S1093-3263(01)00123-1

Goose, J. E., and Sansom, M. S. P. (2013). Reduced lateral mobility of lipids and proteins in crowded membranes. PLoS Comp. Biol. 9:e1003033. doi: 10.1371/journal.pcbi.1003033

Gorter, E., and Grendel (1925). On bimolecular layers of lipoids on the chromocytes of blood. J. Exp. Med. 41, 439-443. doi: 10.1084/jem.41.4.439

Goswami, S., Gong, L., Giacomini, K., Altman, R. B., and Klein, T. E. (2014). PharmGKB summary: very important pharmacogene information for SLC22A1. Pharmacogenet. Genomics 24, 324-328. doi: 10.1097/FPC.00000000 00000048

Grandvuinet, A. S., Vestergaard, H. T., Rapin, N., and Steffansen, B. (2012). Intestinal transporters for endogenic and pharmaceutical organic anions: the challenges of deriving in-vitro kinetic parameters for the prediction of clinically relevant drug-drug interactions. J. Pharm. Pharmacol. 64, 1523-1548. doi: 10.1111/j.2042-7158.2012.01505.x

Grasshoff, C., Drexler, B., Rudolph, U., and Antkowiak, B. (2006). Anaesthetic drugs: linking molecular actions to clinical effects. Curr. Pharm. Des. 12, 3665-3679. doi: 10.2174/138161206778522038

Gray, J. H., Owen, R. P., and Giacomini, K. M. (2004). The concentrative nucleoside transporter family, SLC28. Pflugers Arch. 447, 728-734. doi: 10.1007/s00424003-1107-y

Grime, K., and Paine, S. W. (2013). Species differences in biliary clearance and possible relevance of hepatic uptake and efflux transporters involvement. Drug Metab. Dispos. 41, 372-378. doi: 10.1124/dmd.112.049312

Gruss, M., Bushell, T. J., Bright, D. P., Lieb, W. R., Mathie, A., and Franks, N. P. (2004). Two-pore-domain $\mathrm{K}^{+}$channels are a novel target for the anesthetic gases xenon, nitrous oxide, and cyclopropane. Mol. Pharmacol. 65, 443-452. doi: 10.1124/mol.65.2.443

Gupta, S., and Aires-De-Sousa, J. (2007). Comparing the chemical spaces of metabolites and available chemicals: models of metabolite-likeness. Mol. Divers. 11, 23-36. doi: 10.1007/s11030-006-9054-0

Haenisch, B., Drescher, E., Thiemer, L., Xin, H., Giros, B., Gautron, S., et al. (2012). Interaction of antidepressant and antipsychotic drugs with the human organic cation transporters hOCT1, hOCT2 and hOCT3. Arch Pharmacol. 385, 1017-1023. doi: 10.1007/s00210-012-0781-8

Hagenbuch, B., and Meier, P. J. (2004). Organic anion transporting polypeptides of the OATP/ SLC21 family: phylogenetic classification as OATP/ SLCO superfamily, new nomenclature and molecular/functional properties. Pflugers Arch. 447, 653-665. doi: 10.1007/s00424-003-1168-y

Hagenbuch, B., and Stieger, B. (2013). The SLCO (former SLC21) superfamily of transporters. Mol. Aspects Med. 34, 396-412. doi: 10.1016/j.mam.2012. 10.009

Hagmann, W., Jesnowski, R., and Lohr, J. M. (2010). Interdependence of gemcitabine treatment, transporter expression, and resistance in human pancreatic carcinoma cells. Neoplasia 12, 740-747. doi: 10.1593/neo.10576

Hamada, A., Sissung, T., Price, D. K., Danesi, R., Chau, C. H., Sharifi, N., et al. (2008). Effect of SLCO1B3 haplotype on testosterone transport and clinical outcome in caucasian patients with androgen-independent prostatic cancer. Clin. Cancer Res. 14, 3312-3318. doi: 10.1158/1078-0432.CCR-07-4118

Hamdalla, M. A., Mandoiu, I. I, Hill, D. W., Rajasekaran, S., and Grant, D. F. (2013). BioSM: metabolomics tool for identifying endogenous mammalian biochemical structures in chemical structure space. J. Chem. Inf. Model. 53, 601-612. doi: $10.1021 / \mathrm{ci} 300512 \mathrm{q}$

Han, H. K. (2011). Role of transporters in drug interactions. Arch. Pharm. Res. 34, 1865-1877. doi: 10.1007/s12272-011-1107-y

Han, W., Cheng, R. C., Maduke, M. C., and Tajkhorshid, E. (2014). Water access points and hydration pathways in CLC $\mathrm{H}^{+} / \mathrm{Cl}^{-}$transporters. Proc. Natl. Acad. Sci.U.S.A. 111, 1819-1824. doi: 10.1073/pnas.1317890111

Han, Y. F., Fan, X. H., Wang, X. J., Sun, K., Xue, H., Li, W. J., et al. (2011). Association of intergenic polymorphism of organic anion transporter 1 and 3 genes with hypertension and blood pressure response to hydrochlorothiazide. Am. J. Hypertens. 24, 340-346. doi: 10.1038/ajh.2010.191

Hann, M. M. (2011). Molecular obesity, potency and other addictions in drug discovery. MedChemComm 2, 349-355. doi: 10.1039/c1md00017a

Harwood, M. D., Neuhoff, S., Carlson, G. L., Warhurst, G., and Rostami-Hodjegan, A. (2013). Absolute abundance and function of intestinal drug transporters: a prerequisite for fully mechanistic in vitro-in vivo extrapolation of oral drug absorption. Biopharm. Drug Dispos. 34, 2-28. doi: 10.1002/bdd.1810

Hasannejad, H., Takeda, M., Taki, K., Shin, H. J., Babu, E., Jutabha, P., et al. (2004). Interactions of human organic anion transporters with diuretics. J. Pharmacol. Exp. Ther. 308, 1021-1029. doi: 10.1124/jpet.103.059139

Hazell, L., and Shakir, S. A. (2006). Under-reporting of adverse drug reactions: a systematic review. Drug saf. 29, 385-396. doi: 10.2165/00002018-20062905000003

He, L., Vasiliou, K., and Nebert, D. W. (2009). Analysis and update of the human solute carrier (SLC) gene superfamily. Hum. genomics 3, 195-206. doi: 10.1186/ 1479-7364-3-2-195

Hediger, M. A., Clemencon, B., Burrier, R. E., and Bruford, E. A. (2013). The ABCs of membrane transporters in health and disease (SLC series): introduction. Mol. Aspects Med. 34, 95-107. doi: 10.1016/j.mam.2012.12.009

Herrgård, M. J., Swainston, N., Dobson, P., Dunn, W. B., Arga, K. Y., Arvas, M., et al. (2008). A consensus yeast metabolic network obtained from a community approach to systems biology. Nat. Biotechnol. 26, 1155-1160. doi: $10.1038 / \mathrm{nbt} 1492$

Heurteaux, C., Guy, N., Laigle, C., Blondeau, N., Duprat, F., Mazzuca, M., et al. (2004). TREK-1, a K+ channel involved in neuroprotection and general anesthesia. EMBO J. 23, 2684-2695. doi: 10.1038/sj.emboj.7600234

Hey, T., Tansley, S., and Tolle, K. (eds.). (2009). The Fourth Paradigm: DataIntensive Scientific Discovery. Redmond, WA: Microsoft Research

Higgins, J. W., Bao, J. Q., Ke, A. B., Manro, J. R., Fallon, J. K., Smith, P. C., et al. (2014). Utility of Oatpla/1b-Knockout and OATP1B1/3-humanized mice in the study of OATP-mediated pharmacokinetics and tissue distribution: case studies with pravastatin, atorvastatin, simvastatin, and carboxydichlorofluorescein. Drug Metab. Dispos. 42, 182-192. doi: 10.1124/dmd.113. 054783

Hinderling, P. H. (1997). Red blood cells: a neglected compartment in pharmacokinetics and pharmacodynamics. Pharmacol. Rev. 49, 279-295.

Hogben, C. A. M., Tocco, D. J., Brodie, B. B., and Schanker, L. S. (1959). On the mechanism of intestinal absorption of drugs. J. Pharmacol. Exp. Ther. 125, 275-282.

Hopkins, A. L. (2008). Network pharmacology: the next paradigm in drug discovery. Nat. Chem. Biol. 4, 682-690. doi: 10.1038/nchembio.118

Hopkins, A. L., Mason, J. S., and Overington, J. P. (2006). Can we rationally design promiscuous drugs? Curr. Opin. Struct. Biol. 16, 127-136. doi: 10.1016/j.sbi.2006.01.013

Hosoya, K., and Tachikawa, M. (2011). Roles of organic anion/cation transporters at the blood-brain and blood-cerebrospinal fluid barriers involving uremic toxins. Clin. Exp. Nephrol. 15, 478-485. doi: 10.1007/s10157-011-0460-y

Howard, R. J., Murail, S., Ondricek, K. E., Corringer, P. J., Lindahl, E., Trudell, J. R., et al. (2011a). Structural basis for alcohol modulation of a pentameric ligand-gated ion channel. Proc. Natl. Acad. Sci. U.S.A. 108, 12149-12154. doi: 10.1073/pnas. 1104480108

Howard, R. J., Slesinger, P. A., Davies, D. L., Das, J., Trudell, J. R., and Harris, R. A. (2011b). Alcohol-binding sites in distinct brain proteins: the quest for atomic level resolution. Alcohol. Clin. Exp. Res. 35, 1561-1573. doi: 10.1111/j.15300277.2011.01502.x

Howard, R. J., Trudell, J. R., and Harris, R. A. (2014). Seeking structural specificity: direct modulation of pentameric ligand-gated ion channels by alcohols and general anesthetics. Pharmacol. Rev. 66, 396-412. doi: 10.1124/pr.113. 007468 
Huang, Y., Anderle, P., Bussey, K. J., Barbacioru, C., Shankavaram, U., Dai, Z., et al. (2004). Membrane transporters and channels: role of the transportome in cancer chemosensitivity and chemoresistance. Cancer Res. 64, 4294-4301. doi: 10.1158/0008-5472.CAN-03-3884

Huang, Y., and Sadée, W. (2003). Drug sensitivity and resistance genes in cancer chemotherapy: a chemogenomics approach. Drug Discov. Today 8, 356-363. doi: 10.1016/S1359-6446(03)02654-0

Hughes, J. D., Blagg, J., Price, D. A., Bailey, S., Decrescenzo, G. A., Devraj, R. V., et al. (2008). Physiochemical drug properties associated with in vivo toxicological outcomes. Bioorg. Med. Chem. Lett. 18, 4872-4875. doi: 10.1016/j.bmcl.2008. 07.071

Incecayir, T., Tsume, Y., and Amidon, G. L. (2013). Comparison of the permeability of metoprolol and labetalol in rat, mouse, and Caco-2 cells: use as a reference standard for BCS classification. Mol. Pharm. 10, 958-966. doi: $10.1021 / \mathrm{mp} 300410 \mathrm{n}$

Ioannidis, J. P. A. (2005). Why most published research findings are false. PLoS Med 2:e124. doi: 10.1371/journal.pmed.0020124

Irvine, J. D., Takahashi, L., Lockhart, K., Cheong, J., Tolan, J. W., Selick, H. E., et al. (1999). MDCK (Madin-Darby canine kidney) cells: a tool for membrane permeability screening. J. Pharm. Sci. 88, 28-33. doi: 10.1021/js9803205

Ishida, N., and Kawakita, M. (2004). Molecular physiology and pathology of the nucleotide sugar transporter family (SLC35). Pflugers Arch. 447, 768-775. doi: 10.1007/s00424-003-1093-0

Ishikawa, T., Aw, W., and Kaneko, K. (2013a). Metabolic interactions of purine derivatives with human $\mathrm{ABC}$ transporter ABCG2: genetic testing to assess gout risk. Pharmaceuticals 6, 1347-1360. doi: 10.3390/ph6111347

Ishikawa, T., Kim, R. B., and König, J. (eds.). (2013b). Pharmacogenomics of Human Drug Transporters: Clinical Impacts. New York, NY: Wiley. doi: 10.1002/9781118353240

Ishikawa, T., Tsuji, A., Inui, K., Sai, Y., Anzai, N., Wada, M., et al. (2004). The genetic polymorphism of drug transporters: functional analysis approaches. Pharmacogenomics 5, 67-99. doi: 10.1517/phgs.5.1.67.25683

Ishizuka, H., Konno, K., Naganuma, H., Nishimura, K., Kouzuki, H., Suzuki, H., et al. (1998). Transport of temocaprilat into rat hepatocytes: role of organic anion transporting polypeptide. J. Pharmacol. Exp. Ther. 287, 37-42.

Islam, R., Anzai, N., Ahmed, N., Ellapan, B., Jin, C. J., Srivastava, S., et al. (2008). Mouse organic anion transporter 2 (mOat2) mediates the transport of short chain fatty acid propionate. J. Pharmacol. Sci. 106, 525-528. doi: 10.1254/jphs.SC0070291

Jain, M. K. (1972). The Bimolecular Lipid Membrane. New York, NY: Van Nostrand Reinhold.

Jalencas, X., and Mestres, J. (2013). On the origins of drug polypharmacology. MedChemComm 4, 80-87. doi: 10.1039/c2md20242e

Jasiński, M., Stukkens, Y., Degand, H., Purnelle, B., Marchand-Brynaert, J., and Boutry, M. (2001). A plant plasma membrane ATP binding cassette-type transporter is involved in antifungal terpenoid secretion. Plant Cell 13, 1095-1107. doi: $10.1105 /$ tpc.13.5.1095

Javanainen, M., Hammaren, H., Monticelli, L., Jeon, J. H., Miettinen, M. S., Martinez-Seara, H., et al. (2013). Anomalous and normal diffusion of proteins and lipids in crowded lipid membranes. Faraday Discuss. 161, 397-417. doi: $10.1039 / \mathrm{c} 2 \mathrm{fd} 20085 \mathrm{f}$

Jenkins, S. L., and Ma'ayan, A. (2013). Systems pharmacology meets predictive, preventive, personalized and participatory medicine. Pharmacogenomics 14, 119-122. doi: $10.2217 /$ pgs. 12.186

Johnson, W. D. 2nd., Howard, R. J., Trudell, J. R., and Harris, R. A. (2012). The TM2 $6^{\prime}$ position of $\mathrm{GABA}_{\mathrm{A}}$ receptors mediates alcohol inhibition. J Pharmacol Exp Ther 340, 445-456. doi: 10.1124/jpet.111.188037

Jordheim, L. P., and Dumontet, C. (2013). Do hENT1 and RRM1 predict the clinical benefit of gemcitabine in pancreatic cancer? Biomark. Med. 7, 663-671. doi: 10.2217/bmm. 13.48

Jung, K. Y., Takeda, M., Kim, D. K., Tojo, A., Narikawa, S., Yoo, B. S., et al. (2001). Characterization of ochratoxin A transport by human organic anion transporters. Life Sci. 69, 2123-2135. doi: 10.1016/S0024-3205(01)01296-6

Jurd, R., Arras, M., Lambert, S., Drexler, B., Siegwart, R., Crestani, F., et al. (2003). General anesthetic actions in vivo strongly attenuated by a point mutation in the GABA $_{A}$ receptor $\beta 3$ subunit. FASEB J. 17, 250-252. doi: 10.1096/fj.02-0611fje

Kaldenhoff, R., Kai, L., and Uehlein, N. (2014). Aquaporins and membrane diffusion of $\mathrm{CO}_{2}$ in living organisms. Biochim. Biophys. Acta 1840, 1592-1595. doi: 10.1016/j.bbagen.2013.09.037
Karakoc, E., Sahinalp, S. C., and Cherkasov, A. (2006). Comparative QSARand fragments distribution analysis of drugs, druglikes, metabolic substances, and antimicrobial compounds. J. Chem. Inf. Model. 46, 2167-2182. doi: $10.1021 / \mathrm{ci0601517}$

Karlgren, M., Vildhede, A., Norinder, U., Wisniewski, J. R., Kimoto, E., Lai, Y., et al. (2012). Classification of inhibitors of hepatic organic anion transporting polypeptides (OATPs): influence of protein expression on drug-drug interactions. J. Med. Chem. 55, 4740-4763. doi: 10.1021/jm300212s

Karplus, M., and Kuriyan, J. (2005). Molecular dynamics and protein function. Proc. Natl. Acad. Sci. U.S.A. 102, 6679-6685. doi: 10.1073/pnas.0408930102

Kasim, N. A., Whitehouse, M., Ramachandran, C., Bermejo, M., Lennernäs, H., Hussain, A. S., et al. (2004). Molecular properties of WHO essential drugs and provisional biopharmaceutical classification. Mol. Pharm. 1, 85-96. doi: 10.1021/mp034006h

Kato, Y., Miyazaki, T., Kano, T., Sugiura, T., Kubo, Y., and Tsuji, A. (2009). Involvement of influx and efflux transport systems in gastrointestinal absorption of celiprolol. J. Pharm. Sci. 98, 2529-2539. doi: 10.1002/jps.21618

Keleti, T. (1986). Basic Enzyme Kinetics. Budapest: Akadémiai Kiadó.

Kell, D. B. (1992). The protonmotive force as an intermediate in electron transportlinked phosphorylation: problems and prospects. Curr. Top. Cell. Regul. 33, 279-289. doi: 10.1016/B978-0-12-152833-1.50021-6

Kell, D. B. (2006). Metabolomics, modelling and machine learning in systems biology: towards an understanding of the languages of cells. The 2005 Theodor Bücher lecture. FEBS J. 273, 873-894. doi: 10.1111/j.1742-4658.2006. 05136.x

Kell, D. B. (2012). Scientific discovery as a combinatorial optimisation problem: how best to navigate the landscape of possible experiments? Bioessays 34, 236-244. doi: 10.1002/bies.201100144

Kell, D. B. (2013). Finding novel pharmaceuticals in the systems biology era using multiple effective drug targets, phenotypic screening, and knowledge of transporters: where drug discovery went wrong and how to fix it. FEBS J. 280, 5957-5980. doi: 10.1111/febs.12268

Kell, D. B., and Dobson, P. D. (2009). “The cellular uptake of pharmaceutical drugs is mainly carrier-mediated and is thus an issue not so much of biophysics but of systems biology," in Proc Int Beilstein Symposium on Systems Chemistry, eds M. G. Hicks and C. Kettner (Berlin: Logos Verlag), 149-168.

Kell, D. B., Dobson, P. D., Bilsland, E., and Oliver, S. G. (2013). The promiscuous binding of pharmaceutical drugs and their transporter-mediated uptake into cells: what we (need to) know and how we can do so. Drug Discov. Today 18, 218-239. doi: 10.1016/j.drudis.2012.11.008

Kell, D. B., Dobson, P. D., and Oliver, S. G. (2011). Pharmaceutical drug transport: the issues and the implications that it is essentially carrier-mediated only. Drug Discov. Today 16, 704-714. doi: 10.1016/j.drudis.2011.05.010

Kell, D. B., Ferguson, S. J., and John, P. (1978a). Measurement by a flow dialysis technique of the steady-state protonmotive force in chromatophores from Rhodospirillum rubrum: comparison with the phosphorylation potential. Biochim. Biophys. Acta 502, 111-126. doi: 10.1016/0005-2728(78)90136-6

Kell, D. B., and Goodacre, R. (2014). Metabolomics and systems pharmacology: why and how to model the human metabolic network for drug discovery. Drug Discov. Today 19, 171-182. doi: 10.1016/j.drudis.2013.07.014

Kell, D. B., John, P., and Ferguson, S. J. (1978b). The protonmotive force in phosphorylating membrane vesicles from Paracoccus denitrificans: magnitude, sites of generation and comparison with the phosphorylation potential. Biochem. J. 174, 257-266.

Kell, D. B., Kaprelyants, A. S., Weichart, D. H., Harwood, C. L., and Barer, M. R. (1998). Viability and activity in readily culturable bacteria: a review and discussion of the practical issues. Antonie Van Leeuwenhoek 73, 169-187. doi: 10.1023/A:1000664013047

Kell, D. B., and Knowles, J. D. (2006). "The role of modeling in systems biology," in System Modeling in Cellular Biology: from Concepts to Nuts and Bolts, eds Z. Szallasi, J. Stelling, and V. Periwal (Cambridge: MIT Press), 3-18. doi: 10.7551/mitpress/9780262195485.003.0001

Kell, D. B., and Morris, J. G. (1980). Formulation and some biological uses of a buffer mixture whose buffering capacity is relatively independent of $\mathrm{pH}$ in the range pH 4-9. J. Biochem. Biophys. Methods 3, 143-150. doi: 10.1016/0165022X(80)90013-5

Kell, D. B., and Oliver, S. G. (2004). Here is the evidence, now what is the hypothesis? The complementary roles of inductive and hypothesis-driven science in the post-genomic era. Bioessays 26, 99-105. doi: 10.1002/bies.10385 
Kell, D. B., Peck, M. W., Rodger, G., and Morris, J. G. (1981). On the permeability to weak acids and bases of the cytoplasmic membrane of Clostridium pasteurianum. Biochem. Biophys. Res. Commun. 99, 81-88. doi: 10.1016/0006291X(81)91715-0

Kell, D. B., Ryder, H. M., Kaprelyants, A. S., and Westerhoff, H. V. (1991). Quantifying heterogeneity: flow cytometry of bacterial cultures. Antonie Van Leeuwenhoek 60, 145-158. doi: 10.1007/BF00430362

Kell, D. B., and Sonnleitner, B. (1995). GMP - Good modelling practice: an essential component of good manufacturing practice. Trends Biotechnol. 13, 481-492. doi: 10.1016/S0167-7799(00)89006-X

Kell, D. B., and Westerhoff, H. V. (1986). Metabolic control theory: its role in microbiology and biotechnology. FEMS Microbiol. Rev. 39, 305-320. doi: 10.1111/j.1574-6968.1986.tb01863.x

Kenny, P. W., Leitão, A., and Montanari, C. A. (2014). Ligand efficiency metrics considered harmful. J. Comput. Aided Mol. Des. 28, 699-710. doi: $10.1007 /$ s10822-014-9757-8

Keogh, J. P. (2012). Membrane transporters in drug development. Adv. Pharmacol. 63, 1-42. doi: 10.1016/B978-0-12-398339-8.00001-X

Khalili-Araghi, F., Gumbart, J., Wen, P. C., Sotomayor, M., Tajkhorshid, E., and Schulten, K. (2009). Molecular dynamics simulations of membrane channels and transporters. Curr. Opin. Struct. Biol. 19, 128-137. doi: 10.1016/j.sbi.2009. 02.011

Khamdang, S., Takeda, M., Noshiro, R., Narikawa, S., Enomoto, A., Anzai, N., et al. (2002). Interactions of human organic anion transporters and human organic cation transporters with nonsteroidal anti-inflammatory drugs. J. Pharmacol. Exp. Ther. 303, 534-539. doi: 10.1124/jpet.102.037580

Khanna, V., and Ranganathan, S. (2009). Physicochemical property space distribution among human metabolites, drugs and toxins. BMC Bioinformatics 10:S10. doi: 10.1186/1471-2105-10-S15-S10

Khanna, V., and Ranganathan, S. (2011). Structural diversity of biologically interesting datasets: a scaffold analysis approach. J. Cheminform. 3:30. doi: 10.1186/1758-2946-3-30

Khatib-Shahidi, S., Andersson, M., Herman, J. L., Gillespie, T. A., and Caprioli, R. M. (2006). Direct molecular analysis of whole-body animal tissue sections by imaging MALDI mass spectrometry. Anal. Chem. 78, 6448-6456. doi: 10.1021/ ac060788p

Khersonsky, O., and Tawfik, D. S. (2010). Enzyme promiscuity: a mechanistic and evolutionary perspective. Annu. Rev. Biochem. 79, 471-505. doi: 10.1146/annurev-biochem-030409-143718

Khnykin, D., Miner, J. H., and Jahnsen, F. (2011). Role of fatty acid transporters in epidermis: implications for health and disease. Dermatoendocrinol. 3, 53-61. doi: 10.4161/derm.3.2.14816

Kido, Y., Matsson, P., and Giacomini, K. M. (2011). Profiling of a prescription drug library for potential renal drug-drug interactions mediated by the organic cation transporter 2. J. Med. Chem. 54, 4548-4558. doi: 10.1021/ jm2001629

Kieboom, J., Dennis, J. J., De Bont, J. A., and Zylstra, G. J. (1998a). Identification and molecular characterization of an efflux pump involved in Pseudomonas putida S12 solvent tolerance. J. Biol. Chem. 273, 85-91.

Kieboom, J., Dennis, J. J., Zylstra, G. J., and De Bont, J. A. (1998b). Active efflux of organic solvents by Pseudomonas putida S12 is induced by solvents. J. Bacteriol. 180, 6769-6772.

King, A. E., Ackley, M. A., Cass, C. E., Young, J. D., and Baldwin, S. A. (2006). Nucleoside transporters: from scavengers to novel therapeutic targets. Trends Pharmacol. Sci. 27, 416-425. doi: 10.1016/j.tips.2006.06.004

Kis, O., Zastre, J. A., Hoque, M. T., Walmsley, S. L., and Bendayan, R. (2013). Role of drug efflux and uptake transporters in atazanavir intestinal permeability and drug-drug interactions. Pharm. Res. 30, 1050-1064. doi: 10.1007/s11095-0120942-y

Kiyotani, K., Mushiroda, T., Nakamura, Y., and Zembutsu, H. (2012). Pharmacogenomics of tamoxifen: roles of drug metabolizing enzymes and transporters. Drug Metab. Pharmacokinet. 27, 122-131. doi: 10.2133/dmpk. DMPK-11-RV-084

Klatt, S., Fromm, M. F., and König, J. (2011). Transporter-mediated drugdrug interactions with oral antidiabetic drugs. Pharmaceutics 3, 680-705. doi: 10.3390/pharmaceutics3040680

Knütter, I., Kottra, G., Fischer, W., Daniel, H., and Brandsch, M. (2009). Highaffinity interaction of sartans with $\mathrm{H}^{+}$/peptide transporters. Drug Metab. Dispos. 37, 143-149. doi: 10.1124/dmd.108.022418
Knütter, I., Wollesky, C., Kottra, G., Hahn, M. G., Fischer, W., Zebisch, K., et al. (2008). Transport of angiotensin-converting enzyme inhibitors by $\mathrm{H}^{+}$/peptide transporters revisited. J. Pharmacol. Exp. Ther. 327, 432-441. doi: 10.1124/jpet.108.143339

Koldsø, H., Autzen, H. E., Grouleff, J., and Schiøtt, B. (2013). Ligand induced conformational changes of the human serotonin transporter revealed by molecular dynamics simulations. PLoS One 8:e63635. doi: 10.1371/journal.pone.0063635

Koldsø, H., and Sansom, M. S. P. (2012). Local lipid reorganization by a transmembrane protein domain. J. Phys. Chem. Lett. 3, 3498-3502. doi: 10.1021/jz301570w

Komori, S., Osada, S., and Yoshida, K. (2011). Novel strategy with gemcitabine for advanced pancreatic cancer. ISRN Oncol. 2011:936893. doi: $10.5402 / 2011 / 936893$

Kongkaew, C., Noyce, P. R., and Ashcroft, D. M. (2008). Hospital admissions associated with adverse drug reactions: a systematic review of prospective observational studies. Ann Pharmacother. 42, 1017-1025. doi: 10.1345/aph. $1 \mathrm{~L} 037$

König, J. (2011). Uptake transporters of the human OATP family: molecular characteristics, substrates, their role in drug-drug interactions, and functional consequences of polymorphisms. Handb. Exp. Pharmacol. 201, 1-28. doi: 10.1007/978-3-642-14541-4_1

König, J., Müller, F., and Fromm, M. F. (2013). Transporters and drug-drug interactions: important determinants of drug disposition and effects. Pharmacol. Rev. 65, 944-966. doi: 10.1124/pr.113.007518

Kubo, Y., Kusagawa, Y., Tachikawa, M., Akanuma, S., and Hosoya, K. (2013a). Involvement of a novel organic cation transporter in verapamil transport across the inner blood-retinal barrier. Pharm. Res. 30, 847-856. doi: 10.1007/s11095012-0926-y

Kubo, Y., Shimizu, Y., Kusagawa, Y., Akanuma, S., and Hosoya, K. (2013b). Propranolol transport across the inner blood-retinal barrier: potential involvement of a novel organic cation transporter. J. Pharm. Sci. 102, 3332-3342. doi: 10.1002/jps.23535

Kusumi, A., Suzuki, K. G. N., Kasai, R. S., Ritchie, K., and Fujiwara, T. K. (2011) Hierarchical mesoscale domain organization of the plasma membrane. Trends Biochem. Sci. 36, 604-615. doi: 10.1016/j.tibs.2011.08.001

Lachance, N., Gareau, Y., Guiral, S., Huang, Z., Isabel, E., Leclerc, J. P., et al. (2012a). Discovery of potent and liver-targeted stearoyl-CoA desaturase (SCD) inhibitors in a bispyrrolidine series. Bioorg. Med. Chem. Lett. 22, 980-984. doi: 10.1016/j.bmcl.2011.12.002

Lachance, N., Guiral, S., Huang, Z., Leclerc, J. P., Li, C. S., Oballa, R. M., et al. (2012b). Discovery of potent and liver-selective stearoyl-CoA desaturase (SCD) inhibitors in an acyclic linker series. Bioorg. Med. Chem. Lett. 22, 623-627. doi: 10.1016/j.bmcl.2011.10.070

Laganowsky, A., Reading, E., Allison, T. M., Ulmschneider, M. B., Degiacomi, M. T., Baldwin, A. J., et al. (2014). Membrane proteins bind lipids selectively to modulate their structure and function. Nature 510, 172-175. doi: 10.1038 /nature13419

Lai, Y., and Hsiao, P. (2014). Beyond the ITC White Paper: emerging sciences in drug transporters and opportunities for drug development. Curr. Pharmaceut. Des. 20, 1577-1594. doi: 10.2174/13816128113199990467

Lai, Y., Sampson, K. E., and Stevens, J. C. (2010). Evaluation of drug transporter interactions in drug discovery and development. Comb. Chem. High Throughput Screen 13, 112-134. doi: 10.2174/138620710790596772

Lai, Y., Varma, M., Feng, B., Stephens, J. C., Kimoto, E., El-Kattan, A., et al. (2012). Impact of drug transporter pharmacogenomics on pharmacokinetic and pharmacodynamic variability-considerations for drug development. Expert Opin. Drug Metab. Toxicol. 8, 723-743. doi: 10.1517/17425255.2012. 678048

Landowski, C. P., Anderle, P., Sun, D., Sadee, W., and Amidon, G. L. (2004) Transporter and ion channel gene expression after Caco-2 cell differentiation using 2 different microarray technologies. AAPS J. 6:e21. doi: 10.1208/aapsj060321

Landrum, G., Lewis, R., Palmer, A., Stiefl, N., and Vulpetti, A. (2011). Making sure there's a "give" associated with the "take": producing and using opensource software in big pharma. J. Cheminform. 3:O3. doi: 10.1186/1758-29463-S1-O3

Lanthaler, K., Bilsland, E., Dobson, P., Moss, H. J., Pir, P., Kell, D. B., et al. (2011). Genome-wide assessment of the carriers involved in the cellular uptake of drugs: a model system in yeast. BMC Biol. 9:70. doi: 10.1186/1741-7007-9-70 
Law, V., Knox, C., Djoumbou, Y., Jewison, T., Guo, A. C., Liu, Y., et al. (2014). DrugBank 4.0: shedding new light on drug metabolism. Nucleic Acids Res. 42, D1091-D1097. doi: 10.1093/nar/gkt1068

Lee, A. G. (2011a). Biological membranes: the importance of molecular detail. Trends Biochem. Sci. 36, 493-500. doi: 10.1016/j.tibs.2011.06.007

Lee, A. G. (2011b). "How to understand lipid-protein interactions in biological membranes," in The Structure of Biological Membranes, 3rd Edn., ed P. L. Yeagle (Boca Raton, FL: CRC Press), 273-313.

Lee, N. H. (2010). Pharmacogenetics of drug metabolizing enzymes and transporters: effects on pharmacokinetics and pharmacodynamics of anticancer agents. Anticancer Agents Med. Chem. 10, 583-592. doi: 10.2174/18715201079 4474019

Lee, S. Y., Im, S. A., Park, Y. H., Woo, S. Y., Kim, S., Choi, M. K., et al. (2014). Genetic polymorphisms of SLC28A3, SLC29A1 and RRM1 predict clinical outcome in patients with metastatic breast cancer receiving gemcitabine plus paclitaxel chemotherapy. Eur. J. Cancer 50, 698-705. doi: 10.1016/j.ejca.2013. 11.028

Leeson, P. D., and Springthorpe, B. (2007). The influence of drug-like concepts on decision-making in medicinal chemistry. Nat. Rev. Drug Discov. 6, 881-890. doi: $10.1038 / \mathrm{nrd} 2445$

Lehár, J., Stockwell, B. R., Giaever, G., and Nislow, C. (2008). Combination chemical genetics. Nat. Chem. Biol. 4, 674-681. doi: 10.1038/nchembio.120

Lennernäs, H., Aarons, L., Augustijns, P., Beato, S., Bolger, M., Box, K., et al. (2014). Oral biopharmaceutics tools - time for a new initiative - an introduction to the IMI project OrBiTo. Eur. J. Pharm. Sci. 57, 292-299. doi: 10.1016/j.ejps.2013.10.012

Leontiadou, H., Mark, A. E., and Marrink, S. J. (2004). Molecular dynamics simulations of hydrophilic pores in lipid bilayers. Biophys. J. 86, 2156-2164. doi: 10.1016/S0006-3495(04)74275-7

Leontiadou, H., Mark, A. E., and Marrink, S. J. (2007). Ion transport across transmembrane pores. Biophys. J. 92, 4209-4215. doi: 10.1529/biophysj.106. 101295

Lepist, E. I., and Ray, A. S. (2012). Renal drug-drug interactions: what we have learned and where we are going. Expert Opin. Drug Metab. Toxicol. 8, 433-448. doi: 10.1517/17425255.2012.667401

Li, G. W., Santoni, V., and Maurel, C. (2014). Plant aquaporins: roles in plant physiology. Biochim. Biophys. Acta 1840, 1574-1582. doi: 10.1016/j.bbagen.2013. 11.004

Li, J., and Bluth, M. H. (2011). Pharmacogenomics of drug metabolizing enzymes and transporters: implications for cancer therapy. Pharmacogenomics Pers. Med. 4, 11-33. doi: 10.2147/PGPM.S18861

Li, L. B., Vorobyov, I., and Allen, T. W. (2012). The role of membrane thickness in charged protein-lipid interactions. Biochim. Biophys. Acta 1818, 135-145. doi: 10.1016/j.bbamem.2011.10.026

Li, M., Anderson, G. D., Phillips, B. R., Kong, W., Shen, D. D., and Wang, J. (2006). Interactions of amoxicillin and cefaclor with human renal organic anion and peptide transporters. Drug Metab. Dispos. 34, 547-555. doi: 10.1124/dmd.105. 006791

Li, M., Yuan, H., Li, N., Song, G., Zheng, Y., Baratta, M., et al. (2008). Identification of interspecies difference in efflux transporters of hepatocytes from dog, rat, monkey and human. Eur. J. Pharm. Sci. 35, 114-126. doi: 10.1016/j.ejps.2008. 06.008

Lin, M. H., and Khnykin, D. (2014). Fatty acid transporters in skin development, function and disease. Biochim. Biophys. Acta 1841, 362-368. doi: 10.1016/j.bbalip.2013.09.016

Lindorff-Larsen, K., Piana, S., Dror, R. O., and Shaw, D. E. (2011). How fast-folding proteins fold. Science 334, 517-520. doi: 10.1126/science.1208351

Ling, H., Chen, B., Kang, A., Lee, J. M., and Chang, M. W. (2013). Transcriptome response to alkane biofuels in Saccharomyces cerevisiae: identification of efflux pumps involved in alkane tolerance. Biotechnol. Biofuels 6:95. doi: 10.1186/1754-6834-6-95

Link, E., Parish, S., Armitage, J., Bowman, L., Heath, S., Matsuda, F., et al. (2008). SLCO1B1 variants and statin-induced myopathy-a genomewide study. N. Engl. J. Med. 359, 789-799. doi: 10.1056/NEJMoa0801936

Lipinski, C. A. (2004). Lead- and drug-like compounds: the rule-of-five revolution. Drug Discov. Today Technol. 1, 337-341. doi: 10.1016/j.ddtec.2004. 11.007

Lipinski, C. A., Lombardo, F., Dominy, B. W., and Feeney, P. J. (1997). Experimental and computational approaches to estimate solubility and permeability in drug discovery and development settings. Adv. Drug Deliv. Rev. 23, 3-25. doi: 10.1016/S0169-409X(96)00423-1

Liu, G. (2013). Stearoyl-CoA Desaturase 1 (SCD1) inhibitors: bench to bedside must only go through liver. RSC Drug Discov. 249-269. doi: $10.1002 / 9781118354483$

Lobo, I. A., and Harris, R. A. (2005). Sites of alcohol and volatile anesthetic action on glycine receptors. Int. Rev. Neurobiol. 65, 53-87. doi: 10.1016/S00747742(04)65003-3

Lobo, I. A., and Harris, R. A. (2008). GABA A receptors and alcohol. Pharmacol. Biochem. Behav. 90, 90-94. doi: 10.1016/j.pbb.2008.03.006

Löffler, M., Morote-Garcia, J. C., Eltzschig, S. A., Coe, I. R., and Eltzschig, H. K. (2007). Physiological roles of vascular nucleoside transporters. Arterioscler. Thromb. Vasc. Biol. 27, 1004-1013. doi: 10.1161/ATVBAHA.106.126714

Ma, Q., and Lu, A. Y. (2008). The challenges of dealing with promiscuous drug-metabolizing enzymes, receptors and transporters. Curr. Drug Metab. 9, 374-383. doi: 10.2174/138920008784746337

Mackey, J. R., Mani, R. S., Selner, M., Mowles, D., Young, J. D., Belt, J. A., et al. (1998). Functional nucleoside transporters are required for gemcitabine influx and manifestation of toxicity in cancer cell lines. Cancer Res. 58, 4349-4357.

Mackey, J. R., Yao, S. Y., Smith, K. M., Karpinski, E., Baldwin, S. A., Cass, C. E., et al. (1999). Gemcitabine transport in Xenopus oocytes expressing recombinant plasma membrane mammalian nucleoside transporters. J. Natl. Cancer Inst. 91, 1876-1881. doi: 10.1093/jnci/91.21.1876

Maeda, K., and Sugiyama, Y. (2013). Transporter biology in drug approval: regulatory aspects. Mol. Aspects Med. 34, 711-718. doi: 10.1016/j.mam.2012. 10.012

Maeda, K., Yoshida, K., and Sugiyama, Y. (2011). What kind of assumptions should we use to improve the predictability of drug-drug interactions involving organic anion transporting polypeptide (OATP) substrates? Drug Metab. Rev. 43, 99-99.

Magalon, A., Arias-Cartin, R., and Walburger, A. (2012). Supramolecular organization in prokaryotic respiratory systems. Adv. Microb. Physiol. 61, 217-266. doi: 10.1016/B978-0-12-394423-8.00006-8

Maggiora, G., Vogt, M., Stumpfe, D., and Bajorath, J. (2014). Molecular similarity in medicinal chemistry. J. Med. Chem. 57, 3186-3204. doi: 10.1021/jm401411z

Maggo, S. D., Kennedy, M. A., and Clark, D. W. J. (2011). Clinical implications of pharmacogenetic variation on the effects of statins. Drug Saf. 34, 1-19. doi: 10.2165/11584380-000000000-00000

Maldonado, A. G., Doucet, J. P., Petitjean, M., and Fan, B. T. (2006). Molecular similarity and diversity in chemoinformatics: from theory to applications. Mol. Divers. 10, 39-79. doi: 10.1007/s11030-006-8697-1

Mandery, K., Glaeser, H., and Fromm, M. F. (2012). Interaction of innovative small molecule drugs used for cancer therapy with drug transporters. Br. J. Pharmacol. 165, 345-362. doi: 10.1111/j.1476-5381.2011.01618.x

Mangravite, L. M., Badagnani, I., and Giacomini, K. M. (2003). Nucleoside transporters in the disposition and targeting of nucleoside analogs in the kidney. Eur. J. Pharmacol. 479, 269-281. doi: 10.1016/j.ejphar.2003.08.076

Marcé, S., Molina-Arcas, M., Villamor, N., Casado, F. J., Campo, E., Pastor-Anglada, M., et al. (2006). Expression of human equilibrative nucleoside transporter 1 (hENT1) and its correlation with gemcitabine uptake and cytotoxicity in mantle cell lymphoma. Haematologica 91, 895-902.

Marchetti, S., Mazzanti, R., Beijnen, J. H., and Schellens, J. H. (2007). Clinical relevance of drug drug and herb drug interactions mediated by the $\mathrm{ABC}$ transporter ABCB1 (MDR1, P-glycoprotein). Oncologist 12, 927-941. doi: 10.1634/theoncologist.12-8-927

Maréchal, R., Bachet, J. B., Mackey, J. R., Dalban, C., Demetter, P., Graham, K., et al. (2012). Levels of gemcitabine transport and metabolism proteins predict survival times of patients treated with gemcitabine for pancreatic adenocarcinoma. Gastroenterology 143, 664-674. doi: 10.1053/j.gastro.2012.06.006

Maréchal, R., Mackey, J. R., Lai, R., Demetter, P., Peeters, M., Polus, M., et al. (2009). Human equilibrative nucleoside transporter 1 and human concentrative nucleoside transporter 3 predict survival after adjuvant gemcitabine therapy in resected pancreatic adenocarcinoma. Clin. Cancer Res. 15, 2913-2919. doi: 10.1158/1078-0432.CCR-08-2080

Marko-Varga, G., Fehniger, T. E., Rezeli, M., Döme, B., Laurell, T., and Végvári, A. (2011). Drug localization in different lung cancer phenotypes by MALDI mass spectrometry imaging. J. Proteomics 74, 982-992. doi: 10.1016/j.jprot. 2011.03.019 
Marko-Varga, G., Vegvari, A., Rezeli, M., Prikk, K., Ross, P., Dahlback, M., et al. (2012). Understanding drug uptake and binding within targeted disease microenvironments in patients: a new tool for translational medicine. Clin. Transl. Med. 1:8. doi: 10.1186/2001-1326-1-8

Marzolini, C., Battegay, M., and Back, D. (2011). "Mechanisms of drug interactions II: transport proteins," in Drug Interactions in Infectious Diseases, 3rd Edn., eds S. C. Piscitelli, K. A. Rodvold, and M. P. Pai (Berlin: Springer), 43-72.

Matsushima, S., Maeda, K., Inoue, K., Ohta, K. Y., Yuasa, H., Kondo, T., et al. (2009). The inhibition of human multidrug and toxin extrusion 1 is involved in the drug-drug interaction caused by cimetidine. Drug Metab. Dispos. 37, 555-559. doi: 10.1124/dmd.108.023911

Mazák, K., and Noszál, B. (2014). Drug delivery: a process governed by speciesspecific lipophilicities. Eur. J. Pharm. Sci. 62C, 96-104. doi: 10.1016/j.ejps.2014. 05.017

Mazanetz, M. P., Marmon, R. J., Reisser, C. B. T., and Morao, I. (2012). Drug discovery applications for KNIME: an open source data mining platform. Curr. Top. Med. Chem. 12, 1965-1979. doi: 10.2174/156802612804910331

Mccarthy, J. E., Ferguson, S. J., and Kell, D. B. (1981). Estimation with an ionselective electrode of the membrane potential in cells of Paracoccus denitrificans from the uptake of the butyltriphenylphosphonium cation during aerobic and anaerobic respiration. Biochem. J. 196, 311-321.

Mclaughlin, S., and Murray, D. (2005). Plasma membrane phosphoinositide organization by protein electrostatics. Nature 438, 605-611. doi: 10.1038/nature 04398

Medawar, P. (1982). Pluto's Republic. Oxford: Oxford University Press.

Medina-Franco, J. L., Giulianotti, M. A., Welmaker, G. S., and Houghten, R. A. (2013). Shifting from the single to the multitarget paradigm in drug discovery. Drug Discov. Today 18, 495-501. doi: 10.1016/j.drudis.2013.01.008

Meera, P., Olsen, R. W., Otis, T. S., and Wallner, M. (2010). Alcohol- and alcohol antagonist-sensitive human $\mathrm{GABA}_{\mathrm{A}}$ receptors: tracking delta subunit incorporation into functional receptors. Mol. Pharmacol. 78, 918-924. doi: 10.1124/mol.109.062687

Mestres, J., and Gregori-Puigjané, E. (2009). Conciliating binding efficiency and polypharmacology. Trends Pharmacol. Sci. 30, 470-474. doi: 10.1016/j.tips.2009. 07.004

Metz, J. T., and Hajduk, P. J. (2010). Rational approaches to targeted polypharmacology: creating and navigating protein-ligand interaction networks. Curr. Opin. Chem. Biol. 14, 498-504. doi: 10.1016/j.cbpa.2010.06.166

Meyer, U. A. (2000). Pharmacogenetics and adverse drug reactions. Lancet 356, 1667-1671. doi: 10.1016/S0140-6736(00)03167-6

Miguel, A., Azevedo, L. F., Araújo, M., and Pereira, A. C. (2012). Frequency of adverse drug reactions in hospitalized patients: a systematic review and meta-analysis. Pharmacoepidemiol. Drug Saf. 21, 1139-1154. doi: 10.1002/pds. 3309

Mihic, S. J., Ye, Q., Wick, M. J., Koltchine, V. V., Krasowski, M. D., Finn, S. E., et al. (1997). Sites of alcohol and volatile anaesthetic action on $\mathrm{GABA}_{\mathrm{A}}$ and glycine receptors. Nature 389, 385-389. doi: 10.1038/38738

Minematsu, T., Iwai, M., Sugimoto, K., Shirai, N., Nakahara, T., Usui, T., et al. (2009). Carrier-mediated uptake of 1-(2-methoxyethyl)-2-methyl-4,9-dioxo3-(pyrazin-2-ylmethyl)-4,9-dihydro-1H-napht ho[2,3-d]imidazolium bromide (YM155 monobromide), a novel small-molecule survivin suppressant, into human solid tumor and lymphoma cells. Drug Metab. Dispos. 37, 619-628. doi: 10.1124/dmd.108.025254

Minematsu, T., Iwai, M., Umehara, K., Usui, T., and Kamimura, H. (2010). Characterization of human organic cation transporter 1 (OCT1/SLC22A1)- and OCT2 (SLC22A2)-mediated transport of 1-(2-methoxyethyl)-2-methyl-4,9dioxo-3-(pyrazin-2-ylmethyl)- 4,9-dihydro-1H-naphtho[2,3-d]imidazolium bromide (YM155 monobromide), a novel small molecule survivin suppressant. Drug Metab. Dispos. 38, 1-4. doi: 10.1124/dmd.109.028142

Ming, X., Ju, W., Wu, H., Tidwell, R. R., Hall, J. E., and Thakker, D. R. (2009). Transport of dicationic drugs pentamidine and furamidine by human organic cation transporters. Drug Metab. Dispos. 37, 424-430. doi: 10.1124/dmd.108.024083

Miraglia, L., Pagliarusco, S., Bordini, E., Martinucci, S., and Pellegatti, M. (2010). Metabolic disposition of casopitant, a potent neurokinin-1 receptor antagonist, in mice, rats, and dogs. Drug Metab. Dispos. 38, 1876-1891. doi: 10.1124/dmd.110.033092

Mishra, S., Verhalen, B., Stein, R. A., Wen, P. C., Tajkhorshid, E., and Mchaourab, H. S. (2014). Conformational dynamics of the nucleotide binding domains and the power stroke of a heterodimeric $\mathrm{ABC}$ transporter. Elife e 3:e02740. doi: 10.7554/eLife.02740

Mitra, K., Ubarretxena-Belandia, T., Taguchi, T., Warren, G., and Engelman, D. M. (2004). Modulation of the bilayer thickness of exocytic pathway membranes by membrane proteins rather than cholesterol. Proc. Natl. Acad. Sci. U.S.A. 101, 4083-4088. doi: 10.1073/pnas.0307332101

Mody, I. (2008). Extrasynaptic $\mathrm{GABA}_{\mathrm{A}}$ receptors in the crosshairs of hormones and ethanol. Neurochem. Int. 52, 60-64. doi: 10.1016/j.neuint.2007.07.010

Molina-Arcas, M., and Pastor-Anglada, M. (2010). Role of nucleoside transporters in nucleoside-derived drug sensitivity. Nucleosides Nucleotides Nucleic Acids 29, 335-346. doi: 10.1080/15257771003729823

Molina-Arcas, M., Trigueros-Motos, L., Casado, F. J., and Pastor-Anglada, M. (2008). Physiological and pharmacological roles of nucleoside transporter proteins. Nucleosides, Nucleotides Nucleic Acids 27, 769-778. doi: 10.1080/1525 7770802145819

Moradi, M., and Tajkhorshid, E. (2013). Mechanistic picture for conformational transition of a membrane transporter at atomic resolution. Proc. Natl. Acad. Sci. U.S.A. 110, 18916-18921. doi: 10.1073/pnas.1313202110

Mori, R., Ishikawa, T., Ichikawa, Y., Taniguchi, K., Matsuyama, R., Ueda, M., et al. (2007). Human equilibrative nucleoside transporter 1 is associated with the chemosensitivity of gemcitabine in human pancreatic adenocarcinoma and biliary tract carcinoma cells. Oncol. Rep. 17, 1201-1205.

Morita, N., Kusuhara, H., Nozaki, Y., Endou, H., and Sugiyama, Y. (2005). Functional involvement of rat organic anion transporter 2 (SLC22a7) in the hepatic uptake of the nonsteroidal anti-inflammatory drug ketoprofen. Drug Metab. Dispos. 33, 1151-1157. doi: 10.1124/dmd.104.001552

Morrissey, K. M., Wen, C. C., Johns, S. J., Zhang, L., Huang, S. M., and Giacomini, K. M. (2012). The UCSF-FDA transportal: a public drug transporter database. Clin. Pharmacol. Ther. 92, 545-546. doi: 10.1038/clpt.2012.44

Moschen, I., Bröer, A., Galić, S., Lang, F., and Bröer, S. (2012). Significance of short chain fatty acid transport by members of the monocarboxylate transporter family (MCT). Neurochem. Res. 37, 2562-2568. doi: 10.1007/s11064-0120857-3

Motohashi, H., Uwai, Y., Hiramoto, K., Okuda, M., and Inui, K. (2004). Different transport properties between famotidine and cimetidine by human renal organic ion transporters (SLC22A). Eur. J. Pharmacol. 503, 25-30. doi: 10.1016/j.ejphar.2004.09.032

Mruk, D. D., Su, L., and Cheng, C. Y. (2011). Emerging role for drug transporters at the blood-testis barrier. Trends Pharmacol. Sci. 32, 99-106. doi: 10.1016/j.tips.2010.11.007

Mueller, N. S., Wedlich-Soeldner, R., and Spira, F. (2012). From mosaic to patchwork: matching lipids and proteins in membrane organization. Mol. Membr. Biol. 29, 186-196. doi: 10.3109/09687688.2012.687461

Mulato, A. S., Ho, E. S., and Cihlar, T. (2000). Nonsteroidal anti-inflammatory drugs efficiently reduce the transport and cytotoxicity of adefovir mediated by the human renal organic anion transporter 1. J. Pharmacol. Exp. Ther. 295, 10-15.

Müller, F., and Fromm, M. F. (2011). Transporter-mediated drug-drug interactions. Pharmacogenomics 12, 1017-1037. doi: 10.2217/pgs.11.44

Müller, J., Lips, K. S., Metzner, L., Neubert, R. H., Koepsell, H., and Brandsch, M. (2005). Drug specificity and intestinal membrane localization of human organic cation transporters (OCT). Biochem. Pharmacol. 70, 1851-1860. doi: 10.1016/j.bcp.2005.09.011

Munro, A. W., Girvan, H. M., Mason, A. E., Dunford, A. J., and Mclean, K. J. (2013). What makes a P450 tick? Trends Biochem. Sci. 38, 140-150. doi: 10.1016/j.tibs.2012.11.006

Murakami, Y., Matsuya, T., Kita, A., Yamanaka, K., Noda, A., Mitsuoka, K., et al. (2013). Radiosynthesis, biodistribution and imaging of [11C]YM155, a novel survivin suppressant, in a human prostate tumor-xenograft mouse model. $\mathrm{Nucl}$. Med. Biol. 40, 221-226. doi: 10.1016/j.nucmedbio.2012.10.002

Murata, Y., Hamada, T., Kishiwada, M., Ohsawa, I., Mizuno, S., Usui, M., et al. (2012). Human equilibrative nucleoside transporter 1 expression is a strong independent prognostic factor in UICC T3-T4 pancreatic cancer patients treated with preoperative gemcitabine-based chemoradiotherapy. J. Hepatobiliary Pancreat. Sci. 19, 413-425. doi: 10.1007/s00534-0110440-3

Musther, H., Olivares-Morales, A., Hatley, O. J., Liu, B., and Rostami Hodjegan, A. (2014). Animal versus human oral drug bioavailability: do they correlate? Eur. J. Pharm. Sci. 57, 280-291. doi: 10.1016/j.ejps.2013.08.018 
Nakagawa, N., Murakami, Y., Uemura, K., Sudo, T., Hashimoto, Y., Kondo, N., et al. (2013). Combined analysis of intratumoral human equilibrative nucleoside transporter 1 (hENT1) and ribonucleotide reductase regulatory subunit M1 (RRM1) expression is a powerful predictor of survival in patients with pancreatic carcinoma treated with adjuvant gemcitabine-based chemotherapy after operative resection. Surgery 153, 565-575. doi: 10.1016/j.surg.2012. 10.010

Nakahara, T., Kita, A., Yamanaka, K., Mori, M., Amino, N., Takeuchi, M., et al. (2011). Broad spectrum and potent antitumor activities of YM155, a novel small-molecule survivin suppressant, in a wide variety of human cancer cell lines and xenograft models. Cancer Sci. 102, 614-621. doi: 10.1111/j.13497006.2010.01834.x

Nakamura, Y. (2008). Pharmacogenomics and drug toxicity. N. Engl. J. Med. 359, 856-858. doi: 10.1056/NEJMe0805136

Nakanishi, T., and Tamai, I. (2012). Genetic polymorphisms of OATP transporters and their impact on intestinal absorption and hepatic disposition of drugs. Drug Metab. Pharmacokinet. 27, 106-121. doi: 10.2133/dmpk.DMPK-11-RV-099

Nakano, Y., Tanno, S., Koizumi, K., Nishikawa, T., Nakamura, K., Minoguchi, M., et al. (2007). Gemcitabine chemoresistance and molecular markers associated with gemcitabine transport and metabolism in human pancreatic cancer cells. Br. J. Cancer 96, 457-463. doi: 10.1038/sj.bjc.6603559

Neher, E., and Sakmann, B. (1992). The patch clamp technique. Sci. Am. 266, 44-51. doi: 10.1038/scientificamerican0392-44

Nies, A. T., Damme, K., Schaeffeler, E., and Schwab, M. (2012). Multidrug and toxin extrusion (MATE) proteins as transporters of antimicrobial drugs. Expert Opin. Drug Metab. Toxicol. 8, 1565-1577. doi: 10.1517/17425255.2012.722996

Nies, A. T., Koepsell, H., Damme, K., and Schwab, M. (2011). Organic cation transporters (OCTs, MATEs), in vitro and in vivo evidence for the importance in drug therapy. Handb. Exp. Pharmacol. 105-167. doi: 10.1007/978-3-642-14541-4_3

Nies, A. T., and Schwab, M. (2010). Organic cation transporter pharmacogenomics and drug-drug interaction. Expert Rev. Clin. Pharmacol. 3, 707-711. doi: 10.1586/ecp. 10.60

Nilsson, A., Fehniger, T. E., Gustavsson, L., Andersson, M., Kenne, K., MarkoVarga, G., et al. (2010). Fine mapping the spatial distribution and concentration of unlabeled drugs within tissue micro-compartments using imaging mass spectrometry. PLoS ONE 5:e11411. doi: 10.1371/journal.pone.0011411

Nishida, N., Ozato, N., Matsui, K., Kuroda, K., and Ueda, M. (2013). ABC transporters and cell wall proteins involved in organic solvent tolerance in Saccharomyces cerevisiae. J. Biotechnol. 165, 145-152. doi: 10.1016/j.jbiotec. 2013.03.003

Nobeli, I., Favia, A. D., and Thornton, J. M. (2009). Protein promiscuity and its implications for biotechnology. Nat. Biotechnol. 27, 157-167. doi: $10.1038 /$ nbt1519

Nordh, S., Ansari, D., and Andersson, R. (2014). hENT1 expression is predictive of gemcitabine outcome in pancreatic cancer: a systematic review. World J. Gasteroenterol. 20, 8482-8490. doi: 10.3748/wjg.v20.i26.8482

Nury, H., Van Renterghem, C., Weng, Y., Tran, A., Baaden, M., Dufresne, V., et al. (2011). X-ray structures of general anaesthetics bound to a pentameric ligandgated ion channel. Nature 469, 428-431. doi: 10.1038/nature09647

Nutt, D. J., Besson, M., Wilson, S. J., Dawson, G. R., and Lingford-Hughes, A. R. (2007). Blockade of alcohol's amnestic activity in humans by an alpha 5 subtype benzodiazepine receptor inverse agonist. Neuropharmacology 53, 810-820. doi: 10.1016/j.neuropharm.2007.08.008

Oballa, R. M., Belair, L., Black, W. C., Bleasby, K., Chan, C. C., Desroches, C., et al. (2011). Development of a liver-targeted stearoyl-CoA desaturase (SCD) inhibitor (MK-8245) to establish a therapeutic window for the treatment of diabetes and dyslipidemia. J. Med. Chem. 54, 5082-5096. doi: 10.1021/ jm200319u

O'brien, P. J., and Herschlag, D. (1999). Catalytic promiscuity and the evolution of new enzymatic activities. Chem. Biol. 6, R91-R105. doi: 10.1016/S10745521(99)80033-7

Obuchi, W., Ohtsuki, S., Uchida, Y., Ohmine, K., Yamori, T., and Terasaki, T. (2013). Identification of transporters associated with Etoposide sensitivity of stomach cancer cell lines and methotrexate sensitivity of breast cancer cell lines by quantitative targeted absolute proteomics. Mol. Pharmacol. 83, 490-500. doi: 10.1124/mol.112.081083

Oguri, T., Achiwa, H., Muramatsu, H., Ozasa, H., Sato, S., Shimizu, S., et al. (2007). The absence of human equilibrative nucleoside transporter 1 expression predicts nonresponse to gemcitabine-containing chemotherapy in non-small cell lung cancer. Cancer Lett. 256, 112-119. doi: 10.1016/j.canlet.2007. 06.012

O’Hagan, S., Swainston, N., Handl, J., and Kell, D. B. (2014). A “rule of 0.5" for the metabolite-likeness of approved pharmaceutical drugs. Metabolomics. doi: 10.1007/s11306-11014-10733-z. [Epub ahead of print].

Ohtsuki, S., Ikeda, C., Uchida, Y., Sakamoto, Y., Miller, F., Glacial, F., et al. (2013). Quantitative targeted absolute proteomic analysis of transporters, receptors and junction proteins for validation of human cerebral microvascular endothelial cell line hCMEC/D3 as a human blood-brain barrier model. Mol. Pharm. 10, 289-296. doi: 10.1021/mp3004308

Ohtsuki, S., Uchida, Y., Kubo, Y., and Terasaki, T. (2011). Quantitative targeted absolute proteomics-based ADME research as a new path to drug discovery and development: methodology, advantages, strategy, and prospects. J. Pharm. Sci. 100, 3547-3559. doi: 10.1002/jps.22612

Olsen, R. W., Hanchar, H. J., Meera, P., and Wallner, M. (2007). GABA A receptor subtypes: the "one glass of wine" receptors. Alcohol 41, 201-209. doi: 10.1016/j.alcohol.2007.04.006

Ooms, F., Weber, P., Carrupt, P. A., and Testa, B. (2002). A simple model to predict blood-brain barrier permeation from 3D molecular fields. Biochim. Biophys. Acta 1587, 118-125. doi: 10. 1016/S0925-4439(02)00074-1

Oprea, T. I., (ed.). (2004). Chemoinformatics in Drug Discovery. Weinheim: Wiley/VCH.

O'reilly, E., Corbett, M., Hussain, S., Kelly, P. P., Richardson, D., Flitsch, S. L., et al. (2013). Substrate promiscuity of cytochrome P450 RhF. Catal. Sci. Technol. 3, 1490-1492. doi: 10.1039/c3cy00091e

O'reilly, E., Kohler, V., Flitsch, S. L., and Turner, N. J. (2011). Cytochromes P450 as useful biocatalysts: addressing the limitations. Chem. Commun. (Camb) 47, 2490-2501. doi: 10.1039/c0cc03165h

Overton, E. (1899). Über die allgemeinen osmotischen Eigenschaften der Zelle, ihre vermutliche Ursachen und ihre Bedeutung für die Physiologie Vierteljahrsschr. Naturforsch. Ges. Zürich 44, 88-114.

Pagliarusco, S., Martinucci, S., Bordini, E., Miraglia, L., Cufari, D., Ferrari, L., et al. (2011). Tissue distribution and characterization of drug-related material in rats and dogs after repeated oral administration of casopitant. Drug Metab. Dispos. 39, 283-293. doi: 10.1124/dmd.110.035063

Pang, K. S., Wang, P. J., Chung, A. Y., and Wolkoff, A. W. (1998). The modified dipeptide, enalapril, an angiotensin-converting enzyme inhibitor, is transported by the rat liver organic anion transport protein. Hepatology 28, 1341-1346. doi: 10.1002/hep.510280524

Pardridge, W. M. (2007). Blood-brain barrier delivery. Drug Discov. Today 12, 54-61. doi: 10.1016/j.drudis.2006.10.013

Pardridge, W. M. (2012). Drug transport across the blood-brain barrier. J. Cereb. Blood Flow Metab. 32, 1959-1972. doi: 10.1038/jcbfm.2012.126

Parkinson, F. E., Damaraju, V. L., Graham, K., Yao, S. Y., Baldwin, S. A., Cass, C. E., et al. (2011). Molecular biology of nucleoside transporters and their distributions and functions in the brain. Curr. Top. Med. Chem. 11, 948-972. doi: $10.2174 / 156802611795347582$

Parsegian, A. (1969). Energy of an ion crossing a low dielectric membrane: solutions to four relevant electrostatic problems. Nature 221, 844-846. doi: $10.1038 / 221844 \mathrm{a} 0$

Patel, A. J., Honore, E., Lesage, F., Fink, M., Romey, G., and Lazdunski, M. (1999). Inhalational anesthetics activate two-pore-domain background $\mathrm{K}+$ channels. Nat. Neurosci. 2, 422-426. doi: 10.1038/8084

Pavek, P., Merino, G., Wagenaar, E., Bolscher, E., Novotna, M., Jonker, J. W., et al. (2005). Human breast cancer resistance protein: interactions with steroid drugs, hormones, the dietary carcinogen 2-amino-1-methyl-6-phenylimidazo(4,5b)pyridine, and transport of cimetidine. J. Pharmacol. Exp. Ther. 312, 144-152. doi: 10.1124/jpet.104.073916

Peironcely, J. E., Reijmers, T., Coulier, L., Bender, A., and Hankemeier, T. (2011). Understanding and classifying metabolite space and metabolite-likeness. PLoS ONE 6:e28966. doi: 10.1371/journal.pone.0028966

Penrod, J. T., Mace, C. C., and Roth, J. R. (2004). A pH-sensitive function and phenotype: evidence that EutH facilitates diffusion of uncharged ethanolamine in Salmonella enterica. J. Bacteriol. 186, 6885-6890. doi: 10.1128/JB.186.20.68856890.2004

Persson, A., Hober, S., and Uhlen, M. (2006). A human protein atlas based on antibody proteomics. Curr. Opin. Mol. Ther. 8, 185-190.

Peters, J. U. (2013). Polypharmacology - foe or friend? J. Med. Chem. 56, 8955-8971. doi: 10.1021/jm400856t 
Pfefferkorn, J. A. (2013). Strategies for the design of hepatoselective glucokinase activators to treat type 2 diabetes. Expert Opin. Drug Discov. 8, 319-330. doi: 10. 1517/17460441.2013.748744

Pfefferkorn, J. A., Guzman-Perez, A., Litchfield, J., Aiello, R., Treadway, J. L., Pettersen, J., et al. (2012). Discovery of (S)-6-(3-cyclopentyl-2-(4(trifluoromethyl)-1H-imidazol-1-yl)propanamido)nicotini c acid as a hepatoselective glucokinase activator clinical candidate for treating type 2 diabetes mellitus. J. Med. Chem. 55, 1318-1333. doi: 10.1021/jm2014887

Pfefferkorn, J. A., Litchfield, J., Hutchings, R., Cheng, X. M., Larsen, S. D., Auerbach, B., et al. (2011). Discovery of novel hepatoselective HMG-CoA reductase inhibitors for treating hypercholesterolemia: a bench-to-bedside case study on tissue selective drug distribution. Bioorg. Med. Chem. Lett. 21, 2725-2731. doi: 10.1016/j.bmcl.2010.11.103

Piana, S., Lindorff-Larsen, K., and Shaw, D. E. (2013). Atomic-level description of ubiquitin folding. Proc. Natl. Acad. Sci. U.S.A. 110, 5915-5920. doi: $10.1073 /$ pnas. 1218321110

Pirmohamed, M. (2010). Pharmacogenetics of idiosyncratic adverse drug reactions. Handb. Exp. Pharmacol. 196, 477-491. doi: 10.1007/978-3-642-00663$0 \_17$

Pirmohamed, M. (2011). Pharmacogenetics: past, present and future. Drug Discov. Today 16, 852-861. doi: 10.1016/j.drudis.2011.08.006

Pirmohamed, M. (2012). Genetics and the potential for predictive tests in adverse drug reactions. Chem. Immunol. Allergy 97, 18-31. doi: 10.1159/000335613

Pirmohamed, M. (2013). Drug-grapefruit juice interactions: two mechanisms are clear but individual responses vary. BMJ 346:f1. doi: 10.1136/bmj.f1

Pirmohamed, M. (2014). Personalized pharmacogenomics: predicting efficacy and adverse drug reactions. Annu. Rev. Genomics Hum. Genet. 15, 349-370. doi: 10.1146/annurev-genom-090413-025419

Pirmohamed, M., James, S., Meakin, S., Green, C., Scott, A. K., Walley, T. J., et al. (2004). Adverse drug reactions as cause of admission to hospital: prospective analysis of 18,820 patients. BMJ 329, 15-19. doi: 10.1136/bmj.329.7456.15

Polli, J. W., Wring, S. A., Humphreys, J. E., Huang, L., Morgan, J. B., Webster, L. O., et al. (2001). Rational use of in vitro P-glycoprotein assays in drug discovery. J. Pharmacol. Exp. Ther. 299, 620-628.

Pontén, F., Jirström, K., and Uhlén, M. (2008). The human protein atlas-a tool for pathology. J. Pathol. 216, 387-393. doi: 10.1002/path.2440

Popper, K. R. (1992). Conjectures and Refutations: The Growth of Scientific Knowledge, 5th Edn. London: Routledge \& Kegan Paul.

Powell, D. A., Black, W. C., Bleasby, K., Chan, C. C., Deschenes, D., Gagnon, M., et al. (2011). Nicotinic acids: liver-targeted SCD inhibitors with preclinical anti-diabetic efficacy. Bioorg. Med. Chem. Lett. 21, 7281-7286. doi: 10.1016/j.bmcl.2011.10.040

Pratt, J. M., Simpson, D. M., Doherty, M. K., Rivers, J., Gaskell, S. J., and Beynon, R. J. (2006). Multiplexed absolute quantification for proteomics using concatenated signature peptides encoded by QconCAT genes. Nat. Protoc. 1, 1029-1043. doi: 10.1038/nprot.2006.129

Pshezhetsky, A. V., Fedjaev, M., Ashmarina, L., Mazur, A., Budman, L., Sinnett, D., et al. (2007). Subcellular proteomics of cell differentiation: quantitative analysis of the plasma membrane proteome of Caco-2 cells. Proteomics 7, 2201-2215. doi: 10.1002/pmic.200600956

Qiu, X., Zhang, H., and Lai, Y. (2014). Quantitative targeted proteomics for membrane transporter proteins: method and application. AAPS J. 16, 714-726. doi: 10.1208/s12248-014-9607-6

Quashie, N. B., Dorin-Semblat, D., Bray, P. G., Biagini, G. A., Doerig, C., RanfordCartwright, L. C., et al. (2008). A comprehensive model of purine uptake by the malaria parasite Plasmodium falciparum: identification of four purine transport activities in intraerythrocytic parasites. Biochem. J. 411, 287-295. doi: 10.1042/BJ20071460

Quashie, N. B., Ranford-Cartwright, L. C., and De Koning, H. P. (2010). Uptake of purines in Plasmodium falciparum-infected human erythrocytes is mostly mediated by the human equilibrative nucleoside transporter and the human facilitative nucleobase transporter. Malar. J. 9:36. doi: 10.1186/14752875-9-36

Race, J. E., Grassl, S. M., Williams, W. J., and Holtzman, E. J. (1999). Molecular cloning and characterization of two novel human renal organic anion transporters (hOAT1 and hOAT3). Biochem. Biophys. Res. Commun. 255, 508-514. doi: 10.1006/bbrc.1998.9978

Ramsey, L. B., Johnson, S. G., Caudle, K. E., Haidar, C. E., Voora, D., Wilke, R. A., et al. (2014). The clinical pharmacogenetics implementation consortium guideline for SLCO1B1 and simvastatin-induced myopathy: 2014 update. Clin. Pharmacol. Ther. 96, 423-428. doi: 10.1038/clpt.2014.125

Ramtohul, Y. K., Powell, D., Leclerc, J. P., Leger, S., Oballa, R., Black, C., et al. (2011). Bicyclic heteroaryl inhibitors of stearoyl-CoA desaturase: from systemic to liver-targeting inhibitors. Bioorg. Med. Chem. Lett. 21, 5692-5696. doi: 10.1016/j.bmcl.2011.08.037

Rauchwerger, D. R., Firby, P. S., Hedley, D. W., and Moore, M. J. (2000). Equilibrative-sensitive nucleoside transporter and its role in gemcitabine sensitivity. Cancer Res. 60, 6075-6079.

Raval, A., Piana, S., Eastwood, M. P., Dror, R. O., and Shaw, D. E. (2012). Refinement of protein structure homology models via long, all-atom molecular dynamics simulations. Proteins 80, 2071-2079. doi: 10.1002/Prot.24098

Reiling, J. H., Clish, C. B., Carette, J. E., Varadarajan, M., Brummelkamp, T. R., and Sabatini, D. M. (2011). A haploid genetic screen identifies the major facilitator domain containing 2A (MFSD2A) transporter as a key mediator in the response to tunicamycin. Proc. Natl. Acad. Sci. U.S.A. 108, 11756-11765. doi: 10.1073/pnas. 1018098108

Riches, Z., Cameron, G. A., and Hawksworth, G. M. (2011). Transporter mediated uptake and efflux of antiretroviral drugs: potential for drug-drug interactions. Toxicology 290, 127-128. doi: 10.1016/j.tox.2011.09.048

Riedmaier, A. E., Nies, A. T., Schaeffeler, E., and Schwab, M. (2012). Organic anion transporters and their implications in pharmacotherapy. Pharmacol. Rev. 64, 421-449. doi: 10.1124/pr.111.004614

Rincon-Restrepo, M., Mikhailova, E., Bayley, H., and Maglia, G. (2011). Controlled translocation of individual DNA molecules through protein nanopores with engineered molecular brakes. Nano Lett. 11, 746-750. doi: 10.1021/nll 038874

Rivers, J., Simpson, D. M., Robertson, D. H., Gaskell, S. J., and Beynon, R. J. (2007). Absolute multiplexed quantitative analysis of protein expression during muscle development using QconCAT. Mol. Cell. Proteomics 6, 1416-1427. doi: 10.1074/mcp.M600456-MCP200

Römpp, A., Guenther, S., Schober, Y., Schulz, O., Takats, Z., Kummer, W., et al. (2010). Histology by mass spectrometry: label-free tissue characterization obtained from high-accuracy bioanalytical imaging. Angew. Chem. Int. Ed. Engl. 49, 3834-3838. doi: 10.1002/anie.200905559

Römpp, A., Guenther, S., Takats, Z., and Spengler, B. (2011). Mass spectrometry imaging with high resolution in mass and space $\left(\mathrm{HR}^{2} \mathrm{MSI}\right)$ for reliable investigation of drug compound distributions on the cellular level. Anal. Bioanal. Chem. 401, 65-73. doi: 10.1007/s00216-011-4990-7

Rose, R. H., Neuhoff, S., Abduljalil, K., Chetty, M., Rostami-Hodjegan, A., and Jamei, M. (2014). Application of a physiologically based pharmacokinetic model to predict OATP1B1-related variability in pharmacodynamics of rosuvastatin. CPT Pharmacometrics Syst. Pharmacol. 3:e124. doi: 10.1038/psp.2014.24

Rostami-Hodjegan, A. (2012). Physiologically based pharmacokinetics joined with in vitro-in vivo extrapolation of $\mathrm{ADME}$ : a marriage under the arch of systems pharmacology. Clin. Pharmacol. Ther. 92, 50-61. doi: 10.1038/clpt.2012.65

Rumiato, E., Boldrin, E., Amadori, A., and Saggioro, D. (2013). DMET (DrugMetabolizing Enzymes and Transporters) microarray analysis of colorectal cancer patients with severe 5-fluorouracil-induced toxicity. Cancer Chemother. Pharmacol. 72, 483-488. doi: 10.1007/s00280-013-2210-1

Russell, B. (1947). Am I An Atheist or An Agnostic? [Pamphlet].

Russell, M. R., Achour, B., Mckenzie, E. A., Lopez, R., Harwood, M. D., RostamiHodjegan, A., et al. (2013). Alternative fusion protein strategies to express recalcitrant QconCAT proteins for quantitative proteomics of human drug metabolizing enzymes and transporters. J. Proteome Res. 12, 5934-5942. doi: $10.1021 /$ pr400279u

Saadatmand, A. R., Tadjerpisheh, S., Brockmöller, J., and Tzvetkov, M. V. (2012). The prototypic pharmacogenetic drug debrisoquine is a substrate of the genetically polymorphic organic cation transporter OCT1. Biochem. Pharmacol. 83, 1427-1434. doi: 10.1016/j.bcp.2012.01.032

Sá-Correia, I., Dos Santos, S. C., Teixeira, M. C., Cabrito, T. R., and Mira, N. P. (2009). Drug: $\mathrm{H}^{+}$antiporters in chemical stress response in yeast. Trends Microbiol. 17, 22-31. doi: 10.1016/j.tim.2008.09.007

Sai, Y., and Tsuji, A. (2004). Transporter-mediated drug delivery: recent progress and experimental approaches. Drug Discov. Today 9, 712-720. doi: 10.1016/S1359-6446(04)03198-8

Sakmann, B., and Neher, E. (1984). Patch clamp techniques for studying ionic channels in excitable membranes. Annu. Rev. Physiol. 46, 455-472. doi: 10.1146/annurev.ph.46.030184.002323 
Sakvarelidze, L., Tao, Z., Bush, M., Roberts, G. R., Leader, D. J., Doonan, J. H., et al. (2007). Coupling the GAL4 UAS system with alcR for versatile cell typespecific chemically inducible gene expression in Arabidopsis. Plant Biotechnol. J. 5, 465-476. doi: 10.1111/j.1467-7652.2007.00254.x

Sala-Rabanal, M., Loo, D. D., Hirayama, B. A., Turk, E., and Wright, E. M. (2006). Molecular interactions between dipeptides, drugs and the human intestinal H+ -oligopeptide cotransporter hPEPT1. J. Physiol. 574, 149-166. doi: 10.1113/jphysiol.2006.107904

Sanders, R. D., Franks, N. P., and Maze, M. (2003). Xenon: no stranger to anaesthesia. Br. J. Anaesth. 91, 709-717. doi: 10.1093/bja/aeg232

Santhakumar, V., Wallner, M., and Otis, T. S. (2007). Ethanol acts directly on extrasynaptic subtypes of $\mathrm{GABA}_{A}$ receptors to increase tonic inhibition. Alcohol 41, 211-221. doi: 10.1016/j.alcohol.2007.04.011

Santini, D., Schiavon, G., Vincenzi, B., Cass, C. E., Vasile, E., Manazza, A. D., et al. (2011). Human equilibrative nucleoside transporter 1 (hENT1) levels predict response to gemcitabine in patients with biliary tract cancer (BTC). Curr. Cancer Drug Targets 11, 123-129. doi: 10.2174/156800911793743600

Sá-Pessoa, J., Paiva, S., Ribas, D., Silva, I. J., Viegas, S. C., and Casal, M. (2013). SATP $(\mathrm{YaaH})$, a succinate-acetate transporter protein in Escherichia coli. Biochem. J. 454, 585-595. doi: 10.1042/BJ20130412

Sato, M., Mamada, H., Anzai, N., Shirasaka, Y., Nakanishi, T., and Tamai, I. (2010). Renal secretion of uric acid by organic anion transporter 2 (OAT2/SLC22A7) in human. Biol. Pharm. Bull. 33, 498-503. doi: 10.1248/bpb.33.498

Schlessinger, A., Khuri, N., Giacomini, K. M., and Sali, A. (2013a). Molecular modeling and ligand docking for solute carrier (SLC) transporters. Curr. Top. Med. Chem. 13, 843-856.

Schlessinger, A., Yee, S. W., Sali, A., and Giacomini, K. M. (2013b). SLC classification: an update. Clin. Pharmacol. Ther. 94, 19-23. doi: 10.1038/clpt. 2013.73

Schömig, E., Lazar, A., and Gründemann, D. (2006). Extraneuronal monoamine transporter and organic cation transporters 1 and 2: a review of transport efficiency. Handb. Exp. Pharmacol. 175, 151-180. doi: 10.1007/3-540-297 84-7_8

Schwab, D., Fischer, H., Tabatabaei, A., Poli, S., and Huwyler, J. (2003). Comparison of in vitro P-glycoprotein screening assays: recommendations for their use in drug discovery. J. Med. Chem. 46, 1716-1725. doi: 10.1021/jm021012t

Shahidi-Latham, S. K., Dutta, S. M., Prieto Conaway, M. C., and Rudewicz, P. J. (2012). Evaluation of an accurate mass approach for the simultaneous detection of drug and metabolite distributions via whole-body mass spectrometric imaging. Anal. Chem. 84, 7158-7165. doi: 10.1021/ac3015142

Shaikh, S. A., Li, J., Enkavi, G., Wen, P. C., Huang, Z. J., and Tajkhorshid, E. (2013). Visualizing functional motions of membrane transporters with molecular dynamics simulations. Biochemistry 52, 569-587. doi: 10.1021/ bi301086x

Sharifi, N., Hamada, A., Sissung, T., Danesi, R., Venzon, D., Baum, C., et al. (2008). A polymorphism in a transporter of testosterone is a determinant of androgen independence in prostate cancer. BJU Int. 102, 617-621. doi: 10.1111/j.1464410X.2008.07629.x

Sharma, P., Butters, C. J., Smith, V., Elsby, R., and Surry, D. (2012). Prediction of the in vivo OATP1B1-mediated drug-drug interaction potential of an investigational drug against a range of statins. Eur. J. Pharm. Sci. 47, 244-255. doi: 10.1016/j.ejps.2012.04.003

Shaw, D. E., Deneroff, M. M., Dror, R. O., Kuskin, J. S., Larson, R. H., Salmon, J. K., et al. (2008). Anton, a special-purpose machine for molecular dynamics simulation. Commun. ACM 51, 91-97. doi: 10.1145/1364782.1364802

Sheridan, R. P., Feuston, B. P., Maiorov, V. N., and Kearsley, S. K. (2004). Similarity to molecules in the training set is a good discriminator for prediction accuracy in QSAR. J. Chem. Inf. Comput. Sci. 44, 1912-1928. doi: 10.1021/ ci049782w

Shilling, A. D., Azam, F., Kao, J., and Leung, L. (2006). Use of canalicular membrane vesicles (CMVs) from rats, dogs, monkeys and humans to assess drug transport across the canalicular membrane. J. Pharmacol. Toxicol. Methods 53, 186-197. doi: 10.1016/j.vascn.2005.08.003

Shitara, Y. (2011). Clinical importance of OATP1B1 and OATP1B3 in drug-drug interactions. Drug Metab. Pharmacokinet. 26, 220-227. doi: 10.2133/dmpk.DMPK-10-RV-094

Shitara, Y., Horie, T., and Sugiyama, Y. (2006). Transporters as a determinant of drug clearance and tissue distribution. Eur. J. Pharm. Sci. 27, 425-446. doi: 10.1016/j.ejps.2005.12.003
Shitara, Y., Maeda, K., Ikejiri, K., Yoshida, K., Horie, T., and Sugiyama, Y. (2013). Clinical significance of organic anion transporting polypeptides (OATPs) in drug disposition: their roles in hepatic clearance and intestinal absorption. Biopharm. Drug Dispos. 34, 45-78. doi: 10.1002/bdd.1823

Sissung, T. M., English, B. C., Venzon, D., Figg, W. D., and Deeken, J. F. (2010). Clinical pharmacology and pharmacogenetics in a genomics era: the DMET platform. Pharmacogenomics 11, 89-103. doi: 10.2217/pgs.09.154

Sissung, T. M., Troutman, S. M., Campbell, T. J., Pressler, H. M., Sung, H., Bates, S. E., et al. (2012). Transporter pharmacogenetics: transporter polymorphisms affect normal physiology, diseases, and pharmacotherapy. Discov. Med. 13, 19-34.

Skovstrup, S., David, L., Taboureau, O., and Steen Jørgensen, F. (2012). A steered molecular dynamics study of binding and translocation processes in the GABA transporter. PLoS ONE 7:e39360. doi: 10.1371/journal.pone.0039360

Skrypek, N., Duchêne, B., Hebbar, M., Leteurtre, E., Van Seuningen, I., and Jonckheere, N. (2013). The MUC4 mucin mediates gemcitabine resistance of human pancreatic cancer cells via the concentrative nucleoside transporter family. Oncogene 32, 1714-1723. doi: 10.1038/onc.2012.179

Smith, A. W. (2012). Lipid-protein interactions in biological membranes: a dynamic perspective. Biochim. Biophys. Acta 1818, 172-177. doi: 10.1016/j.bbamem.2011.06.015

Smith, D., Artursson, P., Avdeef, A., Di, L., Ecker, G. F., Faller, B., et al. (2014). Passive lipoidal diffusion and carrier-mediated cell uptake are both important mechanisms of membrane permeation in drug disposition. Mol. Pharm. 11, 1727-1738. doi: 10.1021/mp400713v

Smyth, R. M. D., Gargon, E., Kirkham, J., Cresswell, L., Golder, S., Smyth, R., et al. (2012). Adverse drug reactions in children-a systematic review. PLoS ONE 7:e24061. doi: 10.1371/journal.pone.0024061

Song, Y., Kenworthy, A. K., and Sanders, C. R. (2014). Cholesterol as a cosolvent and a ligand for membrane proteins. Protein Sci. 23, 1-22. doi: 10.1002/ pro. 2385

Song, Z. (2013). Roles of the nucleotide sugar transporters (SLC35 family) in health and disease. Mol. Aspects Med. 34, 590-600. doi: 10.1016/j.mam.2012.12.004

Sorgato, M. C., Ferguson, S. J., Kell, D. B., and John, P. (1978). The protonmotive force in bovine heart submitochondrial particles: magnitude, sites of generation and comparison with the phosphorylation potential. Biochem. J. 174, 237-256.

Spratlin, J., Sangha, R., Glubrecht, D., Dabbagh, L., Young, J. D., Dumontet, C., et al. (2004). The absence of human equilibrative nucleoside transporter 1 is associated with reduced survival in patients with gemcitabine-treated pancreas adenocarcinoma. Clin. Cancer Res. 10, 6956-6961. doi: 10.1158/10780432.CCR-04-0224

Sprowl, J. A., Mikkelsen, T. S., Giovinazzo, H., and Sparreboom, A. (2012). Contribution of tumoral and host solute carriers to clinical drug response. Drug Resist. Updat. 15, 5-20. doi: 10.1016/j.drup.2012.01.009

Sprowl, J. A., and Sparreboom, A. (2012). Drug trafficking: recent advances in therapeutics and disease. Clin. Pharmacol. Ther. 92, 531-534. doi: 10.1038/clpt.2012.167

Sprowl, J. A., and Sparreboom, A. (2014). Uptake carriers and oncology drug safety. Drug Metab. Dispos. 42, 611-622. doi: 10.1124/dmd.113.055806

Srimaroeng, C., Perry, J. L., and Pritchard, J. B. (2008). Physiology, structure, and regulation of the cloned organic anion transporters. Xenobiotica 38, 889-935. doi: 10.1080/00498250801927435

Stankov, K., Sabo, A., and Mikov, M. (2013). Pharmacogenetic biomarkers as tools for pharmacoepidemiology of severe adverse drug reactions. Drug Dev. Res. 74, 1-14. doi: 10.1002/ddr.21050

Stansfeld, P. J., Jefferys, E. E., and Sansom, M. S. P. (2013). Multiscale simulations reveal conserved patterns of lipid interactions with aquaporins. Structure 21, 810-819. doi: 10.1016/j.str.2013.03.005

Stansfeld, P. J., and Sansom, M. S. P. (2011). Molecular simulation approaches to membrane proteins. Structure 19, 1562-1572. doi: 10.1016/j.str.2011.10.002

Stevens, B. D., Litchfield, J., Pfefferkorn, J. A., Atkinson, K., Perreault, C., Amor, P., et al. (2013). Discovery of an intravenous hepatoselective glucokinase activator for the treatment of inpatient hyperglycemia. Bioorg. Med. Chem. Lett. 23, 6588-6592. doi: 10.1016/j.bmcl.2013.10.057

Stieger, B., and Meier, P. J. (2011). Pharmacogenetics of drug transporters in the enterohepatic circulation. Pharmacogenomics 12, 611-631. doi: 10.2217/pgs. 11.53

Stoddart, D., Heron, A. J., Mikhailova, E., Maglia, G., and Bayley, H. (2009). Single-nucleotide discrimination in immobilized DNA oligonucleotides with 
a biological nanopore. Proc. Natl. Acad. Sci. U. S. A. 106, 7702-7707. doi: 10.1073/pnas.0901054106

Stojiljkovic, I., Bäumler, A. J., and Heffron, F. (1995). Ethanolamine utilization in Salmonella typhimurium: nucleotide sequence, protein expression, and mutational analysis of the cchA cchB eutE eutJ eutG eutH gene cluster. J. Bacteriol. 177, 1357-1366.

Strebhardt, K., and Ullrich, A. (2008). Paul Ehrlich's magic bullet concept: 100 years of progress. Nat. Rev. Cancer 8, 473-480. doi: 10.1038/nrc2394

Sugiyama, Y., and Steffansen, B., (eds.). (2013). Transporters in Drug Development: Discovery, Optimization, Clinical Study and Regulation. New York, NY: AAPS/Springer. doi: 10.1007/978-1-4614-8229-1

Sun, S. Y., Zhang, Z. H., Raina, V., Pokrovskaia, N., Hou, D. J., Namdari, R., et al. (2014). Discovery of thiazolylpyridinone SCD1 inhibitors with preferential liver distribution and reduced mechanism-based adverse effects. Bioorg. Med. Chem. Lett. 24, 526-531. doi: 10.1016/j.bmcl.2013.12.035

Sutherland, J. J., Raymond, J. W., Stevens, J. L., Baker, T. K., and Watson, D. E. (2012). Relating molecular properties and in vitro assay results to in vivo drug disposition and toxicity outcomes. J. Med. Chem. 55, 6455-6466. doi: 10.1021/jm300684u

Swainston, N., Mendes, P., and Kell, D. B. (2013). An analysis of a "communitydriven" reconstruction of the human metabolic network. Metabolomics 9, 757-764. doi: 10.1007/s11306-013-0564-3

Tachikawa, M., and Hosoya, K. (2011). Transport characteristics of guanidino compounds at the blood-brain barrier and blood-cerebrospinal fluid barrier: relevance to neural disorders. Fluids Barriers CNS 8:13. doi: 10.1186/2045-811 8-8-13

Takanohashi, T., Kubo, S., Arisaka, H., Shinkai, K., and Ubukata, K. (2012). Contribution of organic anion transporting polypeptide (OATP) $1 \mathrm{~B} 1$ and OATP1B3 to hepatic uptake of nateglinide, and the prediction of drug-drug interactions via these transporters. J. Pharm. Pharmacol. 64, 199-206. doi: 10.1111/j.2042-7158.2011.01389.x

Tamai, I., and Nakanishi, T. (2013). OATP transporter-mediated drug absorption and interaction. Curr. Opin. Pharmacol. 13, 859-863. doi: 10.1016/j.coph.2013.09.001

Tang, H., Shen, D. R., Han, Y. H., Kong, Y., Balimane, P., Marino, A., et al. (2013). Development of novel, 384-well high-throughput assay panels for human drug transporters: drug interaction and safety assessment in support of discovery research. J. Biomol. Screen. 18, 1072-1083. doi: 10.1177/1087057113494807

Tannenbaum, C., and Sheehan, N. L. (2014). Understanding and preventing drugdrug and drug-gene interactions. Expert Rev. Clin. Pharmacol. 7, 533-544. doi 10.1586/17512433.2014.910111

Teixeira, M. C., Godinho, C. P., Cabrito, T. R., Mira, N. P., and Sá-Correia, I. (2012). Increased expression of the yeast multidrug resistance ABC transporter Pdr18 leads to increased ethanol tolerance and ethanol production in high gravity alcoholic fermentation. Microb. Cell Fact. 11:98. doi: 10.1186/14752859-11-98

Teixeira, M. C., Raposo, L. R., Mira, N. P., Lourenço, A. B., and Sá-Correia, I. (2009). Genome-wide identification of Saccharomyces cerevisiae genes required for maximal tolerance to ethanol. Appl. Env. Microbiol. 75, 5761-5772. doi: 10.1128/AEM.00845-09

Thiele, I., Swainston, N., Fleming, R. M. T., Hoppe, A., Sahoo, S., Aurich, M. K., et al. (2013). A community-driven global reconstruction of human metabolism. Nat. Biotechnol. 31, 419-425. doi: 10.1038/nbt.2488

Thompson, S. A., and Wafford, K. (2001). Mechanism of action of general anaesthetics: new information from molecular pharmacology. Curr. Opin. Pharmacol. 1, 78-83. doi: 10.1016/S1471-4892(01)00013-3

Thompson, T. N. (2011). "The clinical significance of drug transporters in drug disposition and drug interactions," in Pharmacokinetics in Drug Development, Vol. 3, Advances and Applications, eds P. L. Bonate and D. R. Howard (Berlin: Springer), 285-313.

Tien, H. T. (1974). Bilayer Lipid Membranes (BLM): Theory and Practice. New York, NY: Marcel Dekker.

Tien, H. T., and Ottova-Leitmannova, A. (eds.). (2003). Planar Lipid Bilayers (BLMs) and Their Applications. New York, NY: Elsevier.

Tirona, R. G. (2011). Molecular mechanisms of drug transporter regulation. Handb. Exp. Pharmacol. 201, 373-402. doi: 10.1007/978-3-642-14541-4_10

Tohkin, M., Ishiguro, A., Kaniwa, N., Saito, Y., Kurose, K., and Hasegawa, R. (2010). Prediction of severe adverse drug reactions using pharmacogenetic biomarkers. Drug Metab. Pharmacokinet. 25, 122-133. doi: 10.2133/dmpk.25.122
Tong, Z., Yerramilli, U., Chen, Y., Kumar, G., and Surapaneni, S. (2014). Paclitaxel enhances cellular uptake of gemcitabine through up-regulation of nucleoside transporters CNT1 and CNT3. Drug Metab. Rev. 45, 118-119.

Torres, A. M., Dnyanmote, A. V., Bush, K. T., Wu, W., and Nigam, S. K. (2011). Deletion of multispecific organic anion transporter (OAT1/SLC22A6) protects from mercury-induced kidney injury. J. Biol. Chem. 286, 26391-26395. doi: 10.1074/jbc.M111.249292

Trigueros-Motos, L., Perez-Torras, S., Casado, F. J., Molina-Arcas, M., and PastorAnglada, M. (2012). Aquaporin 3 (AQP3) participates in the cytotoxic response to nucleoside-derived drugs. BMC Cancer 12:434. doi: 10.1186/1471-24 07-12-434

Tropsha, A. (2010). Best practices for QSAR model development, validation, and exploitation. Mol. Inform. 29, 476-488. doi: 10.1002/minf.201000061

Tropsha, A., Gramatica, P., and Gombar, V. K. (2003). The importance of being earnest: Validation is the absolute essential for successful application and interpretation of QSPR models. QSAR Comb. Sci. 22, 69-77. doi: 10.1002/qsar.200390007

Tsamandouras, N., Dickinson, G., Guo, Y., Hall, S., Rostami-Hodjegan, A. Galetin, A., et al. (2014). Identification of the effect of multiple polymorphisms on the pharmacokinetics of simvastatin and simvastatin acid using a population-modeling approach. Clin. Pharmacol. Ther. 96, 90-100. doi: 10.1038/clpt.2014.55

Tsuda, M., Terada, T., Ueba, M., Sato, T., Masuda, S., Katsura, T., et al. (2009). Involvement of human multidrug and toxin extrusion 1 in the drug interaction between cimetidine and metformin in renal epithelial cells. J. Pharmacol. Exp. Ther. 329, 185-191. doi: 10.1124/jpet.108.147918

Tsukagoshi, N., and Aono, R. (2000). Entry into and release of solvents by Escherichia coli in an organic-aqueous two-liquid-phase system and substrate specificity of the AcrAB-TolC solvent-extruding pump. J. Bacteriol. 182, 4803-4810. doi: 10.1128/JB.182.17.4803-4810.2000

Tsume, Y., Borras Bermejo, B., and Amidon, G. L. (2014). The dipeptide monoester prodrugs of floxuridine and gemcitabine-feasibility of orally administrable nucleoside analogs. Pharmaceuticals 7, 169-191. doi: 10.3390/ph7020169

Tu, M. H., Mathiowetz, A. M., Pfefferkorn, J. A., Cameron, K. O., Dow, R. L., Litchfield, J., et al. (2013). Medicinal chemistry design principles for liver targeting through OATP transporters. Curr. Top. Med. Chem. 13, 857-866. doi: $10.2174 / 1568026611313070008$

Tyx, R. E., Roche-Hakansson, H., and Hakansson, A. P. (2011). Role of dihydrolipoamide dehydrogenase in regulation of raffinose transport in Streptococcus pneumoniae. J. Bacteriol. 193, 3512-3524. doi: 10.1128/JB. 01410-10

Uchida, Y., Ohtsuki, S., Kamiie, J., and Terasaki, T. (2011a). Blood-brain barrier (BBB) pharmacoproteomics: reconstruction of in vivo brain distribution of 11 P-glycoprotein substrates based on the BBB transporter protein concentration, in vitro intrinsic transport activity, and unbound fraction in plasma and brain in mice. J. Pharmacol. Exp. Ther. 339, 579-588. doi: 10.1124/jpet.111. 184200

Uchida, Y., Ohtsuki, S., Katsukura, Y., Ikeda, C., Suzuki, T., Kamiie, J., et al. (2011b). Quantitative targeted absolute proteomics of human blood-brain barrier transporters and receptors. J. Neurochem. 117, 333-345. doi: 10.1111/j.14714159.2011.07208.x

Uchida, Y., Tachikawa, M., Obuchi, W., Hoshi, Y., Tomioka, Y., Ohtsuki, S., et al. (2013). A study protocol for quantitative targeted absolute proteomics (QTAP) by LC-MS/MS: application for inter-strain differences in protein expression levels of transporters, receptors, claudin-5, and marker proteins at the bloodbrain barrier in ddY, FVB, and C57BL/6J mice. Fluids Barriers CNS 10:21. doi: 10.1186/2045-8118-10-21

Uchino, H., Kanai, Y., Kim, D. K., Wempe, M. F., Chairoungdua, A., Morimoto, E., et al. (2002). Transport of amino acid-related compounds mediated by Ltype amino acid transporter 1 (LAT1): insights into the mechanisms of substrate recognition. Mol. Pharmacol. 61, 729-737. doi: 10.1124/mol.61.4.729

Uetrecht, J., (ed.). (2010). Adverse Drug Reactions. Berlin: Springer. doi 10.1007/978-3-642-00663-0

Uwai, Y., Saito, H., Hashimoto, Y., and Inui, K. I. (2000a). Interaction and transport of thiazide diuretics, loop diuretics, and acetazolamide via rat renal organic anion transporter rOAT1. J. Pharmacol. Exp. Ther. 295, 261-265.

Uwai, Y., Saito, H., and Inui, K. (2000b). Interaction between methotrexate and nonsteroidal anti-inflammatory drugs in organic anion transporter. Eur. J. Pharmacol. 409, 31-36. doi: 10.1016/S0014-2999(00)00837-2 
Vallon, V., Rieg, T., Ahn, S. Y., Wu, W., Eraly, S. A., and Nigam, S. K. (2008). Overlapping in vitro and in vivo specificities of the organic anion transporters OAT1 and OAT3 for loop and thiazide diuretics. Am. J. Physiol. Renal Physiol. 294, F867-F873. doi: 10.1152/ajprenal.00528.2007

Van Der Cruijsen, E. A. W., Nand, D., Weingarth, M., Prokofyev, A., Hornig, S., et al. (2013). Importance of lipid-pore loop interface for potassium channel structure and function. Proc. Natl. Acad. Sci. U.S.A. 110, 13008-13013. doi: 10.1073/pnas. 1305563110

Van Der Graaf, P. H., and Benson, N. (2011). Systems pharmacology: bridging systems biology and pharmacokinetics-pharmacodynamics (PKPD) in drug discovery and development. Pharm. Res. 28, 1460-1464. doi: 10.1007/s11095011-0467-9

Varma, M. V., Rotter, C. J., Chupka, J., Whalen, K. M., Duignan, D. B., Feng, B., et al. (2011). pH-Sensitive Interaction of HMG-CoA Reductase Inhibitors (Statins) with organic anion transporting polypeptide 2B1. Mol. Pharm. 8, 1303-1313. doi: $10.1021 / \mathrm{mp} 200103 \mathrm{~h}$

Varma, M. V. S., Lai, Y., Feng, B., Litchfield, J., Goosen, T. C., and Bergman, A. (2012). Physiologically based modeling of pravastatin transportermediated hepatobiliary disposition and drug-drug interactions. Pharm. Res. 29, 2860-2873. doi: 10.1007/s11095-012-0792-7

Viereck, M., Gaulton, A., Digles, D., and Ecker, G. F. (2014). Transporter taxonomy - a comparison of different transport protein classification schemes. Drug Discov. Today Technol. 12, e37-46. doi: 10.1016/j.ddtec.2014.03.004

Vildhede, A., Karlgren, M., Svedberg, E. K., Wisniewski, J. R., Lai, Y., Norén, A., et al. (2014). Hepatic uptake of atorvastatin: influence of variability in transporter expression on uptake clearance and drug-drug interactions. Drug Metab. Dispos. 42, 1210-1218. doi: 10.1124/dmd.113.056309

Villalba, M. S., and Alvarez, H. M. (2014). Identification of a novel ATP-binding cassette transporter involved in long-chain fatty acid import and its role in triacylglycerol accumulation in Rhodococcus jostii RHA1. Microbiology 160, 1523-1532. doi: 10.1099/mic.0.078477-0

Volpe, D. A. (2011). Drug-permeability and transporter assays in Caco-2 and MDCK cell lines. Future Med. Chem. 3, 2063-2077. doi: 10.4155/fmc.11.149

Voora, D., Shah, S. H., Spasojevic, I., Ali, S., Reed, C. R., Salisbury, B. A., et al. (2009). The SLCO1B1*5 genetic variant is associated with statin-induced side effects. J. Am. Coll. Cardiol. 54, 1609-1616. doi: 10.1016/j.jacc.2009.04.053

Waddell, W. J., and Butler, T. C. (1959). Calculation of intracellular pH from the distribution of 5,5-dimethyl-2,4-oxazolidinedione (DMO); application to skeletal muscle of the dog. J. Clin. Invest. 38, 720-729. doi: 10.1172/ JCI103852

Waldman, S. A., and Terzic, A. (2012). Advancing pharmacometrics and systems pharmacology. Clin. Pharmacol. Ther. 92, 535-537. doi: 10.1038/clpt.2012.151

Wallner, M., Hanchar, H. J., and Olsen, R. W. (2003). Ethanol enhances alpha $_{4}$ beta $_{3}$ delta and alpha beta $_{3}$ delta gamma-aminobutyric acid type A receptors at low concentrations known to affect humans. Proc. Natl. Acad. Sci. U.S.A. 100, 15218-15223. doi: 10.1073/pnas.2435171100

Wallner, M., Hanchar, H. J., and Olsen, R. W. (2006). Low-dose alcohol actions on alpha 4 beta 3 delta $\mathrm{GABA}_{\mathrm{A}}$ receptors are reversed by the behavioral alcohol antagonist Ro15-4513. Proc. Natl. Acad. Sci. U.S.A. 103, 8540-8545. doi: 10.1073/pnas.0600194103

Walters, W. P. (2012). Going further than Lipinski's rule in drug design. Exp. Opin. Drug Discov. 7, 99-107. doi: 10.1517/17460441.2012.648612

Wang, H., Word, B. R., and Lyn-Cook, B. D. (2011). Enhanced efficacy of gemcitabine by indole-3-carbinol in pancreatic cell lines: the role of human equilibrative nucleoside transporter 1. Anticancer Res. 31, 3171-3180.

Wang, Y., Cao, J., Wang, X., and Zeng, S. (2010a). Stereoselective transport and uptake of propranolol across human intestinal Caco-2 cell monolayers. Chirality 22, 361-368. doi: 10.1002/chir.20753

Wang, Y., Shaikh, S. A., and Tajkhorshid, E. (2010b). Exploring transmembrane diffusion pathways with molecular dynamics. Physiology 25, 142-154. doi: 10.1152/physiol.00046.2009

Ward, P. (2008). Importance of drug transporters in pharmacokinetics and drug safety. Toxicol. Mech. Methods 18, 1-10. doi: 10.1080/15376510701795306

Wei, C. Y., Lee, M. T., and Chen, Y. T. (2012). Pharmacogenomics of adverse drug reactions: implementing personalized medicine. Hum. Mol. Genet. 21, R58-R65. doi: 10.1093/hmg/dds341

Westerhoff, H. V., Winder, C., Messiha, H., Simeonidis, E., Adamczyk, M., Verma, M., et al. (2009). Systems biology: the elements and principles of life. FEBS Lett. 583, 3882-3890. doi: 10.1016/j.febslet.2009.11.018
Wilke, R. A., Ramsey, L. B., Johnson, S. G., Maxwell, W. D., Mcleod, H. L., Voora, D., et al. (2012). The clinical pharmacogenomics implementation consortium: CPIC guideline for SLCO1B1 and simvastatin-induced myopathy. Clin. Pharmacol. Ther. 92, 112-117. doi: 10.1038/clpt.2012.57

Williams, R. J. (1956). Biochemical Individuality. New York, NY: John Wiley.

Winter, G. E., Radic, B., Mayor-Ruiz, C., Blomen, V. A., Trefzer, C., Kandasamy, R. K., et al. (2014). The solute carrier SLC35F2 enables YM155-mediated DNA damage toxicity. Nat. Chem. Biol. 10, 768-773. doi: 10.1038/nchembio. 1590

Wu, Q., Kazantzis, M., Doege, H., Ortegon, A. M., Tsang, B., Falcon, A., et al. (2006a). Fatty acid transport protein 1 is required for nonshivering thermogenesis in brown adipose tissue. Diabetes 55, 3229-3237. doi: 10.2337/ db06-0749

Wu, Q., Ortegon, A. M., Tsang, B., Doege, H., Feingold, K. R., and Stahl, A. (2006b). FATP1 is an insulin-sensitive fatty acid transporter involved in dietinduced obesity. Mol. Cell Biol. 26, 3455-3467. doi: 10.1128/MCB.26.9.3455-34 67.2006

Wu, X., George, R. L., Huang, W., Wang, H., Conway, S. J., Leibach, F. H., et al. (2000). Structural and functional characteristics and tissue distribution pattern of rat OCTN1, an organic cation transporter, cloned from placenta. Biochim. Biophys. Acta 1466, 315-327. doi: 10.1016/S0005-2736(00)00189-9

Xiao, J. C., Zhang, T. P., and Zhao, Y. P. (2013). Human equilibrative nucleoside transporter 1 (hENT1) predicts the Asian patient response to gemcitabine-based chemotherapy in pancreatic cancer. Hepatogastroenterology 60, 258-262. doi: 10.5754/hge12687

Xie, L., Xie, L., Kinnings, S. L., and Bourne, P. E. (2012). Novel computational approaches to polypharmacology as a means to define responses to individual drugs. Annu. Rev. Pharmacol. Toxicol. 52, 361-379. doi: 10.1146/annurevpharmtox-010611-134630

Xu, A. S. L., Chu, C. K., and London, R. E. (1998). ${ }^{19}$ F NMR study of the uptake of 2 -fluoro-5-methyl-beta-L-arabinofuranosyluracil in erythrocytes: evidence of transport by facilitated and nonfacilitated pathways. Biochem. Pharmacol. 55, 1611-1619. doi: 10.1016/S0006-2952(98)00017-3

Yazaki, K. (2006). ABC transporters involved in the transport of plant secondary metabolites. FEBS Lett. 580, 1183-1191. doi: 10.1016/j.febslet.2005. 12.009

Yeo, K. R., Jamei, M., Aarabi, M., and Rostami-Hodjegan, A. (2012). Application of physiologically based pharmacokinetic (PBPK) modeling for prediction of complex drug-drug interactions (DDIs) involving OATPIB1-mediated uptake and cytochrome P450 (Cyp) metabolism and multiple inhibitors. Clin. Pharmacol. Ther. 91, S47-S48.

Yeo, K. R., Jamei, M., and Rostami-Hodjegan, A. (2013). Predicting drug-drug interactions: application of physiologically based pharmacokinetic models under a systems biology approach. Expert Rev. Clin. Pharmacol. 6, 143-157. doi: 10.1586/ecp.13.4

Yiannakopoulou, E. C. (2013). Pharmacogenomics of phase II metabolizing enzymes and drug transporters: clinical implications. Pharmacogenomics J. 13, 105-109. doi: 10.1038/tpj.2012.42

Yip, V. L., Alfirevic, A., and Pirmohamed, M. (2014). Genetics of immune-mediated adverse drug reactions: a comprehensive and clinical review. Clin. Rev. Allergy Immunol. doi: 10.1007/s12016-014-8418-y. [Epub ahead of print].

Yonezawa, A., and Inui, K. (2011). Importance of the multidrug and toxin extrusion MATE/SLC47A family to pharmacokinetics, pharmacodynamics/toxicodynamics and pharmacogenomics. Br. J. Pharmacol. 164, 1817-1825. doi: 10.1111/j.1476-5381.2011.01394.x

Yoshida, K., Maeda, K., and Sugiyama, Y. (2012). Transporter-mediated drugdrug interactions involving OATP substrates: predictions based on in vitro inhibition studies. Clin. Pharmacol. Ther. 91, 1053-1064. doi: 10.1038/clpt. 2011.351

Yoshida, K., Maeda, K., and Sugiyama, Y. (2013). Hepatic and intestinal drug transporters: prediction of pharmacokinetic effects caused by drug-drug interactions and genetic polymorphisms. Annu. Rev. Pharmacol. Toxicol. 53, 581-612. doi: 10.1146/annurev-pharmtox-011112-140309

Young, J. D., Yao, S. Y. M., Baldwin, J. M., Cass, C. E., and Baldwin, S. A. (2013). The human concentrative and equilibrative nucleoside transporter families, SLC28 and SLC29. Mol. Aspects Med. 34, 529-547. doi: 10.1016/j.mam.2012. 05.007

Zamek-Gliszczynski, M. J., Lee, C. A., Poirier, A., Bentz, J., Chu, X., Ellens, H., et al. (2013). ITC recommendations for transporter kinetic 
parameter estimation and translational modeling of transport-mediated PK and DDIs in humans. Clin. Pharmacol. Ther. 94, 64-79. doi: 10.1038/clpt. 2013.45

Zhang, J., Lushington, G. H., and Huan, J. (2011a). Characterizing the diversity and biological relevance of the MLPCN assay manifold and screening set. J. Chem. Inf. Model. 51, 1205-1215. doi: 10.1021/ci1003015

Zhang, L., Huang, S. M., and Lesko, L. J. (2011b). Transporter-mediated drugdrug interactions. Clin. Pharmacol. Ther. 89, 481-484. doi: 10.1038/clpt. 2010.359

Zhang, X., Scialis, R. J., Feng, B., and Leach, K. (2013). Detection of statin cytotoxicity is increased in cells expressing the OATP1B1 transporter. Toxicol. Sci. 134, 73-82. doi: 10.1093/toxsci/kft085

Zheng, X. L., Yu, Q. Q., Wang, Y., and Zeng, S. (2013). Stereoselective accumulation of propranolol enantiomers in K562 and K562/ADR cells. Chirality 25, 361-364. doi: 10.1002/chir.22178

Zhou, K., Donnelly, L. A., Kimber, C. H., Donnan, P. T., Doney, A. S., Leese, G., et al. (2009). Reduced-function SLC22A1 polymorphisms encoding organic cation transporter 1 and glycemic response to metformin: a GoDARTS study. Diabetes 58, 1434-1439. doi: 10.2337/db08-0896

Zhou, Q., Yu, L. S., and Zeng, S. (2014). Stereoselectivity of chiral drug transport: a focus on enantiomer-transporter interaction. Drug Metab. Rev. 46, 283-290. doi: 10.3109/03602532.2014.887094

Zimmermann, G. R., Lehár, J., and Keith, C. T. (2007). Multi-target therapeutics: when the whole is greater than the sum of the parts. Drug Discov. Today 12, 34-42. doi: 10.1016/j.drudis.2006.11.008
Zolk, O., and Fromm, M. F. (2011). Transporter-mediated drug uptake and efflux: important determinants of adverse drug reactions. Clin. Pharmacol. Ther. 89, 798-805. doi: 10.1038/clpt.2010.354

Zur, M., Gasparini, M., Wolk, O., Amidon, G. L., and Dahan, A. (2014). The low/high BCS permeability class boundary: physicochemical comparison of metoprolol and labetalol. Mol Pharm. 11, 1707-1714. doi: 10.1021/ mp500152y

Conflict of Interest Statement: The authors declare that the research was conducted in the absence of any commercial or financial relationships that could be construed as a potential conflict of interest.

Received: 12 August 2014; accepted: 29 September 2014; published online: 31 October 2014.

Citation: Kell DB and Oliver SG (2014) How drugs get into cells: tested and testable predictions to help discriminate between transporter-mediated uptake and lipoidal bilayer diffusion. Front. Pharmacol. 5:231. doi: 10.3389/fphar.2014.00231

This article was submitted to Drug Metabolism and Transport, a section of the journal Frontiers in Pharmacology.

Copyright (C) 2014 Kell and Oliver. This is an open-access article distributed under the terms of the Creative Commons Attribution License (CC BY). The use, distribution or reproduction in other forums is permitted, provided the original author(s) or licensor are credited and that the original publication in this journal is cited, in accordance with accepted academic practice. No use, distribution or reproduction is permitted which does not comply with these terms. 